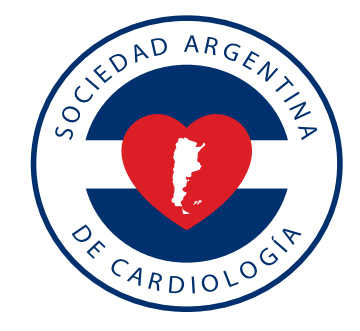

Revista Argentina de Cardiología Argentine Journal of Cardiology

\title{
COVID-19 Y CORAZÓN
}

\section{DOCUMENTO DE POSICIÓN}

\author{
SOCIEDAD ARGENTINA DE CARDIOLOGÍA
}




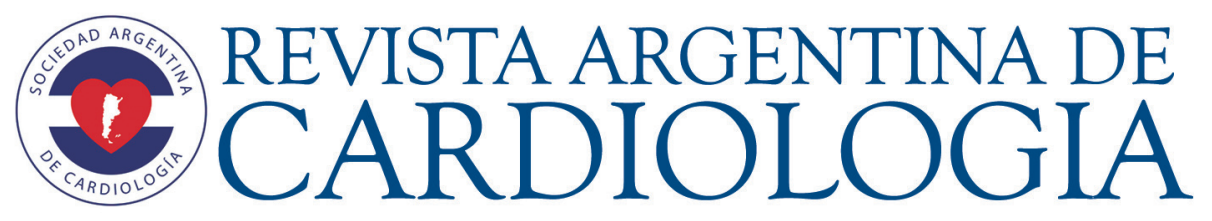

ORGANO CIENTÍFICO DE LA SOCIEDAD ARGENTINA DE CARDIOLOGÍA

\section{COMITÉ EDITOR}

\section{Director}

RAÚL A. BORRACCI ${ }^{+}$

Universidad Austral, Buenos Aires

Director Adjunto

JORGE THIERER

Instituto Universitario CEMIC, CABA

Directores Asociados

JOSÉ LUIS BARISANI

Hospital Presidente Perón, Buenos Aires

DARÍO C. DI TORO

Hospital Argerich, CABA

Instituto Cardiovascular Buenos Aires,

CABA

CLAUDIO C. HIGA

Hospital Alemán, CABA

LUCIANO LUCAS

Instituto Universitario Hospital Italiano

de Buenos Aires, CABA

WALTER M. MASSON

Instituto Universitario Hospital Italiano

de Buenos Aires, CABA

Editor Consultor

HERNÁN C. DOVAL

Hospital Italiano de Buenos Aires, CABA

Delegado por la SAC

DAMIÁN HOLOWNIA

Instituto Antonio Heluane Centro de

Diagnóstico Médico, San Miguel de

Tucumán, Tucumán

Editor de Ciencias básicas

BRUNO BUCHHOLZ

Universidad de Buenos Aires

Vocales

BIBIANA DE LA VEGA

Hospital Zenón Santillán, Tucumán

JAVIER GUETTA

Instituto Universitario CEMIC, CABA

GUILLERMO E. LINIADO

Hospital Argerich, CABA

JORGE LOWENSTEIN

Cardiodiagnóstico Investigaciones Médicas

de Buenos Aires, CABA

GASTÓN RODRÍGUEZ GRANILLO

Instituto Médico ENERI CABA

Clínica La Sagrada Familia, CABA

PABLO ROURA

Instituto Argentino de Diagnóstico y

Tratamiento, CABA

JORGE C. TRAININI

Universidad de Avellaneda, Buenos Aire
MARIANO TREVISÂN

Sanatorio San Carlos, Bariloche, Río Negro

Consultor en Estadística, Buenos Aires

JAVIER MARIANI

Hospital El Cruce, Buenos Aires

Coordinación Editorial

PATRICIA LOPEZ DOWLING

MARIELA ROMANO

\section{COMITÉ HONORARIO}

MARCELO V. ELIZARI (ARGENTINA)

GUILLERMO KREUTZER (ARGENTINA)

JOSÉ NAVIA (ARGENTINA)

\section{COMITÉ EDITOR INTERNACIONAL}

AMBROSIO, GIUSEPPE (ITALIA)

University of Perugia School of Medicine, Perugia

ANTZELEVITCH, CHARLES (EE.UU)

Masonic Medical Research Labo

Cardiovascular Institute, The Mount Sinai School of

Medicine

BARANCHUK, ADRIÁN (CANADÁ)

Queen's University, Kingston

BAZÁN, MANUEL (CUBA)

INCOR, La Habana

BLANKSTEIN, RON

Harvard Medical School (EEUU)

BRUGADA, RAMÓN (ESPAÑA)

Cardiology Department, The Thorax Institute, Hospita

Clinic, University of Barcelona, Barcelona

CABO SALVADOR, JAVIER

Departamento de Ciencias de la Salud de la

Universidad de Madrid UDIMA (ESPAÑA)

CAMM, JOHN (GRAN BRETAÑA)

British Heart Foundation, St. George's University of

London
CARRERAS COSTA, FRANCESC (ESPAÑA)

Hospital de la Santa Creu i Sant Pau, Universitat

Autònoma de Barcelona

CHACHQUES, JUAN CARLOS (FRANCIA)

Pompidou Hospital, University of Paris Descartes,

Paris

DEMARIA, ANTHONY N. (EE.UU)

UCSD Medical Center, San Diego, California

(DICARLI, MARCELO (EE.UU)

Harvard Medical School, Boston, MA

Instituto Cardiológico. Quirónsalud-Teknon, Barcelon

EZEKOWITZ, MICHAEL (EE.UU)

Lankenau Medical Center, Medical Science Building,

Wynnewood, PA

FEIGENBAUM, HARVEY (EE.UU)

Indiana University School of Medicine, Indianapolis

FERRARI, ROBERTO (CANADÁ)

University of Alberta, Edmonton, Alberta

FERRARIO, CARLOS (EE.UU)

Wake Forest University School of Medicine, Winston-

Salem

FLATHER, MARCUS (GRAN BRETAÑA)

Royal Brompton and Harefield NHS Foundation Trust and Imperial College London

FUSTER, VALENTIN (EE.UU.)

The Mount Sinai Medical Center, New York

GARCíA FERNÁNDEZ, MIGUEL ÁNGEL (ESPAÑA)

Universidad Complutense de Madrid. Facultad de

JUFÉ STEIN, ALBERTO (ESPAÑA)

Department of Cardiology, A Coruña University
Hospital, La Coruña
KASKI, JUAN CARLOS (GRAN BRETAÑA)

St George's University of London, Cardiovascular

St George's University of London, Cardiovascular

KHANDERIA, BIJOY (EE.UU)

Aurora Cardiovascular Services

KRUCOFF, MITCHELL W. (EE.UU)

Duke University Medical Center, Durham

Hospital Universitario La Paz, Instituto de

Investigación La Paz, Madrid

LUSCHER, THOMAS (SUIZA)

European Heart Journal, Zuri

MARZILLI, MARIO (ITALIA)

Cardiothoracic Department, Division of Cardiology,

University Hospital of Pisa

MAURER, GERALD (AUSTRIA)

Univ.-Klinik für Psychiatrie und Psychotherapie I,

Christian-Doppler-Klinik, Salzburg

MOHR, FRIEDRICH (ALEMANIA)

Herzzentrum Universität Leipzig, Leipzig

NANDA, NAVIN (EE.UU)

University of Alabama at Birmingham, Birmingham

NEUBAUER, STEFAN

University of Oxford and John Radcliffe Hospital

GRAN BRETAÑA

SEN, DENNIS (NORUEGA)

Department of Cardiology, Stavanger University

Hospital, Stavanger

PALACIOS, IGOR (EE.UU)

PANZA, JULO (EE UU)

PANZA, W W (EE.UU) Hospital Center, Washington, DC

PICANO Washington Hosp

Institute of Clinical Physiology, CNR, Pisa

PINSKI, SERGIO (EE.UU)

RASTAN, ARDAWAN (ALEMANIA)

Universitäts-Herzzentrum Freiburg-Bad Krozingen

SERRUYS, PATRICK W.

Imperial College (GRAN BRETAÑA)

SICOURI, SERGE (EE.UU)

Masonic Medical Research Laboratory, Utica

THEROUX, PIERRE (CANADÁ)

University of Toronto, Ontario

TOGNONI, GIANNI (ITALIA)

Consorzio Mario Negri Sud, Santa Maria Imbaro, Chieti

VENTURA, HÉCTOR (EE.UU)

Ochsner Clinical School-The University of

Queensland School of Medicine, New Orlean

WIELGOSZ, ANDREAS (CANADÁ)

University of Calgary, Calgary, Alberta

PES, DOUGLAS (EE.UU)

Indiana University School of Medicine, Indianapolis
SOCIEDAD ARGENTINA

DE CARDIOLOGÍA

\section{COMISIÓN DIRECTIVA}

\section{Presidente}

ALEJANDRO R. HERSHSON

Presidente Electo

HÉCTOR R. DESCHLE

Vicepresidente $1^{\circ}$

CLAUDIO R. MAJUL

Vicepresidente $2^{\circ}$

RODRIGO A. DE LA FABA

Secretario

RICARDO A. VILLARREAL

Tesorero

ENRIQUE FAIRMAN

Prosecretario

VERÓNICA I. VOLBERG

Protesorero

HÉCTOR R. GÓMEZ SANTA MARÍA

Vocales Titulares

BLANCA M. LOSADA

MARIO J. SZEJFELD

JULIO O. IBAÑEZ

CLAUDIA M. CORTÉS

Vocal Suplentes

MARÍA D. LUCONI

DAMIÁN E. HOLOWNIA

RICARDO LEÓN DE LA FUENTE

JORGE M. CASAS

Presidente Anterior

JOSÉ L. NAVARRO ESTRADA

\section{Revista Argentina de Cardiología}

La Revista Argentina de Cardiología es propiedad de la Sociedad Argentina de Cardiología.

ISSN 0034-7000 ISSN 1850-3748 versión electrónica - Registro de la Propiedad Intelectual en trámite

Full English text available. Indexada en SciELO, Scopus, Embase, LILACS, Latindex, Redalyc, Dialnet y DOAJ. Incluída en el Núcleo Básico de Revistas Científicas Argentinas del CONICET.

\section{VOL $89 \mathrm{~N}^{\circ} 6$ OCTUBRE 2021}

Dirección Científica y Administración

Azcuénaga 980 - (1115) Buenos Aires / Tel.: 4961-6027/8/9 / Fax: 4961-6020 / e-mail: revista@sac.org.ar / web site: www.sac.org.ar

Atención al público de lunes a viernes de 13 a 20 horas 


\title{
COVID-19 Y CORAZÓN DOCUMENTO DE POSICIÓN SOCIEDAD ARGENTINA DE CARDIOLOGÍA
}

\author{
Director: Dr. Maximiliano De Abreu ${ }^{\mathrm{MTSAC}}$ \\ Sub-Director: Dr. Sebastián Peralta ${ }^{\text {MTSAC }}$ \\ Secretario: Dr. Mario Cesar Spennato ${ }^{\text {MTSAC }}$ \\ Vocales \\ Dra. Laura Antonietti ${ }^{\mathrm{MTSAC}}$ \\ Dr. Fernando Garagoli \\ Dr. Ariel Kraselnik \\ Dr. Santiago Lynch \\ Dra. Paola Rojas \\ Dra. Milagros Seijo \\ Comité Asesor \\ Dr. Gustavo Giunta ${ }^{\mathrm{MTSAC}}$ \\ Dr. Ignacio Bluro ${ }^{\mathrm{MTSAC}}$ \\ Dr. Mariano Falconi ${ }^{\mathrm{MTSAC}}$
}

\begin{abstract}
Las opiniones, pautas o lineamientos contenidos en los Consensos o Recomendaciones han sido diseñados y planteados en términos genéricos, a partir de la consideración de situaciones concebidas como un modelo teórico. Alli se describen distintas hipótesis alternativas para arribar a un diagnóstico, a la definición de un tratamiento y/o prevención de una determinada patología. De ningún modo puede interpretarse como un instructivo concreto ni como una indicación absoluta. La aplicación especifica en el paciente individual de cualquiera de las descripciones generales obrantes en los Consensos o Recomendaciones dependerá del juicio médico del profesional interviniente y de las características y circunstancias que se presenten en torno al caso en cuestión, considerando los antecedentes personales del paciente y las condiciones especificas de la patología por tratar, los medios y recursos disponibles, la necesidad de adoptar medidas adicionales y/o complementarias, etc. La evaluación de estos antecedentes y factores quedará a criterio y responsabilidad del médico interviniente en la decisión clínica final que se adoptará.
\end{abstract}




\title{
COVID-19 Y CORAZÓN DOCUMENTO DE POSICIÓN SOCIEDAD ARGENTINA DE CARDIOLOGÍA
}

\author{
Director \\ Carlos Tajer \\ Secretaria \\ Patricia López Dowling \\ Comité de Redacción \\ Lucía Kazelián, Stella Maris Pereiro González, Juan Gagliardi, Heraldo D’Imperio, \\ Mauro Rossi Prat, Francisco Bertolotti, Ariel Estévez, Yenifers Torres, \\ Alejandro Villamil, Adrián Lescano, Ignacio Dávolos, Diego Iglesias

\section{Comité Revisor} \\ Maximiliano de Abreu, Jorge Thierer, Alejandro Deviggiano
}




\section{VOL 89 SUPLEMENTO 6 OCTUBRE 2021}

\section{Capítulo 1. La influencia de la pandemia sobre las enfermedades cardiovasculares Carlos Tajer}

En qué medida la pandemia modificó la mortalidad global

Cambios que indujo la pandemia en la atención cardiovascular.....

La asistencia a las cardiopatías isquémicas agudas.

Otros cambios en la asistencia cardiovascular

El futuro inmediato de la atención cardiovascular hasta el fin de la pandemia

Bibliografía

1

2

Capítulo 2. Complicaciones cardiovasculares de la COVID-19 Lucía Kazelián

Introducción Complicaciones Cardiovasculares en el registro RACCOVID-19....

Comentarios finales

Bibliografía

\section{Capítulo 3. Daño miocárdico por COVID 19 Stella Maris Pereiro González}

Elevación de troponina - Frecuencia e importancia

Implicancias pronósticas de la elevación de troponina

Hallazgos ecocardiográficos en pacientes críticos....

Mecanismos del daño miocárdico causado por COVID-19.

¿Existe la miocarditis viral en COVID-19?

Información de bases administrativas

Miocarditis en autopsias o biopsia endomiocárdica

Rol de la resonancia magnética cardíaca en pacientes con COVID-19

Como hacer el diagnóstico de una miocarditis por COVID-19.

Esquema de diagnóstico frente a la sospecha de miocarditis

¿Existen terapéuticas para la miocarditis por COVID-19?

Etapa tardía post-COVID. COVID largo.

Vacunación y la aparición de miocarditis o pericarditis......

¿Cuál es el mecanismo de la miocarditis por las vacunas?

¿Cuál es nuestra realidad?

Comentarios finales

Bibliografía

Capítulo 4. Síndromes coronarios agudos y accidentes cerebrovasculares asociados a COVID-19 Juan Gagliardi, Heraldo D'Imperio, Mauro Rossi Prat

Introducción

Infarto de miocardio con elevación del ST.....

Evolución y particularidades asociadas a COVID-19

¿COVID-19 incrementa el riesgo de IAM o ACV? 


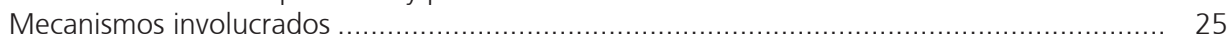

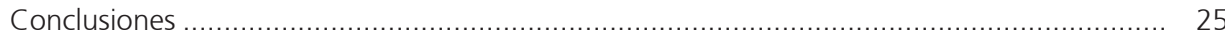

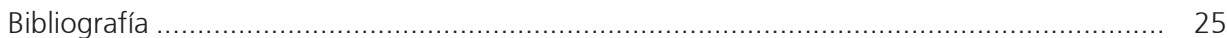

Capítulo 5. Arritmias y disautonomia en COVID-19

Francisco Bertolotti, Ariel Estévez, Yenifers Torres, Alejandro Villamil

Introducción

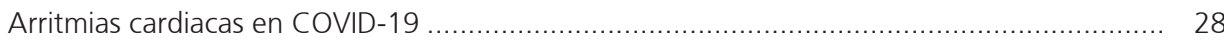

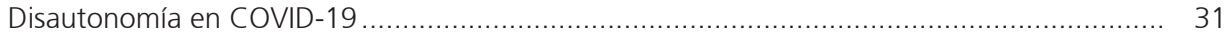

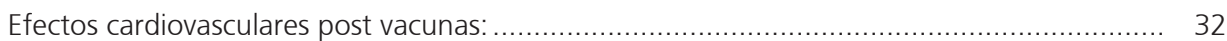

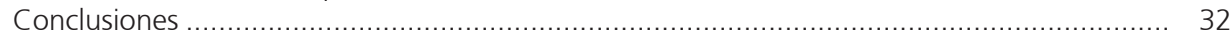

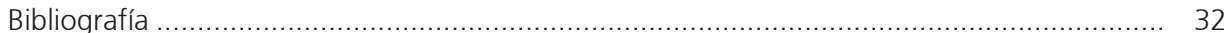

Capítulo 6. Enfermedad Tromboembólica Venosa en COVID-19

Adrián Lescano

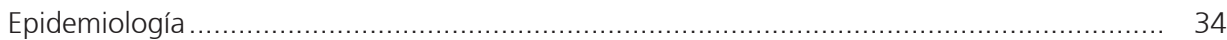

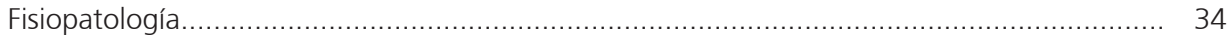

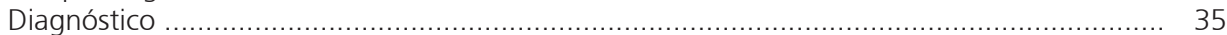

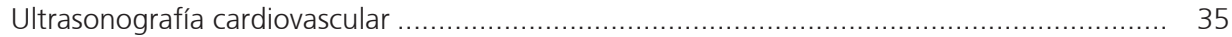

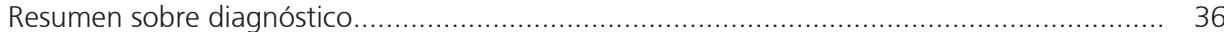

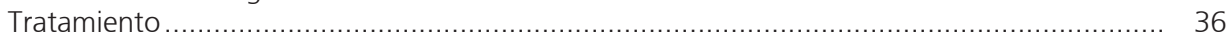

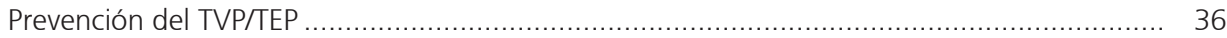

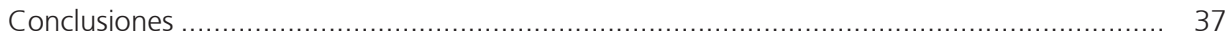

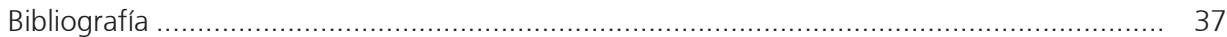

Capítulo 7. Evaluación post-COVID en deportistas para el retorno a la actividad física Ignacio Dávolos, Diego Iglesias

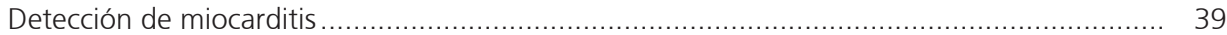

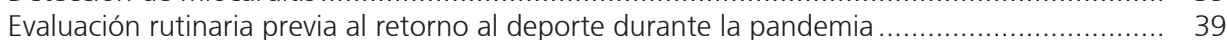

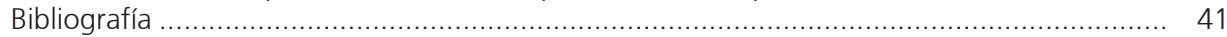

Capítulo 8. Evaluación cardiovascular de los pacientes post-COVID-19 Carlos Tajer

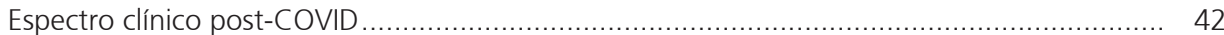

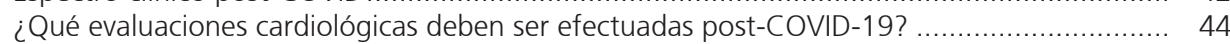

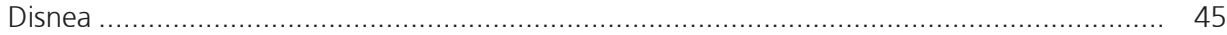

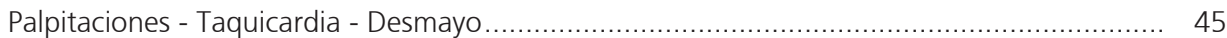

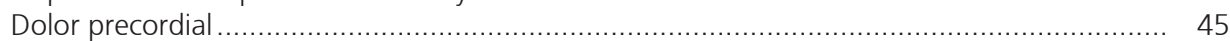

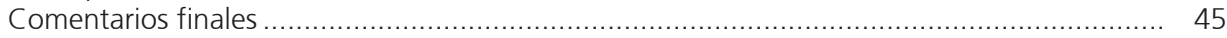

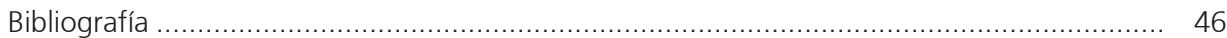




\title{
La influencia de la pandemia sobre las enfermedades cardiovasculares
}

\author{
CARLOS TAJER
}

La pandemia del SARS-CoV-2 persiste con un gran impacto en la salud pública, y genera perjuicios en el trabajo, la producción y la vida cotidiana de la humanidad, con cambios notables en la dinámica de la asistencia médica. Durante las primeras fases la mayoría de los países adoptaron medidas de aislamiento y clausura de actividades, con normas restrictivas a los desplazamientos y un fuerte mensaje publicitario que inducía a no abandonar el domicilio. Estas medidas tuvieron un gran impacto sobre la práctica asistencial: se cerraron los consultorios, cayeron los turnos presenciales programados de todas las especialidades, así como también las intervenciones y estudios complejos. La enfermedad cardiovascular es de alta prevalencia en la población, y requiere conductas preventivas activas y controles periódicos, así como la oportuna decisión de intervenciones tanto de urgencia como programadas.

Las medidas restrictivas, el temor a consultar y ser llevado a una institución que resultara en un potencial riesgo de contagio, la sobresaturación del sistema de atención por la COVID-19 y otros factores tuvieron repercusión sobre la asistencia cardiológica. La pandemia todavía no ha terminado, en varios países se está padeciendo la tercera ola atribuida a la variante delta, y aunque la disponibilidad de vacunas para los países de ingresos medios y altos ayuda a imaginar un final, es posible que por la notable modificación de la práctica que generó, no se vuelva a la normalidad anterior en mucho tiempo o se lo haga con grandes cambios. También la pandemia ha desnudado problemas históricos del sistema de atención en nuestro país, que indican que lo ideal sería analizar comunitariamente los cambios requeridos. La función de los especialistas en patología cardiovascular es compartir sus inquietudes con las autoridades sanitarias y la población, para poder lograr en conjunto estrategias adecuadas.

\section{En qué medida la pandemia modificó la mortalidad global}

La pandemia tuvo un desarrollo desparejo en diferentes regiones del mundo, por motivos diversos que se vincularon a la severidad de las medidas restrictivas y la eficiencia en las estrategias de detección y aislamiento, así como a aspectos estacionales y climáticos. El incremento de la mortalidad global respecto a años previos, conceptualizado como exceso de mortalidad, ha sido muy variado en diferentes países y regiones. En un estudio sobre 21 países de ingresos elevados, el exceso varió de 0-5\% (Noruega, Dinamarca) a 30-45\% (Reino Unido, España). (1) El impacto sobre la mortalidad global en nuestro país ha sido relevante, y en la Figura 1 se observan cifras de exceso de mortalidad respecto a años previos en una comparación entre Chile y Argentina. (2) Chile adoptó tardíamente medidas restrictivas, y cursó con una inmensa ola inicial con grave repercusión. Argentina tuvo una política severa inicial, con una reducción o poco impacto de la mortalidad global durante los primeros meses, y un comienzo más tardío, pero igualmente grave de la enfermedad. En un estudio epidemiológico del Ministerio

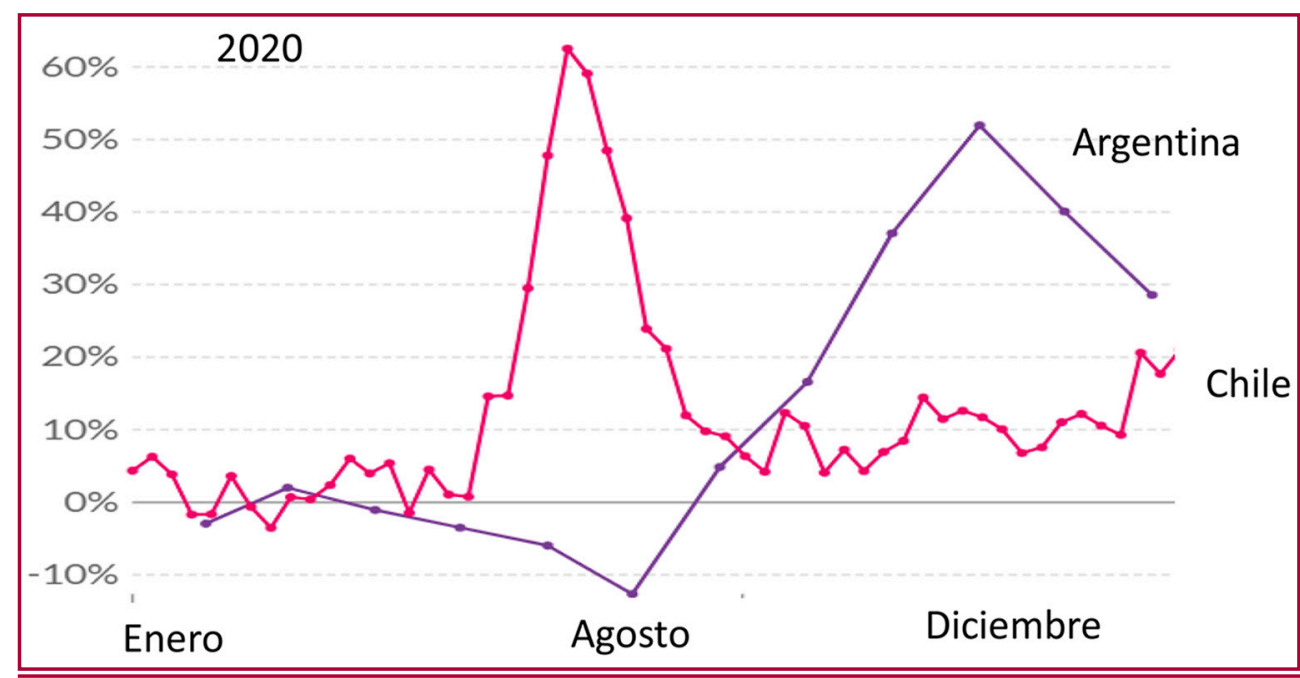

Fig. 1. Evolución del porcentaje de exceso de mortalidad respecto a años previos durante la primera ola en Argentina y Chile (2) 
de Salud de la Nación se informó para el año 2020 un exceso de mortalidad del 10,6\%; aunque no se incrementó en el primer semestre, subió al 25,6\% en el segundo. (3) No contamos con cifras de 2021, pero dado que la peor tasa ocurrió durante la segunda ola en este año, con más de 700 muertes diarias por COVID-19, y en setiembre continúan cifras de 200 muertes diarias, ello hace suponer que esa tasa de incremento del $25 \%$ observada en el segundo semestre de 2020 reflejará la realidad del impacto poblacional para 2021. (Figura 2)

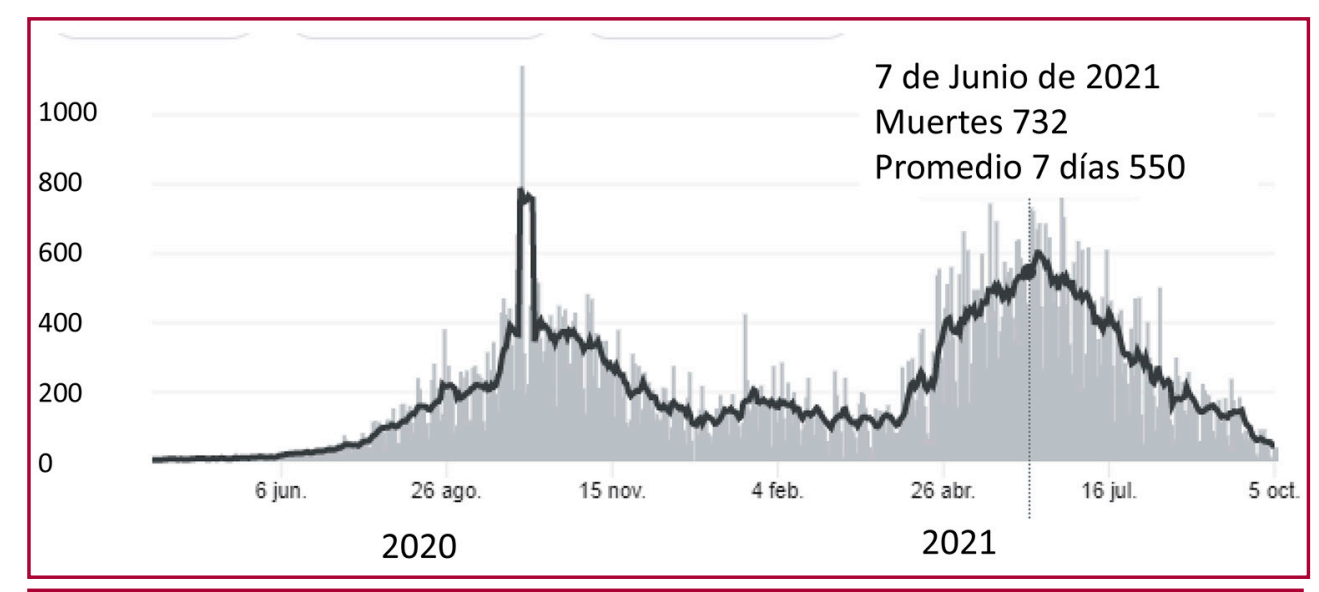

Fig. 2. Evolución del número de fallecimientos por COVID-19 reportados en Argentina. (4)

\section{Cambios que indujo la pandemia en la atención cardiovascular}

Disponemos de múltiples reportes de diferentes países sobre la repercusión de la pandemia en las internaciones cardiovasculares, la atención de la patología aguda, la atención domiciliaria, y algunos datos aún no completos sobre la mortalidad cardiovascular.

En forma general varios países reportaron una caída de las internaciones cardiovasculares. (5) En nuestro país también se reportaron datos de registros. En la Figura 3 se expresa la modificación en las internaciones durante los primeros dos meses de las medidas restrictivas adoptadas en la Argentina, con la salvedad de que a diferencia de otros países no existía una demanda importante de camas para COVID-19 en ese lapso. (6)

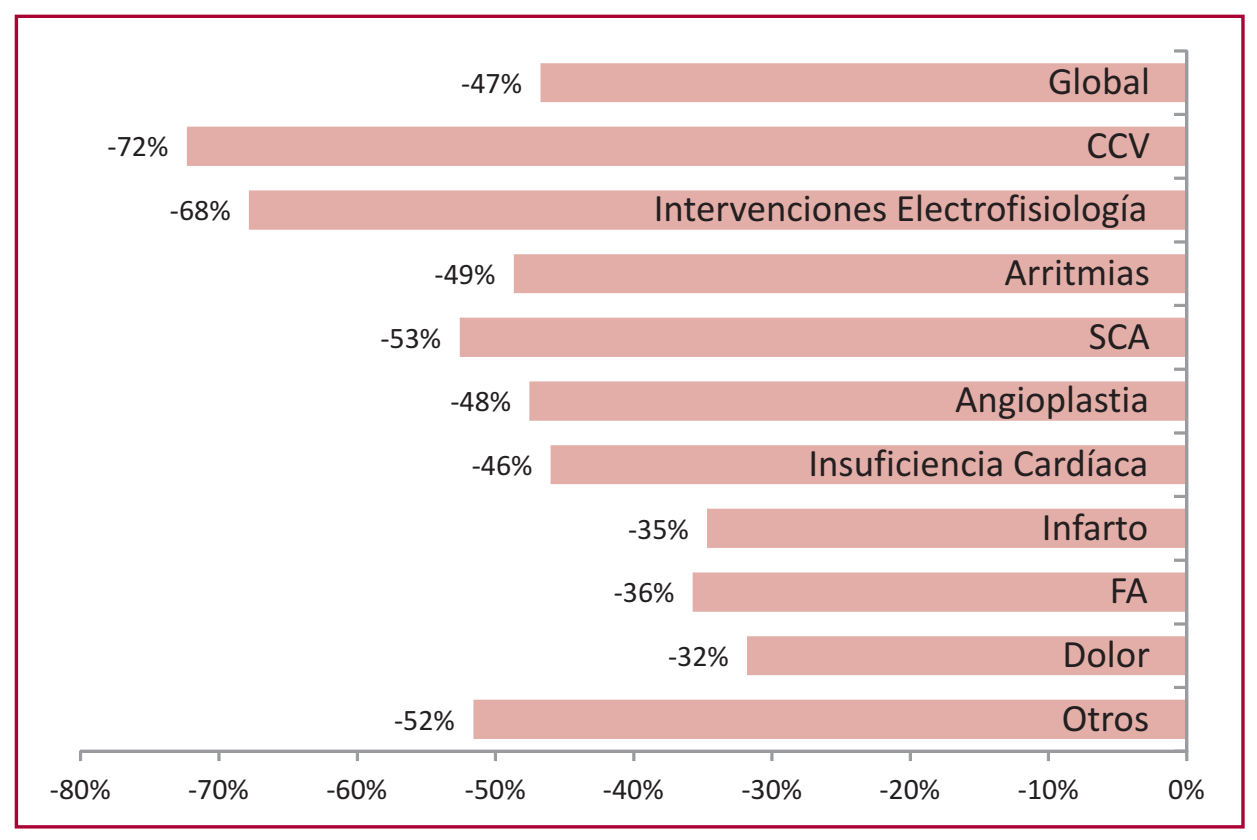

CCV: Cirugía cardiovascular - SCA: Síndrome coronario agudo - FA: Fibrilación auricular

Fig. 3. Caída de las internaciones durante el período marzo-abril 2020 en comparación con los 10 años previos en el registro multicéntrico Epicardio. (6) 
Es sencillo explicar la reducción de los procedimientos programados de cirugía cardiovascular, hemodinamia intervencionista o electrofisiología, acordes a las medidas de suspensión inducidas por las autoridades. Es menos clara la explicación de la caída en patologías de urgencia como síndromes coronarios agudos o insuficiencia cardíaca, y más aún evaluar su eventual repercusión. Se pueden postular diferentes interpretaciones y todavía no contamos con la suficiente información para discriminarlas adecuadamente.

Una explicación posible es una baja real de la patología, relacionada con los cambios en la dinámica de la vida: aislamiento en domicilio, suspensión del trabajo, cierre de espacios, modificación de los hábitos alimentarios. Esta modificación tiene aspectos complejos, dado que conjuga por un lado una menor exposición a contagios por otras patologías como la influenza, que tiene un rol conocido en inducir descompensaciones por insuficiencia cardíaca y muy probable como uno de los mecanismos de activación de la placa para los síndromes coronarios agudos (SCA), así como una menor exposición al stress laboral, también conocido gatillo de SCA. Por otro lado, la reducción de ingresos económicos en particular en los sectores más vulnerables, el aislamiento y el pánico, podrían haber jugado un rol de incremento de los cuadros.

La segunda explicación factible y que sin duda ocurrió es la disminución de los pedidos de asistencia por temor al contagio o la necesidad de una internación. En el caso argentino, aunque todavía no tenemos los datos desagregados, la falta de incremento de la mortalidad global en el primer semestre de 2020, incluye tres meses desde marzo a mayo con pocos casos de COVID-19 y gran reducción de la demanda asistencial. Dado que la mortalidad global incluye muertes por accidentes o violentas que disminuyeron en ese período, el incremento de la mortalidad cardiovascular pudo no haberse reflejado en las cifras globales. En un modelo de análisis prospectivo, ya en los primeros meses se podía predecir un incremento de mortalidad cardiovascular anual de 6000 a 9000 casos, entre otras causas por la reducción de la asistencia de las patologías agudas. (7)

En diferentes países se ha relatado un incremento de los paros cardíacos atendidos en domicilio. (8, 9) A nivel global todavía es difícil estimar el impacto de la desatención de la patología cardiovascular sobre la mortalidad específica y la mortalidad global. El subtítulo de un editorial sobre este tema es claro: solo la historia podrá revelar la profundidad del iceberg. (10)

\section{La asistencia a las cardiopatías isquémicas agudas}

Durante los meses de mayor intensidad de la pandemia, se reportaron caídas en la tasa de angioplastias primarias y tratamiento de reperfusión en diversos contextos asistenciales a nivel internacional (11-13), que se resumen en la Tabla.

El registro permanente ARGEN-IAM (18) analizó en forma comparativa 3188 pacientes ingresados por infarto con elevación del ST durante los años previos con 627 durante el período de la pandemia. Observaron algunas diferencias demográficas, con incremento de la edad, cambios en las conductas institucionales, y menor tasa de derivación de pacientes. Los tiempos pre-hospitalarios se prolongaron con un incremento de 50 minutos (180 vs 130) de demora entre el dolor y el ingreso institucional. No se redujo la tasa de reperfusión ni la preferencia por angioplastia directa ( $88 \%$ en pandemia vs $84 \%$ en los períodos previos). La mortalidad tuvo un pequeño incremento $9,2 \%$ vs $8,6 \%$, no significativo. El registro Stent-Save a Life (19) informó una reducción de las angioplastias primarias en el infarto con elevación del segmento ST (de 628 a 577), aumento de la presentación como shock cardiogénico y de la mortalidad, que pasó de de 6,4 a 10,8\%. Hay múltiples reportes internacionales con caídas similares como se resume en la Tabla.

Tabla. Observaciones de la atención y mortalidad en Síndromes coronarios agudos. Modificada de cita 9.

\begin{tabular}{|lcccc|}
\hline & Impacto & País & $\begin{array}{c}\text { Internaciones } \\
\text { Exceso absoluto } \\
\text { de mortalidad }\end{array}$ \\
\hline Popovic (11) & Alto & Francia & $\downarrow$ & $22 \%$ \\
\hline Nef (12) & Moderado & Alemania & $\downarrow$ & $12 \%$ \\
\hline Primessnig (13) & Moderado & Alemania & $\downarrow$ & $13 \%$ \\
\hline Tam (14) & Alto & Hong Kong & $\downarrow$ & $7 \%$ \\
\hline De Rosa (15) & Alto & Italia & $\downarrow$ & $7 \%$ \\
\hline Wilson (16) & Alto & Reino Unido & $\downarrow$ & $3 \%$ \\
\hline Gluckman (17) & Alto & EEUU & $\downarrow$ & $0 \%$ \\
\hline Charask (18) & Alto & Argentina & $\downarrow$ & $0,6 \%$ \\
\hline Candiello (19) & Alto & Argentina & $\downarrow$ & $4,4 \%$ \\
\hline
\end{tabular}




\section{Otros cambios en la asistencia cardiovascular}

En forma general en todos los países que aportaron información se observó una caída de las consultas cardiovasculares ambulatorias, de la cirugía cardiovascular, intervenciones por angioplastia y electrofisiología, colocación de dispositivos, programas de rehabilitación. Un aspecto puntual que informa sobre la disrupción en la asistencia fue el cierre de los centros de control de coagulación con consecuencias todavía no evaluadas pero que pueden ser evitadas por sistemas a distancia. (20) El sistema de atención no estaba preparado para esta situación inesperada, y el análisis del impacto negativo ha generado propuestas superadoras. En un documento de la ANMCO italiana, los autores proponen un cambio general en la dinámica asistencial cardiovascular, con un mejor orden de las derivaciones, creación de departamentos regionales, por supuesto adaptados a su sistema de salud. (21)

\section{¿Cuáles fueron los cambios que la comunidad médica generó para abordar este desafío?}

Las Sociedades de Cardiología trabajaron desde el comienzo de la pandemia intentando alertar a las autoridades y la población sobre el impacto negativo de la situación de desatención generada. Se elaboró un documento conjunto que ordenaba diferentes propuestas de categorización en fases de la pandemia, como tentativa para un fenómeno inédito y difícil de abordar. Comunitariamente esas medidas no fueron adoptadas más que en forma muy parcial, sin una adecuada difusión, y es posible que se haya pagado un precio elevado del cual tomaremos conciencia cuando contemos con las cifras de mortalidad cardiovascular de las estadísticas de salud.

En la práctica asistencial, sin una guía oficial inicial, se generaron proyectos de teleconsulta con diferentes herramientas, (22) desde el simple llamado telefónico a la configuración de consultas virtuales con visualización y grabación, lo que fue muy bien valorado por los pacientes. (23) Los sistemas de teleconsulta y el denominado eHealth han demostrado beneficios en diferentes contextos (24), y su expansión ayudará en los próximos años a mejorar el control y adherencia de los pacientes. (25) En algunas especialidades, como la psicoterapia, esta modalidad ha tenido una expansión casi universal, aunque es probablemente inadecuada para casos graves como adicciones o patologías psiquiátricas. En cardiología varias instituciones públicas y privadas adoptaron sistemas de telemedicina, y las coberturas aceptaron reconocerlas como práctica remunerada, así como la posibilidad de la receta electrónica que comenzó a ser aceptada en farmacias. (23)

Algunas instituciones públicas y privadas pudieron iniciar o mantener programas de rehabilitación cardiovascular a distancia con resultados favorables en términos de calidad de vida y contención psicológica. (26)

\section{El futuro inmediato de la atención cardiovascular hasta el fin de la pandemia}

La pandemia ha generado un cambio histórico en la mirada atenta de la población a los problemas del sistema de salud y su relevancia, habitualmente ausente en las agendas políticas o en la valoración de prioridades. Señalaremos algunos aspectos que consideramos significativos.

\section{1) La maduración de la teleconsulta y la telemedicina}

$\mathrm{El}$ avance de las teleconsultas tiene un horizonte muy promisorio. Contamos hoy con una gran disponibilidad de recursos en manos de los pacientes (tensiómetros automáticos, oxímetros, electrocardiógrafos a través de smartphones o relojes), y la facilidad de la comunicación visual por Whatsapp o Zoom como ejemplos. Ya cuenta con marco legal en la Argentina, y si bien no es adecuada para todo tipo de práctica, puede abarcar, por lo menos en esta etapa, una buena parte de la asistencia ambulatoria.

\section{2) La necesidad de redes de atención y un orden racional en el sistema de salud}

La decisión de las autoridades sanitarias fue establecer como prioridad la atención de los pacientes con COVID-19, relegando las otras patologías, sin elaborar recomendaciones racionales para su manejo. La situación no se ha normalizado todavía, y no sabemos si tendremos nuevas olas por mutaciones ni contamos con una perspectiva clara. Es importante reflexionar sobre la posibilidad de establecer un orden para la atención de patologías de alta morbimortalidad, como el cáncer, la enfermedad pulmonar obstructiva crónica (EPOC), las patologías cardiovasculares agudas y el accidente cerebrovascular, con campañas comunicacionales y una clara indicación de los caminos a seguir en las diferentes circunstancias incluidas las urgencias. En otro orden aún mayor, desde hace años existe una clara conciencia en la debilidad del sistema sanitario argentino, atomizado, descentralizado y costoso, pero parecería que no está próxima la posibilidad de analizar comunitariamente los eventuales cambios requeridos.

\section{3) Medicina basada en evidencias para la población}

La pedagogía periodística ha difundido el reconocimiento de la importancia de estudios controlados científicos para la toma de decisiones sanitarias. Toda la población asistió a la esperanza de tratamientos inicialmente 
efectivos que luego lamentablemente se descartaron en estudios de mayores dimensiones, y positivamente, al impacto de los ensayos de las vacunas, con la referencia a lo que significa una publicación científica en Lancet. Es un avance cultural inesperado hacia la práctica sanitaria de la medicina basada en evidencias que requerirá refuerzos comunicacionales para su consolidación.

\section{BIBLIOGRAFÍA}

1. Kontis V, Bennett JE, Rashid T, Parks RM, Pearson-Stuttard J, Guillot M, et al. Magnitude, demographics and dynamics of the effect of the first wave of the COVID-19 pandemic on all-cause mortality in 21 industrialized countries Nat Med. 2020;26(12):1919-28.

2. https://ourworldindata.org/excess-mortality-covid

3. Rearte A, Moisés S, Rueda DV, Laurora MA, Flamenco Marucco A, Pennini VA, et al. Exceso de mortalidad por todas las causas en el contexto de la pandemia del COVID-19 en Argentina, 2020. Revista Argentina de Salud Pública. 2021;13 Supl COVID-19:e36.

4. https://github.com/CSSEGISandData/COVID-19 Repositorio de la Universidad de John Hopkins.

5. Konig S, Hohenstein S, Meier-Hellmann A, Kuhlen R, Hindricks G, Bollmann A, et al. In-hospital care in acute heart failure during the COVID-19 pandemic: insights from the German-wide Helios hospital network. Eur J Heart Fail 2020;22:2190-201.

6. Vensentini N, Zaidel EJ, Charask A, Salzberg S, Gagliardi J, Perea J, et al. Internaciones cardiovasculares en Unidades de Cuidados Intensivos durante la pandemia por COVID-19. Medicina (B Aires). 2020;80(5):425-32.

7. Lamelas P, Botto F, Pedermera G, Alves de Lima A, Costabel JP, Belardi J. Enfermedad cardiovascular en tiempos de COVID-19. Medicina (B Aires). 2020;80:248-52.

8. Marijon E, Karam N, Jost D, Perrot D, Frattini B, Derkenne C, et al. Out of- hospital cardiac arrest during the COVID-19 pandemic in Paris, France: a population-based, observational study. Lancet Public Health 2020;5:e437-e443.

9. Baldi E, Sechi GM, Mare C, Canevari F, Brancaglione A, Primi R, et al. Lombardia CARe Researchers. COVID-19 kills at home: the close relationship between the epidemic and the increase of out-of-hospital cardiac arrests. Eur Heart J 2020;41:3045-54.

10. Cannata A, Bromage D, McDonagh T. The collateral cardiovascular damage of COVID-19: only history will reveal the depth of the iceberg. Eur Heart J 2021:42:1524-7.

11. Popovic B, Varlot J, Metzdorf PA, Jeulin H, Goehringer F, Camenzind E, et al. Changes in characteristics and management among patients with ST-elevation myocardial infarction due to COVID-19 infection. Catheter Cardiovasc Interv 2021;97:E319-26.

12. Nef HM, Elsässer A, Mollmann H, Abdel Hadi M, Bauer T, Brück M, et al. Impact of the COVID-19 pandemic on cardiovascular mortality and catherization activity during the lockdown in central Germany: an observational study. Clin Res Cardiol 2021;110:292-301.

13. Primessnig U, Pieske B, Sherif M. Increased mortality and worse cardiac outcome of acute myocardial infarction during the early COVID-19 pandemic. ESC Heart Fail 2020;8:333-343.

14. Tam CF, Cheung KS, Lam S, Wong A, Yung A, Sze M, et al. Impact of coronavirus disease 2019 (COVID-19) outbreak on outcome of myocardial infarction in Hong Kong, China. Catheter Cardiovasc Interv 2021;97(2):E194-E197.

15. De Rosa S, Spaccarotella C, Basso C, Calabrò MP, Curcio A, Filardi PP, et al. Societa` Italiana di Cardiologia and the CCU Academy Investigators Group. Reduction of hospitalizations for myocardial infarction in Italy in the COVID-19 era. Eur Heart J 2020;41:2083-8.

16. Wilson SJ, Connolly MJ, Elghamry Z, Cosgrove C, Firoozi S, Lim P, et al. Effect of the COVID-19 pandemic on ST-segment-elevation myocardial infarction presentations and in-hospital outcomes. Circ Cardiovasc Interv 2020;13:e009438.

17. Gluckman T, Wilson MA, Chiu ST, Penny BW, Chepuri VB, Waggoner JW, et al. Case rates, treatment approaches, and outcomes in acute myocardial infarction during the coronavirus disease 2019 pandemic. JAMA Cardiol 2020;5:1-6.

18. Charask A, D Imperio H. Reporte del registro continuo de infarto ARGEN-IAM-ST en el primer año de pandemia. Congreso SAC . 2021 19. https://www.sac.org.ar/stent-life/que-sucedio-con-los-infartos-con-suprast-durante-la-pandemia-por-covid-19-datos-de-la-iniciativa-stentsave-a-life-argentina/

20. Shambu SK, B SPS, Gona OJ, Desai N, B M, Madhan R, V R, et al. Implementation and Evaluation of Virtual Anticoagulation Clinic Care to Provide Incessant Care During COVID-19 Times in an Indian Tertiary Care Teaching Hospital.

Front. Cardiovasc. Med., 29 March 2021 | https://doi.org/10.3389/fcvm.2021.648265

21. Caldarola P, Murrone A, Roncon L, Di Pasquale G, Tavazzi L, Amodeo V, et al. ANMCO POSITION PAPER: The reorganization of cardiology in times of the SARS-CoV-2 pandemic. Eur Heart J Supplements 2021;23(Supplement C), C154-C163.

22. Hollander J, Carr B. Virtually Perfect? Telemedicine for Covid-19. N Engl J Med 2020;382:1679-81.

23. Velazco P, Streitenberger G, Kyle D, Koch A, De la Fuente V, Tajer C. Consultorio externo virtual en un Hospital Público durante la Pandemia. Rev Argent Cardiol 2020;88:281-2.

24. Zhu Y, Gu X, Xu C. Effectiveness of telemedicine systems for adults with heart failure: a meta-analysis of randomized controlled trials. Heart Fail Rev 2020;25:231-43.

25. Ferrante D, Varini S, Macchia A, Soifer S, Badra R, Nul D, Grancelli H, Doval H; GESICA Investigators. Long-term results after a telephone intervention in chronic heart failure: DIAL (Randomized Trial of Phone Intervention in Chronic Heart Failure) follow-up. J Am Coll Cardiol. 2010;56(5):372-8

26. Davolos I, Bermejo A, Gomez A, et al. ¿Rehabilitación Cardiovascular con distancia o a distancia? - Poster Congreso Argentino de Cardiología 2020. 


\title{
Complicaciones cardiovasculares de la COVID-19
}

\author{
LUCÍA KAZELIAN
}

\section{Introducción}

Desde el inicio de la pandemia de COVID-19 se informaron múltiples complicaciones cardiovasculares asociadas a la morbimortalidad, en particular en pacientes con patologías previas. Las complicaciones referidas fueron elevación de los niveles de troponina, cuadros de insuficiencia cardíaca, episodios de infarto, accidente cerebrovascular, tromboembolismo y diferentes arritmias. (1-3)

Contamos con un registro nacional argentino efectuado durante el año 2020, en colaboración de la Sociedad Argentina de Cardiología y la Federación Argentina de Cardiología, el RACCOVID-19. (4) Describiremos los hallazgos principales del estudio y luego una comparación con otras series publicadas.

El registro se llevó a cabo en 50 centros de 11 provincias entre el 18 de mayo y 31 de octubre de 2020, durante la curva ascendente de la primera ola de nuestro país (Figura 1). Se incluyeron 2750 pacientes de los cuales 420 presentaron complicaciones cardiovasculares, una tasa de 15,3\%. La edad promedio de este grupo fue de $67 \pm 14$ años, predominó el sexo masculino (68\%), el 88,3\% tenía algún factor de riesgo coronario y el 80,4\% antecedentes cardiovasculares. Solo el 26,4\% sumaba otros antecedentes patológicos. (Tabla 1).

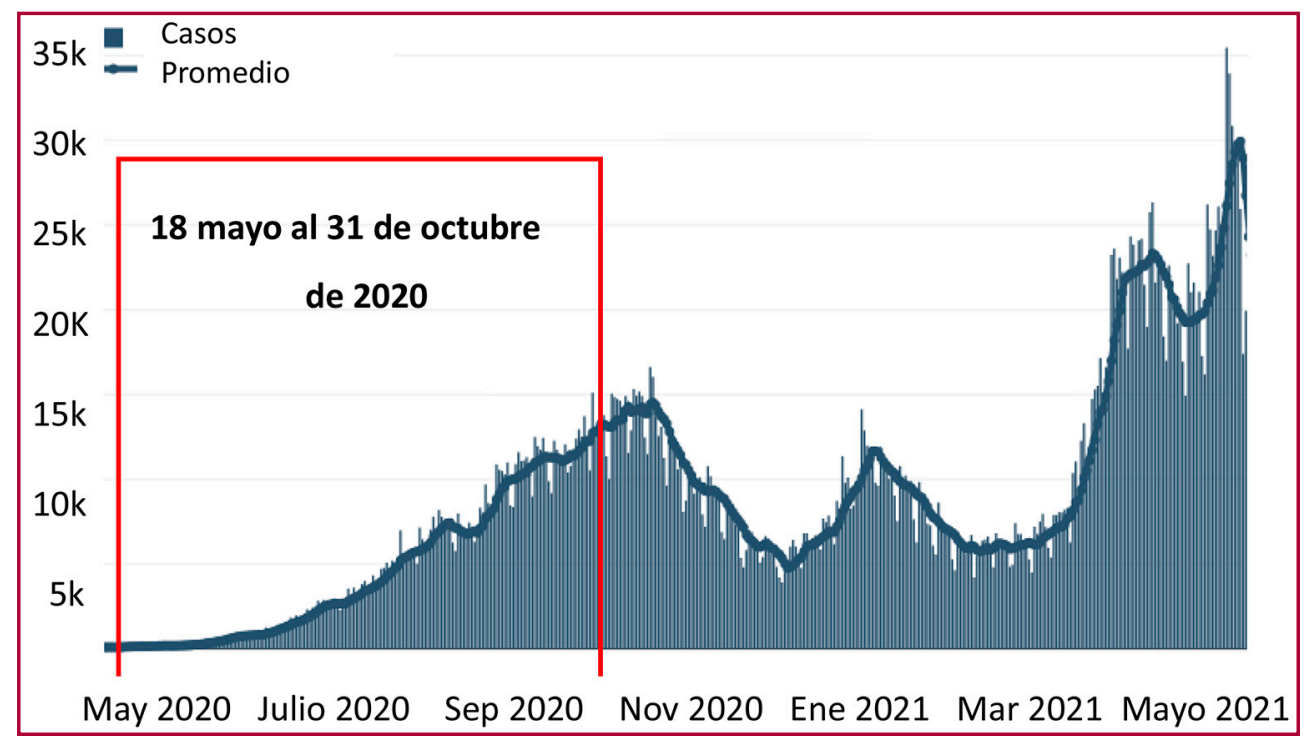

Fig. 1. Período de realización del RACCOVID-19 y su relación con la primera ola de COVID-19 en Argentina.

\begin{tabular}{lcc}
\hline Tabla 1. Características de la población del registro RACCOVID-19 \\
\hline RACCOVID-19 & $\begin{array}{c}\text { Grupo total } \\
\mathbf{N = \mathbf { 2 7 5 0 }}\end{array}$ & $\begin{array}{c}\text { Grupo CCV } \\
\mathbf{N}=\mathbf{4 2 0}\end{array}$ \\
\hline Edad en años (media) & $57 \pm 18$ & $67 \pm 14$ \\
\hline Sexo masculino (\%) & 60,2 & 68,5 \\
\hline Factores de riesgo cardiovascular (\%) & 67,4 & 88,3 \\
\hline Antecedentes cardiovasculares (\%) & 44,2 & 80,4 \\
\hline Otros antecedentes patológicos (\%) & 41,1 & 26,4 \\
\hline Estado clínico (\%) Leve & 50,7 & 18,9 \\
$\quad$ Moderado/Grave & 36,5 & 47,6 \\
Crítico & 12,8 & 33,5
\end{tabular}

CCV: complicaciones cardiovasculares 


\section{Complicaciones Cardiovasculares en el registro RACCOVID-19}

La incidencia de complicaciones cardiovasculares observada fue del 15,3\%; las más comunes fueron la insuficiencia cardíaca, la lesión miocárdica, determinada por el aumento de las troponinas en sangre, y la fibrilación auricular. (Tabla 2).

\begin{tabular}{|c|c|c|}
\hline $\begin{array}{l}\text { Complicaciones } \\
\text { Cardiovasculares }\end{array}$ & $\begin{array}{c}\text { Frecuencia } \\
\text { N (\%) }\end{array}$ & $\begin{array}{c}\text { Mortalidad } \\
\text { N (\%) }\end{array}$ \\
\hline Total & $420(100)$ & $201(47,86)$ \\
\hline Insuficiencia cardíaca & $183(43,5)$ & $109(59,56)$ \\
\hline Complicaciones arrítmicas & $141(33,5)$ & $77(55,32)$ \\
\hline Injuria miocárdica & $131(31,1)$ & $47(35,88)$ \\
\hline Embolias & $47(11,1)$ & $26(55,32)$ \\
\hline Miocarditis & $8(1,9)$ & $1(12,5)$ \\
\hline
\end{tabular}

De las complicaciones cardiovasculares registradas, la insuficiencia cardíaca fue la más frecuente, con 183 pacientes $(6,7 \%$ de la población global - 43,5\% de las complicaciones cardiovasculares), y comprendió la definición clínica determinada por dos cardiólogos o médicos intensivistas distintos, el shock cardiogénico, las alteraciones diastólicas por ecocardiograma Doppler y la congestión pulmonar por ecopleura, detalladas en la Tabla 3. Las arritmias fueron la segunda complicación más frecuente, en 141 pacientes (5,13\% y 33,5\%). Esta categoría incluyó la fibrilación auricular, otras arritmias supraventriculares, las arritmias ventriculares y la prolongación del intervalo QT. La fibrilación auricular fue la arritmia más común, se presentó en 74 pacientes $(2,69 \%$ y 17,6\%).

Se documentó daño miocárdico en 131 pacientes (31,1\%), incluyendo lesión miocárdica (elevación de troponina), infarto agudo de miocardio y trastornos de motilidad en el ecocardiograma.

Tabla 3. Registro RACCOVID19: Tipo específico de complicación cardiovascular Valores expresados en porcentaje sobre 420 pacientes con complicaciones

\begin{tabular}{|lc|}
\hline Complicación cardiovascular & $\%$ \\
\hline Insuficiencia cardíaca & 28,3 \\
\hline Shock cardiogénico/mixto & 16,9 \\
\hline Disfunción diastólica & 3,3 \\
\hline Congestión pulmonar & 2,6 \\
\hline Fibrilación auricular & 17,6 \\
\hline Arritmia supraventricular & 10 \\
\hline Arritmia ventricular & 7,3 \\
\hline Prolongación QT & 2,3 \\
\hline Lesión miocárdica & 18,3 \\
\hline Infarto de miocardio sin ST elevado & 6,9 \\
\hline Infarto de miocardio con ST elevado & 5,7 \\
\hline Trastornos motilidad & 2,3 \\
\hline Tromboembolismo pulmonar & 6,4 \\
\hline Trombosis venosa profunda & 3 \\
\hline Tromboembolismo arterial & 3 \\
\hline Miocarditis & 1,9 \\
\hline
\end{tabular}


Durante la hospitalización, 53 pacientes tuvieron un infarto agudo de miocardio. Presentaron infarto con elevación del segmento ST 24 pacientes, y 22 de ellos (91,7\%) recibieron alguna estrategia de reperfusión: angioplastia primaria en el $66,7 \%$ y trombolíticos en el $25 \%$.

Se observaron complicaciones tromboembólicas en 47 pacientes $(11,1 \%)$, entre ellas, tromboembolismo pulmonar, trombosis venosa profunda y embolias arteriales. Se reportó miocarditis en el 1,9\% de los pacientes.

Fallecieron durante la hospitalización 523 personas (19,3\%). La mortalidad abarcó a 201 pacientes de todos los que tuvieron complicaciones cardiovasculares $(47,86 \%)$. Una serie de variables se relacionaron significativamente con la mortalidad; estas fueron la edad, el sexo masculino, los antecedentes patológicos, hematocrito y creatinina al ingreso, formas más graves de la COVID-19 y complicaciones cardiovasculares.

Los pacientes con enfermedades preexistentes o factores de riesgo cardiovascular son los más propensos a presentar complicaciones; asimismo, cursan con inflamación sistémica más grave y niveles más altos de marcadores inflamatorios. (5) Es importante destacar que, en nuestro registro, estos pacientes eran más añosos, con más factores de riesgo y antecedentes cardiovasculares.

Tanto la tasa de complicaciones cardiovasculares como la mortalidad global en nuestro registro fueron similares a las reportadas en otros registros internacionales del año $2020 \mathrm{y}$, sobre todo, a las que surgen del registro español SEMI-COVID-19 (6) y del registro multicéntrico CAPACITY-COVID. (7) Este último, que abarcó 13 países y fue diseñado para evaluar complicaciones cardiovasculares, reportó una tasa del 11,6\% y una mortalidad global del 19,8\%, datos similares a los de nuestro registro. En la Tabla 4 y la Figura 2 resumimos una comparación entre nuestro registro y el CAPACITY-COVID.

\begin{tabular}{|c|c|c|c|c|}
\hline \multirow[b]{2}{*}{ Complicaciones cardiovasculares } & \multicolumn{2}{|c|}{ RACCOVID $(n=2750)$} & \multicolumn{2}{|c|}{ CAPACITY $(n=3011)$} \\
\hline & 420 & $15,27 \%$ & 349 & $11,59 \%$ \\
\hline Insuficiencia cardíaca & 183 & $6,65 \%$ & 55 & $1,83 \%$ \\
\hline Arritmias & 141 & $5,13 \%$ & 258 & $8,57 \%$ \\
\hline Miocarditis & 8 & $0,29 \%$ & 3 & $0,10 \%$ \\
\hline Fibrilación Auricular & 74 & $2,69 \%$ & 142 & $4,72 \%$ \\
\hline IAM $\sin$ STE & 29 & $1,05 \%$ & 24 & $0,80 \%$ \\
\hline IAM con STE & 24 & $0,87 \%$ & 15 & $0,50 \%$ \\
\hline
\end{tabular}

IAM sin STE: infarto de miocardio sin elevación del ST. IAM con STE: infarto de miocardio con elevación del ST.

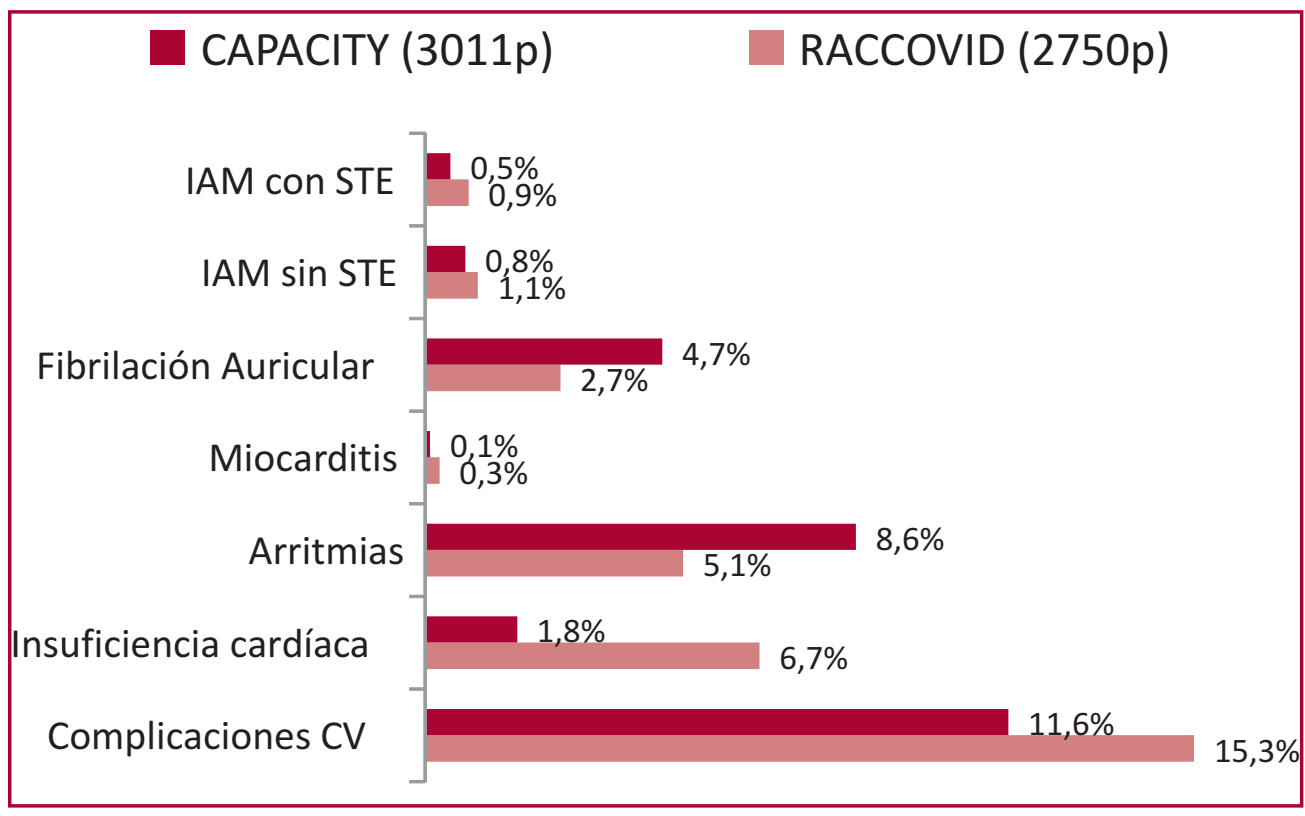

Fig. 2. Complicaciones cardiovasculares (CV) sobre la población total de los dos registros. IAM con STE: infarto agudo de miocardio con elevación del segmento ST. IAM sin STE: sin elevación del segmento ST 


\section{Comentarios finales}

El registro RACCOVID-19 es el único registro de pacientes internados por infección por SARS-CoV-2 en la Argentina durante el año 2020 que analizó las complicaciones cardiovasculares. La presencia de factores de riesgo cardiovascular y antecedentes cardiovasculares fue alta, la aparición de complicaciones cardiovasculares fue del $15,3 \%$ y su presencia se asoció con mayor mortalidad intrahospitalaria. La mortalidad global del 19,3\% coincide con las de otras series internacionales. Es difícil atribuir las complicaciones cardiovasculares a un efecto directo de la infección viral o a las complicaciones generales que el COVID-19 induce en particular en pacientes críticos. En las próximas secciones analizaremos algunas complicaciones en detalle con el objeto de precisar su etiopatogenia y proponer conductas para su manejo y control.

\section{BIBLIOGRAFÍA}

1. Dong E, Du H and Gardner L. An interactive web-based dashboard to track COVID-19 in real time. Lancet Infect Dis 2020:533-4. https:// doi.org/10.1016/S1473-3099(20)30120-1.

2. Clerkin KJ, Fried JA, Raikhelkar J, Sayer G, Griffin JM, Masoumi A. Coronavirus Disease 2019 (COVID-19) and Cardiovascular Disease. https://doi.org/10.1161/CIRCULATIONAHA.120.046941

3. Rozadoa J, Ayestaa A, Morisa C, Avanzasa P. Fisiopatologia de la enfermedad cardiovascular en pacientes con COVID-19. Isquemia, trombosis y disfuncion cardiaca. Rev Esp Cardiol Supl. 2020;20(E):2-8

4. Kazelian LR, Zapata G, Pereiro Gonzalez S, Maydana M, Lescano A, Lorenzatti E, Navarro Estrada JL. RACCOVID-19: primer Registro Argentino de Complicaciones Cardiovasculares en pacientes con COVID-19. Rev Argent Cardiol 2021;89:285-92. http://dx.doi.org/10.7775/ rac.es.v89.i4.20408

5. Babapoor-Farrikhran S, Gill D, Walker J, Tarigathi Rasekhi R, Bozorgnia B, Amanullah A. Cardiovascular disease and COVID-19: possible mechanisms. Life Sci 2021;15:477

6. Casas-Rojo JM, Antón-Santos JM, Millán-Núñez-Cortés J, Lumbreras-Bermejo C, Ramos-Rincón JM, Roy-Vallejo E, et al. Características clínicas de los pacientes hospitalizados con COVID-19 en España: resultados del Registro SEMI-COVID-19. Rev Clin Esp 2020;220:480-94.

7. Linschoten M, Peters S, van Smeden M, Jewbali LS, Schaap J, Siebelink HM et al. Cardiac complications in patients hospitalized with COVID-19. The CAPACITY -COVID collaborative consortium. Eur Heart J Acute Cardiovasc Care 2020;9:817-23. https://doi. org/10.1177/2048872620974605. 


\title{
Daño miocárdico por COVID-19
}

\author{
STELLA MARIS PEREIRO GONZÁLEZ
}

La infección por SARS-CoV-2 puede generar daño miocárdico (injuria) por diferentes mecanismos, lo que se sospecha en la práctica clínica por el incremento de los niveles de troponina. El incremento de troponina fue reconocido ya en las primeras series publicadas y se asocia a peor pronóstico (1-3), lo que ha generado una serie de exploraciones para comprender su origen y relevancia. El espectro clínico es amplio, y el significado de este hallazgo resulta muy variado: desde pacientes con daño indirecto vinculado a la complejidad de la situación clínica (hipoxemia, taquiarritmia, tromboembolismo, falla multiorgánica, tormenta de citoquinas) a pacientes con afectación directa por cuadros isquémicos primarios (4), Takotsubo (5) o miocarditis, en ambos casos sumado a las patologías preexistentes de alta prevalencia en casos graves (diabetes, hipertensión, coronariopatía).

\section{Elevación de troponina - Frecuencia e importancia}

La elevación de troponina es frecuente en pacientes internados por COVID-19, con incidencias de hasta un 50\%, y guarda relación con la gravedad del cuadro. (1-3) La incidencia de injuria miocárdica expresada por la elevación de troponina ha sido variable en diferentes series, aunque en todas se refiere su asociación con una mayor mortalidad (1, 6-8). En un metaanálisis de seis series en China, la incidencia de injuria miocárdica varió del 8 al $27 \%$ y se asoció a un riesgo relativo (RR) de mortalidad de 3,41 (9). La serie del Mount Sinai en EEUU informó una incidencia del $36 \%$, y un RR de muerte de 3,03. (10)

En una revisión, los pacientes que tenían troponinas elevadas mostraban un fenotipo de mayor edad, sexo masculino, más presencia de comorbilidades como hipertensión, enfermedad coronaria, miocardiopatía y enfermedad renal crónica y tenían niveles más altos de leucocitos, péptidos natriuréticos, dímero $\mathrm{D}$, proteína $\mathrm{C}$ reactiva, interleuquina IL6 y procalcitonina, pero un recuento de linfocitos menor. Estos pacientes presentaban síndrome de distrés respiratorio agudo y mayor mortalidad que aquellos en los que no se sospechaba lesión cardíaca. (11)

En series históricas de pacientes con compromiso multiorgánico (12) internados en cuidados intensivos también se informó una incidencia de elevación de troponina del 50\%. Una serie actual (13) incluyó 243 pacientes intubados por COVID-19 y lo comparó con un grupo similar con distrés respiratorio no COVID. En el grupo COVID-19 la incidencia de troponina elevada fue del 51\% y se asoció con mayor mortalidad. Llamativamente la frecuencia de injuria miocárdica en los pacientes COVID-19 fue menor que en el grupo no COVID-19, con un odds ratio de 0,55 .

Los pacientes más graves, con mayor compromiso multiorgánico y más patología preexistente se complican con injuria miocárdica y mayor mortalidad, lo que no diferencia a la COVID-19 de otras infecciones respiratorias o enfermedades en pacientes críticos.

\section{Implicancias pronósticas de la elevación de troponina}

La elevación de niveles de troponina en la COVID-19 se asocia a un peor pronóstico en general y acompaña a un cuadro de compromiso general más grave.

En marzo de 2020 se publicó un análisis retrospectivo (14) de 191 pacientes de Wuhan donde se describe que la elevación de troponina I cardiaca de alta sensibilidad, así como otros biomarcadores, eran mucho más frecuentes en pacientes que no sobrevivieron a la COVID-19 y aumentaron con el agravamiento del curso clínico. La troponina I aumentó rápidamente desde el día 16 del inicio de la enfermedad. El aumento de troponina pudo observarse en $17 \%$ del total de pacientes en los que se contó con este dato (145), con una distribución de $46 \%$ en los no sobrevivientes (23 de 50) y $1 \%$ de los sobrevivientes (1/95). (Figura 1)

Diferentes publicaciones coinciden en que los pacientes hospitalizados con COVID-19 que evidencian lesión miocárdica manifestada por elevación de la troponina, tuvieron tasa de mortalidad hospitalaria significativamente mayor que aquellos sin lesión miocárdica. $(15,16)$ Las mayores tasas de mortalidad se observaron en aquellos que además de la elevación de troponinas tenían enfermedad cardiovascular subyacente, llegando en estos casos al 70\%, pero fue también elevada aún sin enfermedad cardiovascular (37\%). Los pacientes sin elevación de troponinas con enfermedad cardiovascular conocida, tuvieron un pronóstico relativamente más favorable (mortalidad 13\%). (Figura 2) 


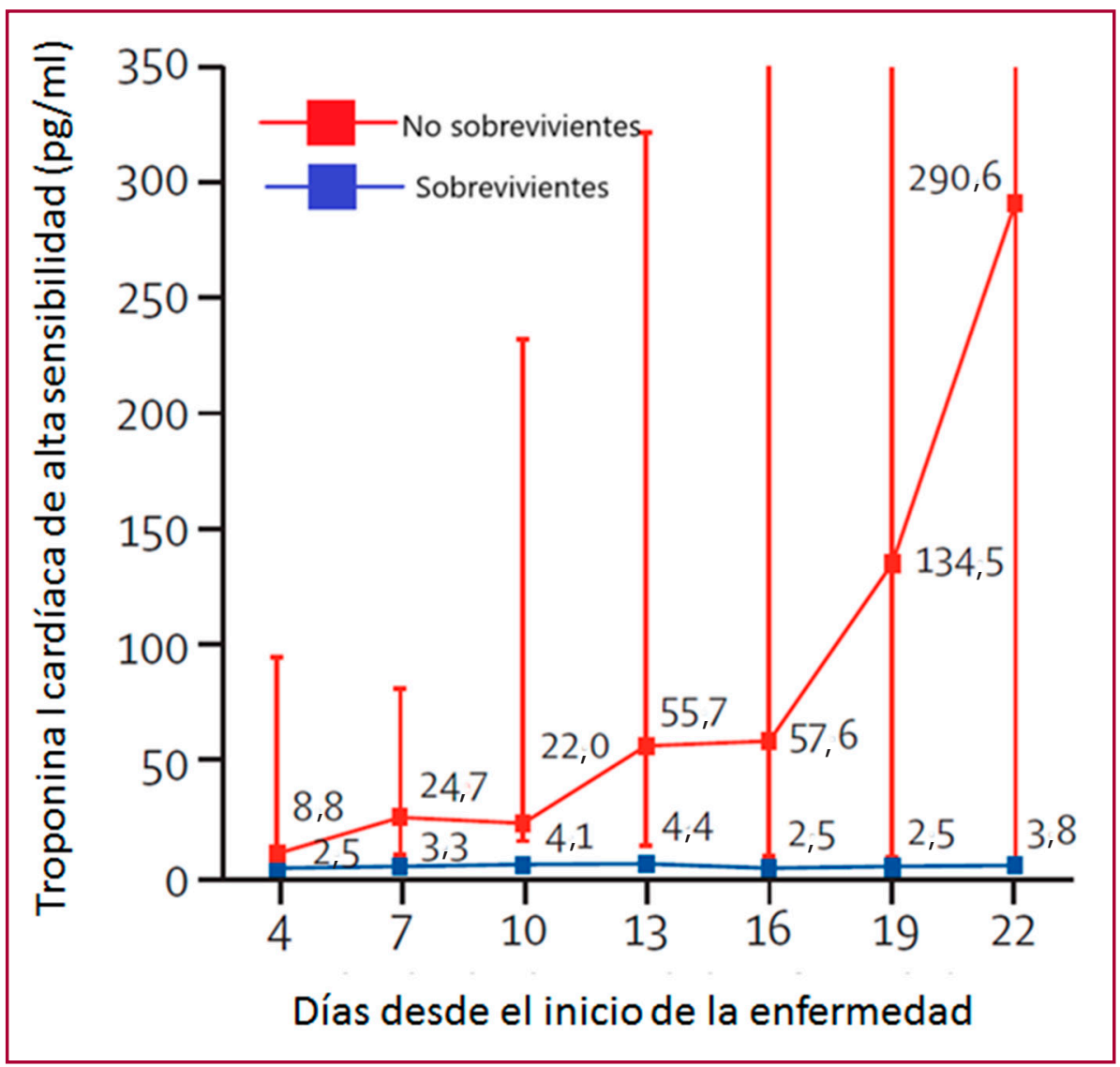

Fig. 1. Elevación de troponina I y sobrevida. Adaptado de Zhou F et al. Lancet 2020, etc

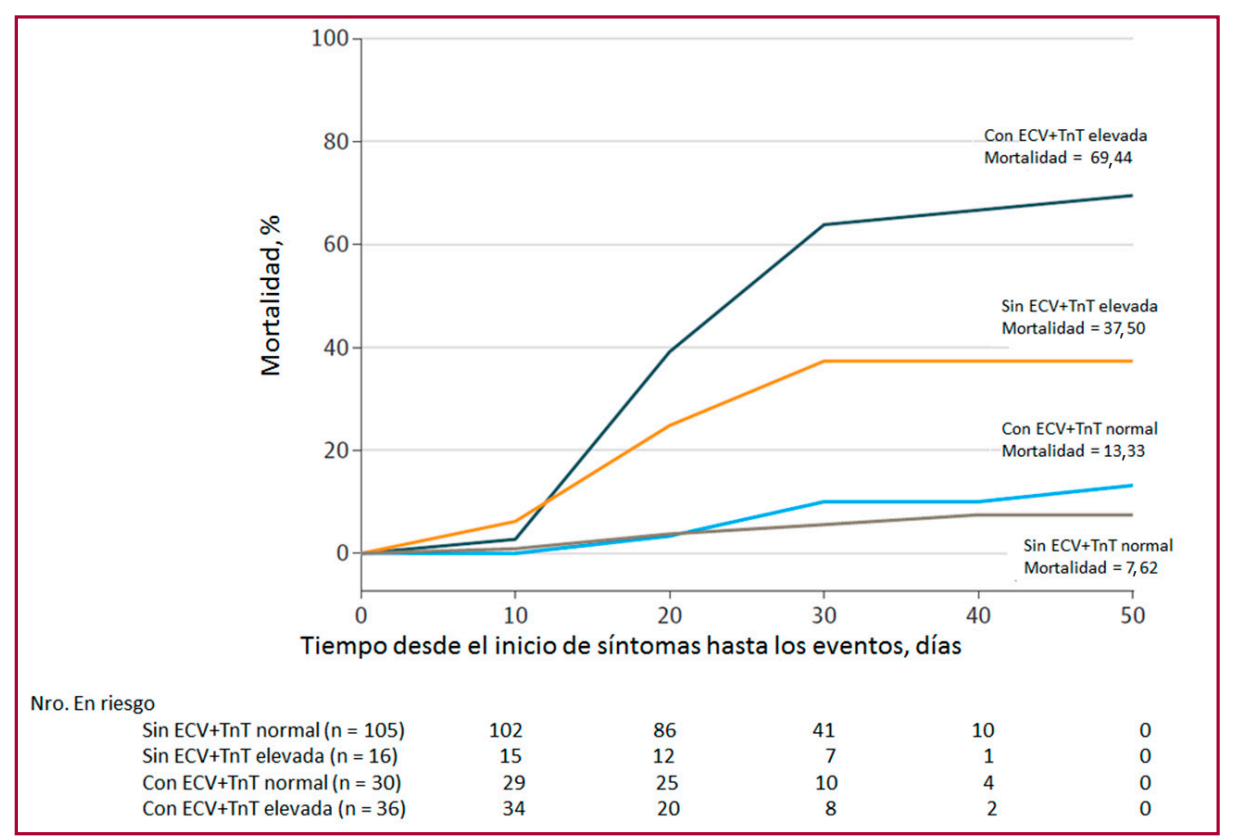

Adaptado de Guo T et al. JAMA Cardiol. 2020;5:811-818 (1)

Fig. 2. Mortalidad de pacientes con enfermedad por coronavirus 2019 (COVID-19) con o sin enfermedad cardiovascular (ECV) y con / sin niveles elevados de troponina T (TnT) 
Los niveles de troponinas se vieron significativamente asociados con los de proteína $\mathrm{C}$ reactiva y péptidos natriuréticos, lo cual vincula la lesión miocárdica con la gravedad de la inflamación y la disfunción ventricular. Aquellos pacientes con un curso clínico en deterioro hasta la muerte mostraron aumentos progresivos de TnT y NT-proBNP. (17) En la serie del Hospital Mount Sinai (10) incorporaron 2737 pacientes con una edad promedio de 66,4 años; la prevalencia de elevación menor de troponina fue el 16,6\% con un RR de mortalidad de 1,7, y elevaciones mayores de troponina se observaron en 19,4\%, con $\mathrm{RR}$ de mortalidad de 3,03. La elevación de troponina coincidió con mayores antecedentes de hipertensión, enfermedad coronaria, insuficiencia cardíaca y diabetes. También coincidió con evidencias de inflamación sistémica más grave: mayor recuento de leucocitos, mayores niveles de niveles de proteína $\mathrm{C}$ reactiva y procalcitonina, así como de otros biomarcadores de lesión miocárdica y estrés como creatina quinasa, mioglobina y NT-proBNP. Los pacientes que desarrollaron lesión miocárdica tuvieron evidencia de mayor compromiso clínico, síndrome de dificultad respiratoria aguda y necesidad de ventilación asistida que aquellos sin lesión miocárdica por lo que surge la hipótesis de que pacientes mayores, con comorbilidades cardiovasculares y diabetes, son propensos a desarrollar una enfermedad más grave asociada a mayor riesgo de lesión miocárdica, y mortalidad a corto plazo marcadamente más elevada.

\section{Hallazgos ecocardiográficos en pacientes críticos}

Un estudio multicéntrico evaluó en forma prospectiva con ecocardiografía transtorácica una cohorte de 305 pacientes, y lo relacionó con la presencia de lesión miocárdica, definida por cualquier elevación de la troponina durante la evolución. (18) Un 62,3\% de los pacientes elevaron la troponina, lo que coincidió con mayor frecuencia de anomalías electrocardiográficas, biomarcadores inflamatorios más altos y mayor prevalencia de anomalías ecocardiográficas importantes: alteración de la motilidad parietal y/o disfunción global del ventrículo izquierdo, disfunción diastólica grado II o III, disfunción derecha y derrame pericárdico. La mortalidad hospitalaria fue de 5,2\% en pacientes sin lesión miocárdica, 18,6\% con lesión miocárdica sin anomalías ecocardiográficas y 31,7\% con anomalías ecocardiográficas. (Figura 3). Sobre la base de estos resultados se sugiere la evaluación ecocardiográfica de rutina en todos los pacientes con elevación de troponina. (19)

Un registro escandinavo (20) evaluó los hallazgos ecocardiográficos durante la fase aguda y a los 2-3 meses en 91 pacientes COVID-19 de 63 años promedio de edad, y a su vez los comparó con un grupo control apareado con similares características clínicas. El 27,7\% habían cursado con elevación de troponina. Durante la internación los parámetros grupales promedio anormales fueron en el ventrículo izquierdo el strain global longitudinal (SGLVI), y en el ventrículo derecho la excursión sistólica del plano del anillo tricuspídeo (TAPSE) y el strain global longitudinal (SGLVD). No se afectó la fracción de eyección del VI ni los volúmenes de ambos ventrículos. En la evolución la fracción de eyección del ventrículo izquierdo bajó levemente de 59,9 $\pm 6,2$ a 57,1 \pm 7,4, sin diferencias con el grupo control. El SGLVI no mejoró evolutivamente (17,6 $\pm 3,3$ vs 17,4 $\pm 2,9 \%)$, y se mantuvo más bajo que en el grupo control, 18,8 $\pm 2,9 \%$. El TAPSE mejoró levemente pero se mantuvo más bajo que en el grupo control. También mejoró el SLGVD de 19,9 \pm 5,8 a 25,3 \pm 5,5\%, cercano a valores del grupo control, 26,6 $\pm 0,44 \%$. En forma global este estudio muestra que la afectación ventricular evaluada por strain no se normalizó en la evolución, pero dado que no era de magnitud relevante, la implicancia de este hallazgo en el largo plazo es difícil de estimar.

La angiografía coronaria debe aconsejarse sólo en pacientes con elevación de troponinas y síntomas sugestivos de síndrome coronario agudo.

\section{Mecanismos del daño miocárdico causado por COVID-19 (Figura 4)}

Es de gran interés explorar cuáles son los mecanismos de injuria miocárdica en las infecciones por COVID-19, su frecuencia relativa e importancia clínica, tanto para el manejo agudo como para la evolución alejada.

En los primeros meses de la pandemia se detectaron con frecuencia diferentes afectaciones cardíacas, y se sospechó una posible agresión directa del virus al miocardio en forma de miocarditis viral como causa prevalente. Las posteriores exploraciones aclararon que en la mayor parte de los casos la agresión al miocardio es indirecta, secundaria a diferentes factores que complican la evolución clínica en pacientes críticos: hipoxemia, taquiarritmias, tromboembolismo pulmonar, tormenta de citoquinas, agresión multiorgánica. Esta agresión se multiplica por la morbilidad previa, y es mayor ante antecedentes de insuficiencia cardíaca, coronariopatía, diabetes y otras condiciones de riesgo cardiovascular.

Aunque menos frecuente, la agresión al miocardio por COVID-19 puede ser directa y se han descrito casos de Takotsubo, infarto de miocardio tipo I clásico y miocarditis. La miocarditis requiere un repaso detallado, por el riesgo potencial que implica a futuro. 


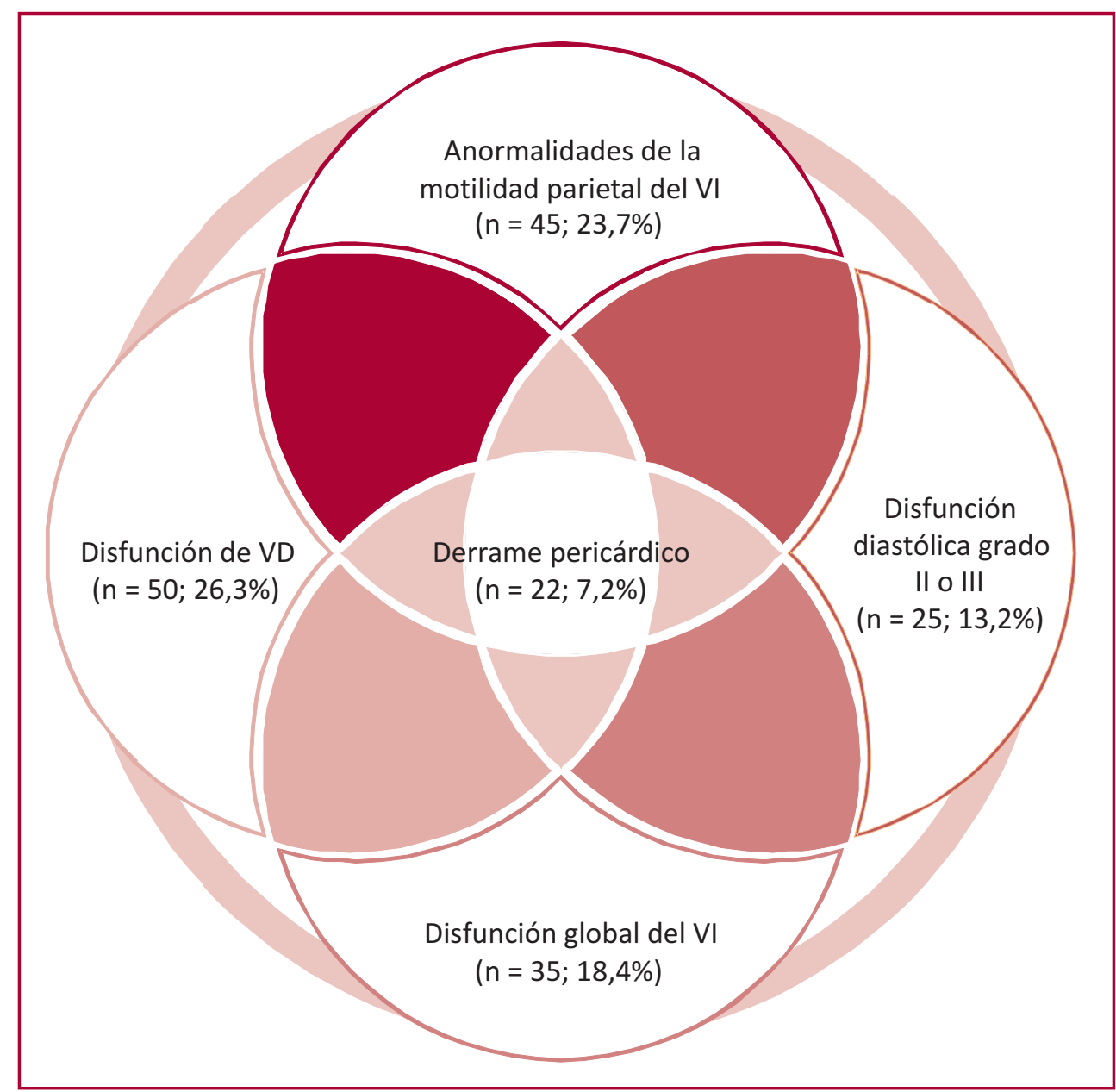

VI: ventrículo izquierdo VD: ventrículo derecho. Adaptado de Giustino et al. J Am Coll Cardiol 2020;76:2043-55 (18)

Fig. 3. Espectro de anomalías ecocardiográficas en pacientes con evidencia de biomarcadores de lesión miocárdica y COVID-19

\section{¿Existe la miocarditis viral en COVID-19?}

Como hemos comentado, el hallazgo de injuria miocárdica y otras alteraciones cardiovasculares es frecuente, pero en la mayoría de los casos está vinculado a patologías preexistentes o a la gravedad del cuadro clínico general. La información sobre la incidencia de miocarditis y su relevancia clínica tiene fuentes muy heterogéneas que intentaremos resumir para poder definirla con mayor precisión.

\section{Información de bases administrativas}

El diagnóstico clínico de miocarditis no es un reporte frecuente en pacientes con COVID-19. Una fuente relevante para estimar su incidencia con un enfoque epidemiológico son las bases administrativas

En una evaluación de datos de 900 hospitales el CDC comparó la cantidad de casos con diagnóstico de miocarditis de marzo 2020 a enero del 2021. (21) El riesgo de miocarditis se estimó en 0,146\% en pacientes con diagnóstico de COVID-19 y de 0,009\% entre los pacientes sin este diagnóstico, lo que resulta en un riesgo ajustado 15,7 veces mayor (14,1 a 17). Comparada con el año 2019, la incidencia de miocarditis fue de un 42,3\% mayor en el 2020. Como resumen, 1,5 casos cada 1000 pacientes con COVID-19.

Otro estudio poblacional de USA analizó 70288 pacientes con COVID-19 de una base administrativa, la mitad de ellos internados y el $5 \%$ que requirió cuidados intensivos. (22) Los diagnósticos de mayor incidencia y valor absoluto fueron la neumonía (riesgo absoluto 27,6\%) y la insuficiencia respiratoria (22,6\%). La miocarditis tuvo una fuerte vinculación con COVID-19, OR 8,17, pero con un riesgo absoluto bajo, del 0,1\%, es decir, 1 en 1000 casos.

Un estudio israelí incluyó dos grupos similares de 884828 personas con o sin vacunación para COVID-19 con la vacuna BNT162b2 mRNA (Pfizer) (23) La vacunación se asoció con un incremento de riesgo de miocarditis 


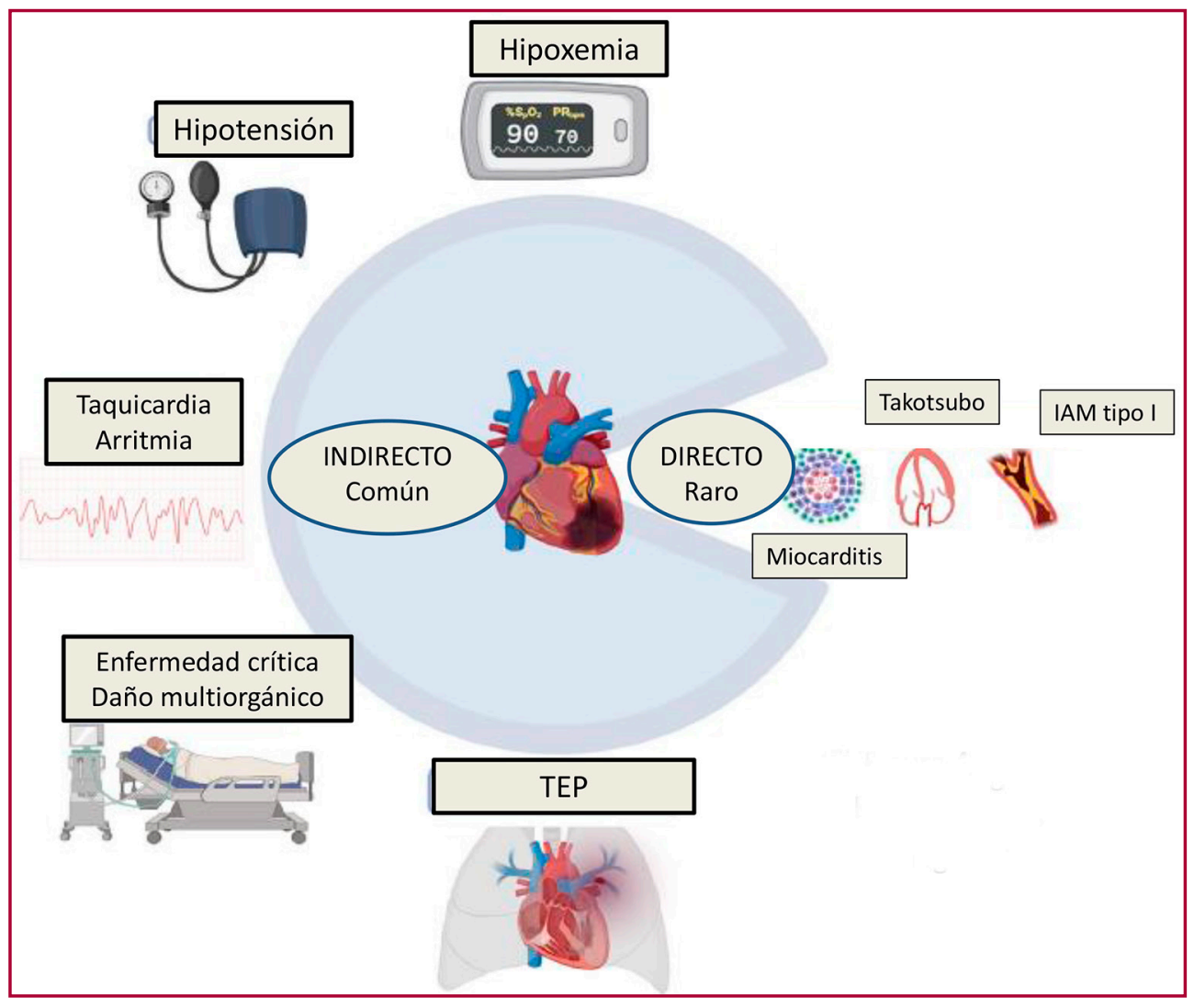

Fig. 4. Mecanismos de daño miocárdico en COVID-19. Modificado de Chilazi M, Duffy E, Thakkar A, Michos D. COVID and Cardiovascular Disease: What We Know in 2021. Current Atherosclerosis Reports (2021) 23: 37

(RR 3,24; IC 95\% 1,55 a 12,44; diferencia de riesgos, 2,7 eventos por cada 100000 personas; IC95\%, 1,0 a 4,6). La infección por SARS-CoV-2 se asoció a un riesgo sustancialmente mayor de miocarditis (RR 18,28; IC 95\%, 3,95 a 25,12; diferencia de riesgos 11,0 eventos por 100000 personas). Estos datos demuestran que la COVID-19 tiene mucho mayor riesgo de miocarditis que las vacunas que intentan evitar el contagio o la complicación. En comparación con las dos series poblacionales anteriores, el diagnóstico de miocarditis fue de solo 21 casos, 2 en 100000.

Las bases administrativas tienen muchas limitaciones, entre ellas el desconocimiento de cuáles fueron los criterios para el diagnóstico. Sin embargo, brindan una primera información relevante: el diagnóstico clínico de miocarditis es muy infrecuente en pacientes con COVID-19, y no es la interpretación habitual que dan los profesionales a la elevación de troponina.

\section{Miocarditis en autopsias o biopsia endomiocárdica}

La histopatología de la miocarditis requiere para el diagnóstico la suma de inflamación y daño miocárdico. En 21 autopsias de personas fallecidas por COVID-19, Basso et al (24) confirmaron el diagnóstico de miocarditis linfocítica real en 3 casos (14\%), mientras que en 18 (86\%) hallaron infiltración intersticial generalizada de macrófagos en el miocardio sin lesión de miocitos. Sugieren que, en comparación con el virus SARS-CoV anterior, los cambios cardíacos inflamatorios observados con el virus actual parecen ser más acentuados.

En una revisión sistemática (25) sobre COVID-19 y casos reportados de miocarditis desde diciembre de 2019 a septiembre de 2020 los autores agruparon 38 casos (26 pacientes varones, 24 menores de 50 años). Se encontraron datos histológicos en 12 casos (8 biopsias y 4 autopsias) y la resonancia magnética cardíaca (RMC) fue la principal modalidad de imagen para confirmar el diagnóstico de miocarditis ( 25 pacientes). El $45 \%$ de los casos tenían fiebre en el momento de la presentación o aumento leve de la temperatura. A nivel de laboratorio, los niveles de troponina fueron muy variables, y los péptidos natriuréticos se elevaron en pocos casos. La mayoría de los pacientes presentaron alteraciones en los electrocardiogramas, pero los hallazgos difirieron entre sí. Algunos pacientes no presentaron anomalías estructurales o funcionales en el ecocardiograma (20\%). Dos tercios de los pacientes fueron evaluados por RMC, con realce tardío de gadolinio evidente en la mitad de los casos. En 19 de los casos se observó edema difuso e inflamación miocárdica. En los casos evaluados, se realizó biopsia endomiocárdica solo en 8 y uno solo describió claramente la presencia de SARS-CoV-2 en el cardiomiocito. Los 


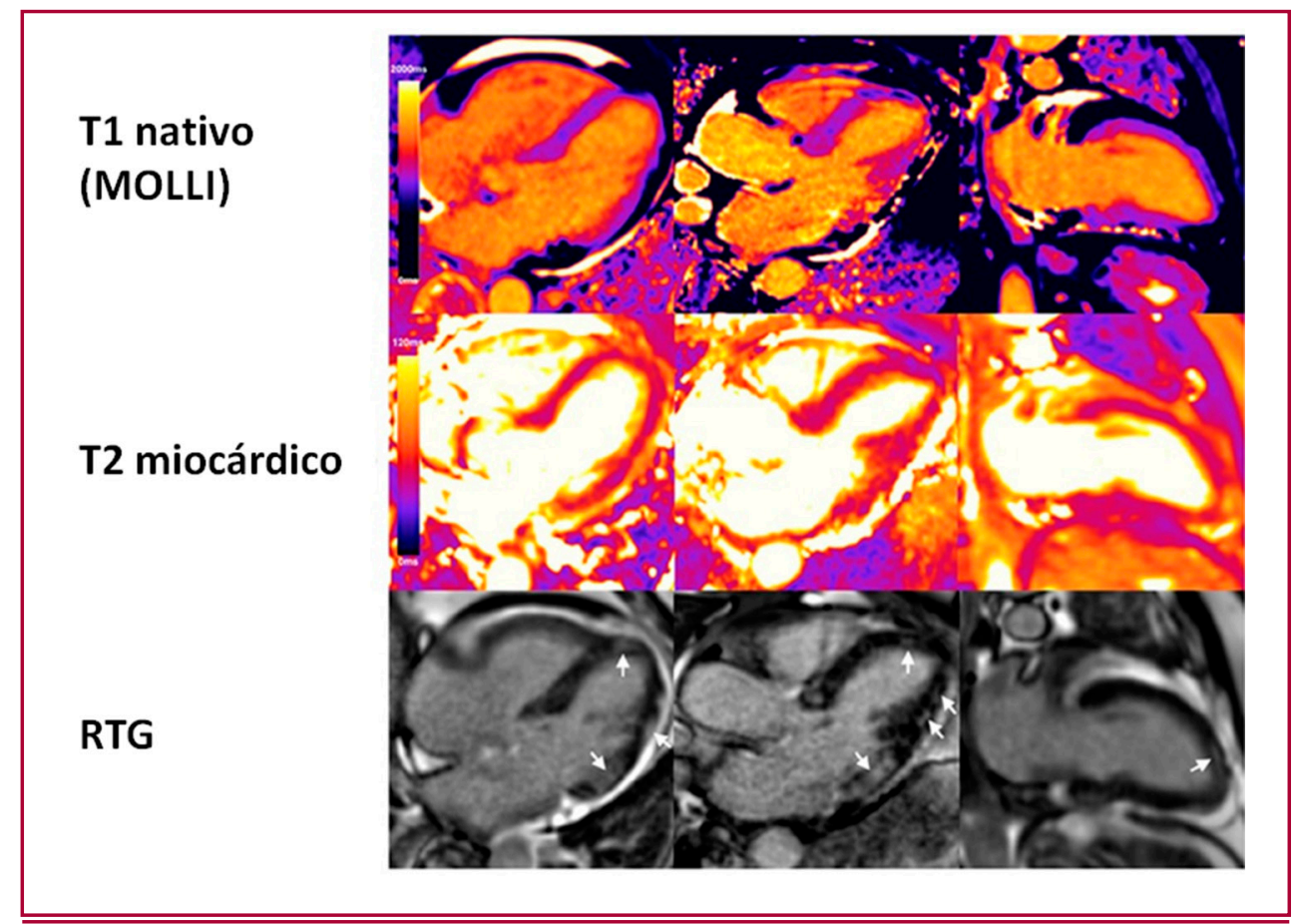

Fig. 5. Ejemplo de paciente con realce tardío de gadolinio con patrón de miocarditis y evidencia de inflamación activa. T1 nativo y T2 miocárdico estaban elevados en la pared inferolateral (T1 $1261 \mathrm{~ms}$, T2 $56 \mathrm{~ms}$ ) y normales en el inferoseptum basal (T1 $983 \mathrm{~ms}, \mathrm{~T} 250 \mathrm{~ms}$ ). Las imágenes de realce tardío con gadolinio muestran áreas parcheadas de realce subepicárdico en la pared lateral y la pared basal inferior, y realce de la pared media en el tabique distal y la pared anterior distal (flechas blancas). Cita 38. Eur Heart J 2021;42:1866-1878

hallazgos histológicos mostraron inflamación miocárdica con predominio de macrófagos, pero limitada necrosis de los miocitos. Los hallazgos de autopsias en 4 pacientes incluyeron acumulación de células inflamatorias en el endotelio e infiltrados inflamatorios.

En una revisión de casos de autopsia publicados por COVID-19, se analizó el corazón de 99 pacientes. El hallazgo más frecuente fue la cardiomegalia e hipertrofia ventricular izquierda por cardiopatías preexistentes. Si bien el $24 \%$ tuvo inflamación miocárdica, sólo se confirmó miocarditis linfocítica en 3 casos y eosinofílica en un caso, publicado como reporte individual en una joven de 17 años. (26)

La biopsia endomiocárdica es el estándar de oro para el diagnóstico de miocarditis, pero su aplicación es muy limitada. El hallazgo histopatológico más común es la miocarditis linfocítica, que se caracteriza por infiltrados de linfocitos T y macrófagos, con escasos linfocitos B, pero la primera presentación clínica descrita sugestiva de miocarditis fulminante en contexto de shock séptico por COVID-19, no cumplió con los criterios de Dallas para miocarditis, hallazgo descrito en otras infecciones virales. $(25,27)$ De acuerdo a las guías de la Asociación Europea de Patología Cardiovascular (28), para el diagnóstico de miocarditis, no es suficiente un infiltrado inflamatorio en parches, en ausencia de necrosis de miocitos.

Un estudio reportó dos casos de pacientes jóvenes con sospecha clínica por hallazgos de ondas T negativas en cara anterior y disfunción miocárdica en el ecocardiograma, a los cuales se efectuó biopsia endomiocárdica. (29) La disfunción había aparecido en forma alejada a un cuadro agudo, con hisopado y PCR negativa al momento de la consulta, pero con anticuerpos IgG positivos para SARS-CoV-2. Observaron inflamación del miocardio por inmunohistoquímica e histología, en ausencia de necrosis de cardiomiocitos (criterios de Dallas de 'miocarditis límite'), con aumento de linfocitos, macrófagos (Mac-1) y células T citotóxicas positivas. El proceso inflamatorio parecía ir acompañado de un aumento del grosor de las arterias pequeñas. Detectaron ácidos nucleicos específicos del SARS-CoV-2 en el miocardio. Este hallazgo indica que la posible miocarditis puede ocurrir luego de una presentación respiratoria curada o en un curso clínico leve. Estas miocarditis subagudas fueron similares a otras formas virales de miocarditis y podrían tener implicaciones modestas en la función cardíaca, como se observó en uno de los pacientes, o evolucionar a insuficiencia cardíaca con fracción de eyección reducida, como sucedió en el otro. Ambos pacientes eran jóvenes y uno de ellos físicamente activo; por el contrario, el otro tenía antecedentes 
cardiovasculares. Otros reportes de autopsias informaron también evidencias de ARNm viral en el miocardio, aunque no se confirmó miocarditis por criterios clásico. (30)

Halushka et al (31) analizaron una gran serie de autopsias (277 casos) y la tasa de miocarditis fue de 7,2\%, aunque no todos los casos cumplían con criterios clásicos. En este análisis los hallazgos cardíacos más frecuentes fueron infiltrados inflamatorios no miocarditis, e isquemia en el 12,6\% y el 13,7\% de los casos. Se observaron infartos agudos de miocardio en el $4,7 \%$ de los individuos.

\section{Rol de la resonancia magnética cardíaca en pacientes con COVID-19}

La RMC permite la caracterización de los tejidos y puede conducir al diagnóstico de miocarditis según los criterios de Lake Louise. (32) El edema miocárdico evaluado con secuencias ponderadas en T2 proporciona un papel único para la RM en la valoración cardíaca no invasiva de pacientes con sospecha de inflamación en curso. (33) (Figura 5)

En casos de COVID-19 se han observado hallazgos típicos de miocarditis, diferentes grados de realce tardío con gadolinio, y en algunos casos se observó edema sin realce tardío. Las series iniciales reportaron un $60 \%$ de hallazgos patológicos con inflamación y una pequeña proporción con escasa fibrosis miocárdica (34) en pacientes añosos, lo que generó una grave preocupación sobre la eventualidad de que evolucionara tardíamente a miocardiopatía. Esta alteración, según un informe, en pacientes jóvenes, previamente sanos, atletas de alta competición con síntomas leves o sin síntomas, fue menor a $15 \%$. (35)

Estudios posteriores no confirmaron esa prevalencia de inflamación, aunque también encontraron algún grado de fibrosis. (36) En series poblacionales de personas sin cardiopatía se reportó el hallazgo de fibrosis miocárdica en el 4\%, sin implicancias clínicas, lo que hace sospechar que es una secuela de menor magnitud de otras infecciones virales. (37)

Un estudio llevado a cabo por Kotecha et al (38) informó 148 pacientes hospitalizados con COVID-19, con lesión cardíaca aguda por valores elevados de troponina, a los que alrededor de 2 meses luego de la recuperación se aplicó un protocolo de RMC estándar. El 54\% presentó anomalías cardíacas, 38\% tuvieron un patrón de cicatriz/ lesión de tipo inflamatorio y $28 \%$ de tipo isquémico. Nueve pacientes presentaron un patrón dual, y $8 \%$ de los pacientes aún tenían evidencia de inflamación miocárdica en curso. En este informe se evidencia que la lesión cardíaca es común luego de 2 meses posteriores al cuadro agudo. Raman (39) et al reportaron tasas más bajas, con solo un $26 \%$ con $\mathrm{T} 1$ anormal y un $11,5 \%$ con un patrón de realce tardío inflamatorio.

Dado que el diagnóstico anatomopatológico de miocarditis es excepcional mientras que la inflamación miocárdica por RMC es frecuente, debemos interpretar estos hallazgos no como patognomónicos de miocarditis sino como un grado de inflamación miocárdica que hasta ahora ha tenido un comportamiento benigno clínicamente. Es difícil saber cuál es su implicancia alejada.

\section{Como hacer el diagnóstico de una miocarditis por COVID-19}

En general, la lesión cardíaca coexiste con casos graves e insuficiencia multiorgánica, mientras que la miocarditis continúa siendo anecdótica. Para la diferenciación entre miocarditis y lesión cardíaca en contexto de COVID-19 grave y/o fallo multiorgánico, se han utilizado los criterios diagnósticos de miocarditis aguda, que requieren al menos una presentación clínica compatible y un criterio diagnóstico junto con la exclusión de la enfermedad coronaria (angiográfica) y de otras causas cardiovasculares o no cardíacas. (11)

La elevación de troponinas es el marcador más utilizado de lesión miocárdica y es un primer elemento de orientación al posible diagnóstico de miocarditis. Su hallazgo, en ausencia de un cuadro clínico grave de COVID-19 agresiva, podría hacer sospechar en una afectación cardíaca aislada. En contraposición, elevaciones de troponina combinadas con un aumento generalizado de los marcadores inflamatorios sugerirían fallo multiorgánico y una respuesta hiperinflamatoria. El aumento de péptidos natriuréticos se asocia con peor evolución, porque refleja una sobrecarga hemodinámica y disfunción cardíaca. Ninguno de estos marcadores distingue entre las etiologías de la afectación cardíaca.

Las alteraciones electrocardiográficas en las miocarditis no son patognomónicas, ya que se han descrito una variedad de patrones que van desde lo más simple, la taquicardia sinusal o extrasístoles, hasta elevación del ST e inversión de la onda T. (18)

El método más accesible para evaluar el compromiso funcional cardíaco es la ecocardiografía transtorácica. Es crítica para definir el compromiso de la función global y la diferenciación con cuadros isquémicos o Takotsubo. Los hallazgos en la miocarditis relacionada con COVID-19 incluyen desde la hipocinesia global o regional, hasta el aumento del grosor parietal que sugiere edema miocárdico, aunque es difícil de valorar este último debido a condiciones cardiovasculares preexistentes como la hipertrofia ventricular secundaria a hipertensión. Pero cabe destacar que pacientes con miocarditis sospechada por otros criterios como la resonancia pueden tener un examen ecocardiográfico normal. 
Los estudios histopatológicos de series de autopsias (24) sugieren que la miocarditis aguda es poco frecuente en pacientes que sucumbieron a COVID-19. Tomados en conjunto, los estudios sugieren que hasta el $64 \%$ de los pacientes con COVID-19 aguda sintomática pueden haber sufrido síntomas prolongados que incluyen fatiga y dificultad para respirar a pesar de una tasa muy baja de insuficiencia cardíaca sistólica. Las anomalías del tejido miocárdico caracterizadas por resonancia magnética son comunes durante la recuperación de COVID-19, pero aún no se conocen las relaciones causales de estos cambios tisulares con los síntomas y los eventos cardíacos futuros.

La resonancia magnética nuclear es un método de gran utilidad. Es difícil de aplicar en la fase aguda en pacientes graves, pero se ha utilizado con frecuencia en el período alejado. Como hemos comentado en la sección anterior, el hallazgo de inflamación miocárdica ha sido reportado con incidencias muy elevadas, por encima de la posible incidencia real de miocarditis, por lo que su rol en la secuencia diagnóstica debe ser restringido a pacientes con fuerte sospecha clínica.

La biopsia endomiocárdica es el patrón de oro para el diagnóstico, pero debe ser indicada con criterios muy restringidos, acordes a la gravedad del cuadro y tras descartar otras posibles etiologías.

\section{Esquema de diagnóstico frente a la sospecha de miocarditis}

El diagnóstico de miocarditis puede sospecharse ante la presencia de niveles elevados de troponina en pacientes sin grave compromiso por COVID-19, con cambios electrocardiográficos o la presencia de arritmias, y en los que se confirma disfunción sistólica no segmentaria por ecocardiografía. En ausencia de otras etiologías, la RMC puede confirmar la presencia de inflamación miocárdica y en casos graves indicar biopsia endomiocárdica. Esto puede ocurrir durante la fase aguda del COVID-19 o en el período posterior.

En una evaluación de 789 atletas competitivos post COVID (40), aplicaron un enfoque clínico como el enunciado anteriormente y encontraron sólo 10 con sospecha por troponina, ECG o ecocardiograma. Evaluados con resonancia, confirmaron 3 miocarditis y 2 pericarditis. Solo en este pequeño grupo se indicó evitar el deporte por unos meses. En el retorno a la práctica de toda la cohorte, no se verificaron problemas cardiovasculares.

\section{¿Existen terapéuticas para la miocarditis por COVID-19?}

En la revisión sistemática de Castiello (25) los pacientes fueron tratados en forma empírica con hidroxicloroquina y/o antivirales, corticoides, o tocilizumab. No disponemos de estudios controlados dada la infrecuencia del cuadro. Ensayos actuales están explorando la terapia inmunosupresora en la fase de hiperinflamación para objetivar si puede ser beneficiosa en este tipo de miocarditis (41-44)

En la fase aguda se plantea el alta en estos pacientes cuando hayan normalizado los niveles de troponina o estos sean decrecientes, sin evidencia de arritmias malignas. En la revisión, 28 de 33 casos con resultados disponibles, fueron dados de alta con función cardíaca recuperada. Los autores sostienen que la miocarditis aguda en COVID-19 tiene un pronóstico moderado si se trata con prontitud debido a que se informaron sólo 3 muertes, pero destacan que dada la posible subnotificación de casos relevantes solo se pueden extraer conclusiones preliminares.

\section{Etapa tardía post-COVID. COVID largo}

Después de la recuperación de la enfermedad aguda COVID-19, la dificultad para respirar y la fatiga pueden persistir. La incidencia de sintomatologías diversas post-COVID-19 se ha estimado en 10-35\%, aunque para pacientes hospitalizados puede alcanzar 85\%. Los síntomas más frecuentes son la fatiga (15-70\%) y la disnea (10-40\%). (45) Las razones del 'COVID prolongado' no se conocen bien, y pueden estar asociadas con persistencia de cuadro inflamatorio, así como de anomalías tisulares de los pulmones, el corazón y los riñones, identificadas por imágenes de resonancia magnética. (32)

La evaluación cardiológica no difiere de otros pacientes con sintomatología similar, y será discutida en el último capítulo de este documento.

\section{Vacunación y la aparición de miocarditis o pericarditis}

El CDC informó recientemente una posible asociación entre las vacunas de ARNm de COVID-19 y la aparición de miocarditis, principalmente en varones jóvenes unos días después de la segunda vacunación, con una incidencia aproximada de 4,8 casos por 1 millón. Se han informado cuadros de miocarditis y /o pericarditis como efectos secundarios raros después de las vacunas de ARNm COVID-19 (incluidas la Comirnaty de Pfizer y la Spikevax de Moderna) en adultos jóvenes, en varios países. También se han notificado casos en adolescentes. (46-54)

Hasta el 8 de septiembre de 2021, en Reino Unido, la tasa global de notificación de miocarditis (incluida la miocarditis viral) para la vacuna de Pfizer, después de la primera y la segunda dosis, es de 6,8 casos por millón de dosis, y de pericarditis (incluida la pericarditis viral y la pericarditis infecciosa) de 5,2 casos por millón de dosis. 
Nótese que suman los pacientes con miocarditis/pericarditis post-vacunación con aquellos que lo desarrollan vinculado al COVID-19 que cursó luego de las vacunas. (55)

Para la vacuna de Moderna, la tasa global de notificación de miocarditis es de 21,6 por millón de dosis y de pericarditis es de 16,3 por millón de dosis. Para Astra Zeneca, la tasa global de notificación de miocarditis es de 2,2 por millón de dosis y la de pericarditis de 3,4 por millón de dosis. Para esta última vacuna, no se han reportado casos con más frecuencia de lo esperado en ausencia de vacunación. (56)

La mayoría de los casos de miocarditis y pericarditis relacionados con la vacunación con ARNm han requerido hospitalización; sin embargo, la mayoría ha respondido bien al tratamiento estándar con un curso leve y autolimitado Los síntomas suelen aparecer dentro de 1 a 5 días (mediana 2 días) después de la vacunación.

En un análisis de casos de miocarditis notificados después de las vacunas de ARNm en los EE. UU (Vaccine Adverse Events Reporting System (VAERS)), el 76\% de los casos fueron en hombres, y la edad promedio de los 323 casos notificados que cumplían con la definición de caso de los CDC fue de 19 años (rango 12-29 años). El riesgo de miocarditis o pericarditis parece ser mayor después de la segunda dosis de una vacuna de ARNm COVID-19, pero también se han notificado casos después de la primera dosis. El 76\% de los casos notificados al VAERS de EE. UU. ocurrieron después de una segunda dosis. La tasa bruta de notificación en hombres de 12 a 29 años fue de 40,6 casos por millón de segundas dosis de una vacuna de ARNm COVID-19, y en mujeres de 12 a 29 años fue de 4,2 casos por millón. La tasa en hombres de 30 años o más fue de 2,4 casos por millón de segundas dosis, y en mujeres de la misma edad fue de 1,0 caso por millón de segundas dosis. (56)

En un relevamiento llevado a cabo en Estados Unidos, con los datos de 40 hospitales, se identificaron todos los pacientes con vacunas COVID-19 y se evaluó el diagnóstico de miocarditis, miopericarditis o pericarditis. Entre 2.000.287 personas que recibieron al menos 1 vacuna COVID-19 (76,5\% recibió dos dosis), 20 personas tuvieron miocarditis relacionada con la vacuna, (1 por 100 000, IC 95\% 0,61-1,54) y 37 pericarditis $(1,8$ por 100000 , IC $95 \%$ 1,30-2,55). (57)

La miocarditis se desarrolló más rápido (mediana de 3,5 días después de la vacunación), en pacientes jóvenes (36 años, RIQ 26-48 años), en particular después de la segunda vacunación, con predominio en hombres (75\%). La pericarditis afectó a pacientes de más edad (mediana de 59 años, RIQ 46-69 años), principalmente hombres (73\%), de aparición más tardía (mediana de aparición 20 días (RIQ 6-41 días) y luego de la primera o segunda dosis (40,5\% y 59,5\% respectivamente). En ninguno de los cuadros hubo reingresos o muertes hasta los últimos seguimientos disponibles, y la mayor parte de los casos habían resuelto o estaban en mejoría. En el caso de la miocarditis, 2 de los pacientes recibieron la segunda dosis sin empeoramiento de los síntomas. (58)

En la comparación con el periodo anterior a la vacuna, se observó una media mensual de casos de miocarditis o miopericarditis de 16,9 (IC95\%, 15,3-18,6) frente a 27,3 (IC95\%, 22,4-32,9) durante el período de la vacuna (p $<0,001)$. El número medio de casos de pericarditis durante los mismos períodos fue 49,1 (IC95\%, 46,4-51,9) y 78,8 (IC95\%, 70,3-87,9), respectivamente ( $\mathrm{p}<0,001$ ). Si bien la asociación temporal no prueba la causalidad, el breve lapso entre la vacunación y el inicio de la miocarditis y la elevada incidencia de miocarditis y pericarditis en los hospitales del estudio de Díaz et al (57), apoyan la posible relación.

\section{¿Cuál es el mecanismo de la miocarditis por las vacunas?}

A pesar de no establecerse causalidad, existen numerosos casos descritos de miocarditis, miopericarditis y pericarditis en relación con la administración de diferentes vacunas. (58) Este efecto, no se describió en el estudio de seguridad de la vacuna BNT162b2 (BioNTech \& Pfizer). (59)

Se describe una posible relación entre la infección por SARS-CoV-2 y el desarrollo de afecciones autoinmunitarias a través de un mecanismo de mimetismo molecular y reacción cruzada. En base a esto, se propone que estas reacciones podrían desencadenarse luego de la vacunación, principalmente en individuos predispuestos genéticamente, pero, si bien son muchas las hipótesis, estamos lejos de saberlo con seguridad. (60)

\section{¿Cuál es nuestra realidad?}

En el reporte de seguridad en vacunas del Ministerio de Salud de agosto de 2021 se informó que tras la aplicación de 32187823 dosis de vacunas contra la COVID-19 al 31-7-2021 (Sputnik V 11368 965, Covishield /Astra Zeneca 11145461 y Sinopharm 9673 401) hubo 1 solo caso de pericarditis, con una tasa de 0,008/100000 dosis aplicadas. No se informaron eventos de miocarditis o pericarditis relacionados a las vacunas Astra Zeneca / Covishield o Sinopharm. (61)

Los abrumadores beneficios de la vacunación con una vacuna de ARNm para proteger a las personas contra el COVID-19 y sus graves consecuencias, como la hospitalización y la muerte, así como los beneficios más amplios de reducir la propagación de la enfermedad en la comunidad, hacen que esta baja incidencia de miocarditis no resulte un obstáculo para su recomendación. 


\section{Comentarios finales}

Los pacientes que padecen COVID-19 pueden presentar diversas complicaciones cardiovasculares que guardan relación con la gravedad del cuadro y la patología preexistente. El abordaje de las complicaciones agudas se orienta a los problemas específicos (infarto con ST elevado, fibrilación auricular, arritmias ventriculares, insuficiencia cardíaca). La elevación de los niveles de troponina constituye un marcador de injuria miocárdica inespecífica que indica sufrimiento miocárdico sin identificar la etiología, pero con implicancias de peor pronóstico. Los mecanismos de afectación miocárdica son múltiples e indirectos en los pacientes graves: hipoxemia, respuesta hiperinflamatoria, hipotensión arterial, shock séptico. El daño directo al miocardio puede deberse a la agresión viral por miocarditis en casos muy aislados, a enfermedad aterosclerótica accidentada como infarto y casos excepcionales de Takotsubo.

El problema de la afectación miocárdica a largo plazo es un gran enigma abierto, en particular el rol de la miocarditis y relación con los cuadros de COVID-largo o post COVID. Algunos puntos claves

1) En pacientes con cardiopatías preexistentes no sorprende que la función ventricular sufra un deterioro transitorio o persistente con el curso del COVID-19, en particular en casos graves. Esto no es específico del COVID-19.

2) En estudios de anatomía patológica el diagnóstico de miocarditis exige la combinación de inflamación y necrosis miocárdica. El hallazgo más característico en COVID-19 es el infiltrado inflamatorio con predominio intersticial, sin afectación del miocito ni necrosis. La confirmación de miocarditis viral por COVID-19 es muy rara, solo en casos muy aislados de reporte. También la sospecha clínica es muy baja en las series epidemiológicas.

3) Esto contrasta con los hallazgos de inflamación miocárdica por resonancia magnética nuclear en hasta el $60 \%$ aún en pacientes no complicados, con varios casos de fibrosis, lo que generó una gran inquietud. Estudios posteriores no confirmaron esa prevalencia de inflamación, y también encontraron algún grado de fibrosis. (62) En series poblacionales de personas sin cardiopatía se reportó también el hallazgo de fibrosis miocárdica en el 4\%, sin implicancias clínicas, lo que hace sospechar que es una secuela de menor magnitud de otras infecciones virales.

4) El temor a largo plazo es que la inflamación miocárdica persistente pueda llevar a un deterioro progresivo de la función ventricular o complicaciones arrítmicas. Por el momento no se han informado casos de miocardiopatía progresiva.

5) Para evitar el sobre-diagnóstico de afectación miocárdica que puede aportar la resonancia magnética, se propone encarar estrategias para la evaluación del compromiso cardíaco post-COVID que parten de la clínica: presencia o ausencia de síntomas de disnea o fatiga, alteraciones electrocardiográficas, análisis de sangre para evaluar la presencia de troponina elevada en la evolución alejada, y ecocardiograma. La resonancia quedaría como estudio para pacientes con afectación de la función ventricular, para caracterizar el daño y el eventual diagnóstico de miocarditis.

6) Aplicando este enfoque, que resultó seguro en diferentes series, la incidencia de daño miocárdico que pueda limitar el retorno a la actividad es muy baja.

7) Esta información apoya una evaluación conservadora de los pacientes post-COVID. Si bien no descarta que en el futuro alejado pueda surgir algún trastorno inesperado, esto parece por el momento improbable.

8) Aunque se han reportado casos de miocarditis y pericarditis post vacunación, en particular con las vacunas de ARN (Pfizer-Moderna) la tasa de aparición es extremadamente baja, mucho más que el evento espontáneo en no vacunados, y cursa con formas leves y de recuperación rápida. No es un motivo para limitar el uso de las vacunas.

\section{BIBLIOGRAFÍA}

1. Guo T, Fan Y, Chen M, Wu X, Zhang L, He T, et al. Cardiovascular Implications of Fatal Outcomes of Patients With Coronavirus Disease 2019 (COVID-19)- JAMA Cardiol. 2020;5(7):1-8.

2. Jaffe AS, Cleland JG, Katus HA. Myocardial injury in severe COVID-19 infection. Eur Heart J. 2020;41(22):2080-2.

3. Lippi G, Lavie CJ, Sanchis-Gomar F. Cardiac troponin I in patients with coronavirus disease 2019 (COVID-19): evidence from a metaanalysis. Prog Cardiovasc Dis. 2020;63(3):390-1.

4. Fried JA, Ramasubbu K, Bhatt R, Topkara VK, Clerkin KJ, Horn E et al. The variety of cardiovascular presentations of COVID-19. Circulation. 2020;141(23):1930-6.

5. Minhas AS, Scheel P, Garibaldi B, Liu G, Horton M, Jennings M, et al. Takotsubo syndrome in the setting of COVID-19. JACC Case Rep. 2020;2(9):1321-5.

6. Huang C, Wang Y, Li X, Ren L, Zhao J, Hu Y, et al. Clinical features of patients infected with 2019 novel coronavirus in Wuhan, China. Lancet. 2020;395(10223):497-506. 
7. Li B, Yang J, Zhao F, Zhi L, Wang X, Liu L, et al. Prevalence and impact of cardiovascular metabolic diseases on COVID-19 in China. Clin Res Cardiol. 2020;109(5):531-8.

8. Chen C, Zhou Y, Wang DW. SARS-CoV-2: a potential novel etiology of fulminant myocarditis. Herz. 2020;45(3):230-2.

9. Shi S, Qin M, Shen B, Cai Y, Liu T, Yang F, et al. Association of cardiac injury with mortality in hospitalized patients with COVID-19 in Wuhan, China. JAMA Cardiol. Published online March 25, 2020. doi:10.1001/jamacardio.2020.0950

10. Lala A, Johnson K, Januzzi J, Cai Y, Liu T, Yang F, et al. Prevalence and Impact of Myocardial Injury in Patients Hospitalized With COVID-19 Infection. J Am Coll Cardiol 2020;76:533-46.

11. Madjid M, Safavi-Naeini P, Solomon SD, Vardeny O. Potential Effects of Coronaviruses on the Cardiovascular System. A Review. JAMA Cardiol. 2020;5(7):831-40.

12. Lim W, Qushmaq I, Devereaux P, Heels-Ansdell D, Lauzier F, Ismaila AS, et al. Elevated Cardiac Troponin Measurements in Critically Ill Patients Arch Intern Med. 2006;166(22):2446-54.

13. Metkus TS, Sokoll LJ, Barth AS, Czarny MJ, Hays AG, Lowenstein CJ, et al. Myocardial injury in severe COVID-19 compared with nonCOVID-19 acute respiratory distress syndrome. Circulation. 2021;143(6):553-65.

14. Zhou F, Yu T, Du R, Fan G, Liu Y, Liu Z et al. Clinical course and risk factors for mortality of adult inpatients with COVID-19 in Wuhan, China: a retrospective cohort study. Lancet 2020;395:1054-62

15. Shi S, Qin M, Shen B, Cai Y, Liu T, Yang F, et al. Association of cardiac injury with mortality in hospitalized patients with COVID-19 in Wuhan, China. JAMA Cardiol. 2020 Jul 1;5(7):802-810. doi:10.1001/jamacardio.2020.0950

16. Guo T, Fan Y, Chen M, Wu X, Zhang L, He T, et al. Cardiovascular Implications of Fatal Outcomes of Patients With Coronavirus Disease 2019 (COVID-19). JAMA Cardiol. 2020 Jul 1;5(7):811-8. doi: 10.1001/jamacardio.2020.1017.

17. Gong J, Dong H, Xia QS, Huang ZY, Wang DK, Zhao Y, et al. Q (2020) Correlation analysis between disease severity and inflammationrelated parameters in patients with COVID-19 pneumonia. medRxiv 2020;20(1):963. doi: https://doi.org/10.1101/2020.02.25.20025643

18. Giustino G, Croft L, Stefanini F, Bragato R, Silbiger JJ, Vicenzi M, et al. Characterization of Myocardial Injury in Patients With COVID-19. J Am Coll Cardiol 2020;76:2043-55.

19. Lavie C, Sanchis-Gomar D, Lippi G. Cardiac Injury in COVID-19-Echoing Prognostication. J Am Coll Cardiol 2020;76:2056-9.

20. Lassen MC, Skaarup KG, Lind JN, Alhakak AS, Sengeløv M, Nielsen AB, et al. Recovery of Cardiac Function Following COVID-19 - ECHOVID-19: A Prospective Longitudinal Cohort Study. Eur J Heart Fail 2021 Sep 12. Epub ahead of print. doi: 10.1002/ejhf.234.

21. Boehmer TK, Kompaniyets L, Lavery AM, Hsu J, Ko JY, Yusuf H, et al. Association Between COVID-19 and Myocarditis Using HospitalBased Administrative Data - United States, March 2020-January 2021. MMWR Morb Mortal Wkly Rep. 2021 Sep 3;70(35):1228-32. doi: 10.15585/mmwr.mm7035e5. PMID: 34473684

22. Murk W, Gierada M, Fralick M, Weckstein A, Klesh R, Rassen JA. Diagnosis-wide analysis of COVID-19 complications: an exposure-crossover study. CMAJ. 2021;193(1):E10-E18. doi: 10.1503/cmaj.201686.

23. Barda N, Dagan N, Ben-Shlomo Y, Kepten E, Waxman J, Ohana R, et al. Safety of the BNT162b2 mRNA Covid-19 Vaccine in a Nationwide Setting. N Engl J Med. 2021;385(12):1078-90. PMID:34432976 https://doi.org/10.1056/ NEJMoa2110475

24. Basso C, Leone O, Rizzo S, De Gaspari M, van der Wal AC, Aubry MC, et al. Pathological features of COVID-19-associated myocardial injury: a multicentre cardiovascular pathology study. Eur Heart J 2020:41:3827-35.

25. Castiello T, Georgiopoulos G, Finocchiaro G, Claudia M, Gianatti A, Delialis D, et al. COVID-19 and myocarditis: a systematic review and overview of current challenges. Heart Fail Rev 2021:1-11. https://doi.org/10.1007/s10741-021-10087-9

26. Satturwar S, Fowkes M, Farver C, Wilson AM, Eccher A, Girolami I, et al. Postmortem Findings Associated With SARS-CoV-2 Systematic Review and Meta-analysis Am J Surg Pathol 2021;45(5):587-603.

27. Roshdy A, Zaher S, Fayed H, Coghlan JG. COVID-19 and the Heart: A Systematic Review of Cardiac Autopsies. Front Cardiovasc Med. 2021 Jan 28;7:626975. doi: 10.3389/fcvm.2020.626975. PMID: 33585586; PMCID: PMC7876291.

28. Basso C, Aguilera B, Banner J, Cohle S, d'Amati G, de Gouveia RH. Guidelines for autopsy investigation of sudden cardiac death: 2017 update from the Association for European Cardiovascular Pathology. Virchows Arch 2017:471:691-705.

29. Wenzel P, Kopp S, Göbel S, Jansen T, Geyer M, Hahn F, et al. Evidence of SARS-CoV-2 mRNA in endomyocardial biopsies of patients with clinically suspected myocarditis tested negative for COVID-19 in nasopharyngeal swab. Cardiovasc Res. 2020;116(10):1661-3.

30. Wichmann D, Sperhake JP, Lütgehetmann M, Steurer S, Edler C, Heinemann A, et al. Autopsy Findings and Venous Thromboembolism in Patients With COVID-19: A Prospective Cohort Study. Ann Intern Med. 2020;173(4):268-77.

31. Halushka MK, Vander Heide RS. Myocarditis is rare in COVID-19 autopsies: cardiovascular findings across 277 postmortem examinations. Cardiovasc Pathol 2021;50:107300.

32. Friedrich MG, Sechtem U, Schulz-Menger J, Holmvang G, Alakija P, Cooper LT,et al. Cardiovascular magnetic resonance in myocarditis: J Am Coll Cardiol 2009;53:1475-87.

33. Ojha V, Verma M, Pandey NN, Mani A, Malhi AS, Kumar S, et al. Cardiac magnetic resonance imaging in coronavirus disease 2019 (COVID-19): a systematic review of cardiac magnetic resonance imaging findings in 199 patients. J Thorac Imaging 2021;36:73-83.

34. Puntmann VO, Carerj ML, Wieters I, Fahim M, Arendt C, Hoffmann J, , et al. Outcomes of cardiovascular magnetic resonance in patients recently recovered from coronavirus disease 2019 (COVID-19). JAMA Cardiol. 2020;5(11):1265-73. doi:10.1001/jamacardio.2020.3557

35. Rajpal S, Tong MS, Borchers J, Zareba KM, Obarski TP, Simonetti OP, et al. Cardiovascular Magnetic Resonance Findings in Competitive Athletes Recovering From COVID-19 Infection. JAMA Cardiol. 2021;6(1):116-8.

36. Kravchenko D, Isaak A, Zimmer S, Mesropyan N, Reinert M, Faron A, et al. Cardiac MRI in patients with prolonged cardiorespiratory symptoms after mild to moderate COVID-19. Radiology 2021 Aug 10. https://doi.org/10.1148/radiol.2021211162

37. Lima J, Bluemke D. Myocardial Scar in COVID-19: Innocent Marker versus Harbinger of Clinical Disease Radiology 2021 Aug 10;211710. doi: 10.1148/radiol.2021211710

38. Kotecha T, Knight DS, Razvi Y, Kumar K, Vimalesvaran K, Thornton G, et al. Patterns of myocardial injury in recovered troponin-positive COVID-19 patients assessed by cardiovascular magnetic resonance. Eur Heart J 2021;42:1866-78.

39. Raman B, Cassar MP, Tunnicliffe EM, Filippini N, Griffanti L, Alfaro-Almagro F, et al. Medium-term effects of SARS-CoV-2 infection on multiple vital organs, exercise capacity, cognition, quality of life and mental health, post-hospital discharge. EClinicalMedicine 2021;31:100683. 40. Martinez M, Tucker A, Bloom J, Green G, DiFiori JP, Solomon G, et al. Prevalence of Inflammatory Heart Disease Among Professional Athletes With Prior COVID-19 Infection Who Received Systematic Return-to-Play Cardiac Screening. JAMA Cardiol. 2021;6(7):745-52. doi:10.1001/jamacardio.2021.0565 
41. NCT04392531 Clinical Trial to Assess Efficacy of cyclosporine Plus Standard of Care in Hospitalized Patients With COVID-19. https:// clinicaltrials.gov/ct2/show/NCT04392531

42. NCT04375202 Colchicine in COVID-19: a Pilot Study (COLVID-19). https://clinicaltrials.gov/ct2/show/NCT04375202

43. NCT04339712 Personalised Immunotherapy for SARS-CoV-2 (COVID-19) Associated With Organ Dysfunction (ESCAPE). https://clinicaltrials.gov/ct2/show/NCT04339712

44. NCT04365153 Canakinumab in Covid-19 Cardiac Injury (The Three C Study) https://clinicaltrials.gov/ct2/show/NCT04365153

45. Pavli A, Theodoridou M, Maltezouc H. Post-COVID Syndrome: Incidence, Clinical Spectrum, and Challenges for Primary Healthcare Professionals. Arch Med Res. 2021;52(6): 575-81.

46. Wallace M, Oliver S. COVID-19 mRNA vaccines in adolescents and young adults: benefit-risk discussion. Accesed July 7, 2021. https:// www.cdc.gov/vaccines/acip/meetings/downloads/slides-2021-06/05-COVID-Wallace-508.pdf

47. Montgomery J, Ryan M, Engler R, Hoffman D, McClenathan B, Collins L. Myocarditis Following Immunization With mRNA COVID-19 Vaccines in Members of the US Military. JAMA Cardiol. Published online. June 29, 2021. doi:10.1001/jamacardio.2021.2833

48. Kim HW, Jenista ER, Wendell DC, Azevedo CF, Campbell MJ, Darty SN, et al. Patients With Acute Myocarditis Following mRNA COVID-19 Vaccination. JAMA Cardiol. Published online June 29, 2021. doi:10.1001/jamacardio.2021.2828

49. Abu Mouch S, Roguin A, Hellou E, Ishai A, Shoshan U, Mahamid L, et al. Myocarditis following COVID-19 mRNA vaccination. Vaccine. 2021;39(29):3790-3. doi:10.1016/j.vaccine.2021.05.087

50. Rosner CM, Genovese L, Tehrani BN, Atkins M, Bakhshi H, Chaudhri S, et al. Myocarditis Temporally Associated with COVID-19 Vaccination. Circulation. 0(0). doi:10.1161/CIRCULATIONAHA.121.055891

51. Larson KF, Ammirati E, Adler ED, Cooper LT Jr, Hong KN, Saponara G, et al. Myocarditis after BNT162b2 and mRNA-1273 Vaccination. Circulation. 2021;144(6):506-8. doi:10.1161/CIRCULATIONAHA.121.055913

52. Marshall M, Ferguson ID, Lewis P, Jaggi P, Gagliardo C, Collins JS,, et al. Symptomatic acute myocarditis in seven adolescents following Pfizer-BioNTech COVID-19 vaccination. Pediatrics. 2021;148(3):e2021052478. Published online 2021:2.

53. Snapiri O, Rosenberg Danziger C, Shirman N, Weissbach A, Lowenthal A Ayalon I, et al. Transient Cardiac Injury in Adolescents Receiving the BNT162b2 mRNA COVID-19 Vaccine. Pediatr Infect Dis J. 2021;40(10):e360-e363. Published online June 2, 2021. doi:10.1097/ INF.0000000000003235

54. Gargano JW. Use of mRNA COVID-19 Vaccine After Reports of Myocarditis Among Vaccine Recipients: Update from the Advisory Committee on Immunization Practices -United States, June 2021. MMWR Morb Mortal Wkly Rep. 2021;70. doi:10.15585/mmwr.mm7027e2

55. https://www.gov.uk/government/publications/coronavirus-covid-19-vaccine-adverse-reactions/coronavirus-vaccine-summary-of-yellowcard-reporting

56. Vaccine Adverse Event Reporting System. Accessed June 8, 2021. https://vaers.hhs.gov.

57. Diaz GA, Parsons GT, Gering SK, Meier AR, Hutchinson IV, Robicsek A. Myocarditis and Pericarditis After Vaccination for COVID-19. JAMA. 2021;326(12):1210-2. doi: 10.1001/jama.2021.13443.

58. Su JR, McNeil MM, Welsh KJ, Marquez PL, Ng C, Yan M, Cano MV. Myopericarditis after vaccination, Vaccine Adverse Event Reporting System (VAERS), 1990-2018. Vaccine. 2021;39(5):839-45. doi: 10.1016/j.vaccine.2020.12.046.

59. Polack FP, Thomas SJ, Kitchin N, Absalon J, Gurtman A, Lockhart S, et al. Safety and efficacy of the BNT162b2 mRNA COVID-19 vaccine. 2020;383(27):2603-15.

60. Talotta R.Do COVID-19 RNA-based vaccines put at risk of immune-mediated diseases? In reply to "Potential antigenic cross-reactivity between SARS-CoV-2 and human tissue with a possible link to an increase in autoimmune diseases". Clin Immunol 2021;224:108665

61. https://bancos.salud.gob.ar/recurso/14o-informe-de-vigilancia-de-seguridad-en-vacunas

62. Kravchenko D, Isaak A, Zimmer S, Mesropyan N, Reinert M, Faron A, et al. Cardiac MRI in patients with prolonged cardiorespiratory symptoms after mild to moderate COVID-19. Radiology 2021: 211162. https://doi.org/10.1148/radiol.2021211162 


\title{
Síndromes coronarios agudos y accidentes cerebrovasculares asociados a COVID-19
}

\author{
JUAN GAGLIARDI, HERALDO D'IMPERIO, MAURO ROSSI PRAT
}

\section{Introducción}

Es ampliamente conocida la relación entre ciertas infecciones y los eventos cardiovasculares como el infarto agudo de miocardio (IAM) y el accidente cerebrovascular (ACV). (1-3) Se ha reportado una asociación entre los brotes epidémicos por el virus SARS y el virus MERS con el ACV. $(4,5)$ A su vez, la presencia de factores de riesgo cardiovascular tradicionales aumenta el riesgo de un evento tras la infección. (6-8)

En el caso del SARS-CoV-2, causante de la pandemia actual por COVID-19, también se ha descripto una asociación importante con eventos trombóticos a nivel de múltiples órganos, con especial énfasis en el IAM y el ACV.

La identificación de un síndrome coronario agudo (SCA) en el contexto de la COVID-19 requiere distinguirlo de otras causas que puedan inducir injuria cardíaca aguda, definida por la evaluación de troponina. Esta elevación, como se ha comentado en el capítulo precedente, se diagnostica en forma frecuente (9-12) y se ha asociado con mayor mortalidad. (13-15)

La elevación de troponina en estos casos suele ser persistente y no sigue la curva típica de ascenso y caída posterior como clásicamente se observa en los SCA. Estos pacientes presentan además mayor carga de enfermedad cardiovascular de base, altos niveles de marcadores séricos de inflamación, y la lesión cardíaca es motivada en su mayoría por causas no isquémicas o infarto tipo II (por disbalance entre la oferta y la demanda de oxígeno). (16-18)

El riesgo de mortalidad puede predecirse por los niveles pico de troponina durante la internación (19) pero a esto se agregan otros predictores de peso como la edad, la presencia de coagulopatías, comorbilidades y el síndrome de distrés respiratorio. $(20,21)$

El diagnóstico diferencial es fundamental ya que la injuria cardiaca aguda puede estar relacionada con la presencia de miocarditis, síndrome de Takotsubo, insuficiencia cardiaca aguda o una injuria directa por COVID-19. (22) También el embolismo pulmonar, la enfermedad crítica y la sepsis pueden ser causas de elevación de troponina y deben ser consideradas como alternativas diagnósticas. (17)

\section{Infarto de miocardio con elevación del segmento ST \\ Evolución y particularidades asociadas a COVID-19}

Desde el comienzo, la pandemia provocada por la infección por COVID-19 ha tenido un impacto en el infarto agudo de miocardio y el accidente cerebrovascular.

Los estudios publicados de esta etapa inicial de la pandemia, fueron en general de pequeño tamaño e incluyeron sólo pacientes hospitalizados, la mayor parte con enfermedad por COVID moderada-grave. (23-27)

En la mayoría de los estudios multicéntricos observacionales de países como Italia (28), España, (29), Alemania (30) Francia (31), Austria (32), Arabia Saudita (33), y Lituania (34), se ha reportado una disminución de las internaciones por infarto de miocardio. Los tiempos de consulta de los pacientes fueron prolongados con respecto a la comparación con los períodos sin pandemia y se han realizado encuestas donde los pacientes mencionan el miedo a contagiarse como el motivo principal de retraso al momento de la consulta.

Un estudio realizado sobre la base de un sistema de salud del Norte de California mostró una reducción del 48\% de la hospitalización semanal por IAM en el periodo enero-abril de 2020 comparado con un periodo similar de 2019. (35) La reducción fue similar en los IAM con elevación del segmento ST, IAMEST, (tasa de reducción: 0,60; IC 95\% 0,33-1,08) y en aquellos sin elevación del segmento ST, IAMSEST (tasa de reducción: 0,51; IC 95\% 0,38-0,68), y las características de los pacientes fueron similares en ambos periodos.

En otras publicaciones la incidencia de infección por COVID-19 con IAMEST varía entre el 17 y el $27 \%$. $(34,36,37)$ Estos pacientes se presentan relativamente más tarde, comparado con series históricas, (37) reciben menos tratamiento de reperfusión y sobre todo tienen niveles de marcadores de inflamación significativamente más altos lo que conlleva peor pronóstico y mayor mortalidad.

La mortalidad por IAM en el período de pandemia también se distribuye de manera heterogénea y parece estar asociada a los tiempos prolongados de consulta y respuesta del sistema de salud.

En una encuesta de percepción de la Sociedad Europea de Cardiología a profesionales de la salud en su mayoría cardiólogos y enfermeros en 141 países y 6 continentes se reportó una disminución de las internaciones, aunque no fue uniforme ya que el $17 \%$ de los profesionales no reportaron cambios en las admisiones por IAM e incluso mencionaron aumento de las internaciones por esta patología. 
Con respecto a este punto, un registro multicéntrico israelí de esa etapa inicial mostró un incremento del 12\% de las admisiones por IAM, aunque sólo fue del 1,7\% cuando se consideró el IAMEST. (38) Los pacientes consultaron 55 minutos más tarde que un grupo control en el mismo periodo, pero de 2018, el tiempo del ingreso a la reperfusión se incrementó 7 minutos y el tiempo total de isquemia pasó de 180 minutos a 290. Estas mayores demoras fueron independientes del mes de ingreso, la edad o el género.

En este registro, la presencia de coronarias normales o sin lesiones angiográficamente significativas (MINOCA) fue 8 veces menor que en el periodo control (1,4\% vs 11,8\%) mientras que la lesión de 1 vaso fue el hallazgo más frecuente durante la etapa de COVID-19.

Se observó una mayor incidencia de evento combinado, pero a expensas de una mayor incidencia de arritmias ventriculares, mientras que no hubo variación significativa de la mortalidad por IAMEST comparando los 2 periodos. Sin embargo, la mortalidad de los pacientes con IAMEST durante el curso de la COVID-19 fue significativamente mayor que la de los pacientes sin COVID-19 ingresados en el mismo período. (39)

En el Registro Continuo ARGEN-IAM-ST observamos una caída absoluta de 16\% en las internaciones desde el inicio de la cuarentena en nuestro país respecto del mismo periodo de 2019. Sin embargo, no se encontraron diferencias en las características generales de los pacientes, los tiempos de consulta, tratamiento ni en la mortalidad intrahospitalaria. (40)

De acuerdo con los datos del Registro Argentino de Complicaciones Cardiovasculares en pacientes con COVID-19 (RACCOVID), de un total de 2728 pacientes, el 15,3\% (420 pacientes) presentó alguna complicación cardiovascular y de éstos, 131 pacientes presentaron daño miocárdico (31,3\%), la mayoría (77 pacientes - 58,7\%) manifestada por injuria miocárdica. Sólo 24 presentaron un IAMEST (91,7\% reperfundidos) y 29 pacientes un IAMSEST.

\section{¿La COVID-19 incrementa el riesgo de IAM o ACV?}

Un estudio multicéntrico danés evaluó la asociación entre la fase aguda de la infección y el riesgo de ACV isquémico e IAM en un estudio de propio individuo como control. (27) Definieron como periodo de riesgo los 14 días posteriores a la infección y el periodo control a los 180 días previos a la misma y luego de los 14 días hasta donde estuvieran disponibles los datos. De un total de 5119 pacientes con COVID-19 se registraron 44 ACV y 17 IAM. Durante el intervalo de riesgo ocurrieron $18 \mathrm{ACV}, 10$ veces más que en el periodo control, y se registraron 4 IAM con una incidencia 5 veces mayor que en el periodo control.

Un estudio poblacional realizado en Suecia sobre más de 85000 pacientes con COVID-19 y casi 350000 controles emparejados, (41) utilizando un método de propio individuo como control y una cohorte apareada, observó una asociación significativa entre el IAM y la COVID-19 en el mes anterior a la infección con una tasa de incidencia de 2,04 (IC 95\% 1,30-3,21). Asimismo, el odds de IAM en las 2 semanas posteriores a la infección fue de 3,41 (IC 95\% 1,58-7,36) respecto de grupo control en el análisis multivariado.

Por su parte, el riesgo de incidencia de ACV isquémico se incrementó significativamente (entre 2 y 3 veces) tanto en el periodo previo a la infección como en las 2 semanas posteriores. El odds se incrementó 4 veces en las 2 semanas posteriores comparando con el grupo control. De esta forma, los autores concluyen que la COVID-19 es un factor de riesgo independiente de ACV isquémico e infarto agudo de miocardio.

El incremento en el número de IAM y ACV en el mes previo a la infección probablemente es un indicador de infección nosocomial por lo que se hace hincapié en la necesidad de proteger a los pacientes de ésta. (41)

Sumado esto a los datos aportados por el estudio danés, (27) los hallazgos mencionados sugieren que el verdadero riesgo de IAM luego de la COVID-19 se incrementa entre 3 y 8 veces y el de ACV entre 3 y 7 veces. (41)

Esto aporta evidencia que la COVID-19 puede incrementar el riesgo de ACV y IAM y que los mecanismos subyacentes podrían incluir la desestabilización de la placa mediada por citoquinas y la hipercoagulabilidad. La respuesta inflamatoria exagerada (tormenta de citoquinas) (42) y el efecto directo del virus sobre las células endoteliales, (43) podrían precipitar los eventos cardiovasculares a través de una disminución en la actividad de los receptores ACE2, activación plaquetaria, hipercoagulabilidad, y efectos sobre las células endoteliales (activación, injuria, disfunción y apoptosis).

Es importante además considerar que el estrés psicosocial se ha asociado con un incremento del riesgo del IAM, (44) de la misma forma que otros desastres naturales o los ataques terroristas se han asociado con un aumento de los eventos cardiovasculares. $(45,46)$ Por lo tanto, de manera similar, las circunstancias estresantes que resultan de las restricciones a la libertad de movimiento, las penurias económicas, el distanciamiento y aislamiento social impuestos por la cuarentena podrían resultar en un incremento en la incidencia de IAM.

\section{MINOCA-INOCA}

En pacientes con infección por COVID-19 se ha reportado una incidencia variable de MINOCA según los registros. $(47,48)$ Este cuadro se ha acompañado de trastornos ecocardiográficos de la motilidad parietal y hallazgos 
angiotomográficos de irregularidades coronarias y engrosamientos parietales focales, que podrían haber gatillado una disfunción endotelial y vasoespasmo. (49) Se ha asociado también a un aumento del estrés emocional provocado no sólo por la infección sino también por las medidas de aislamiento, el temor al contagio, y otros factores.

La prevalencia de MINOCA sería del 30-55\% de los pacientes COVID que se presentan con IAMEST. (48, 50,51) En estos pacientes se observan mayores niveles de marcadores de inflamación (por ejemplo de PCR), de fibrinólisis (Dímero D) e incluso anticuerpos antifosfolipídicos.

\section{ACV en el contexto de COVID-19}

La incidencia de ACV es infrecuente en el escenario de la COVID-19, pero no debe ser subestimada. En distintos registros se ha descripto una incidencia de ACV isquémico en los pacientes hospitalizados entre 0,9 y $4,6 \%$, mientras que para el ACV hemorrágico la incidencia reportada varió de 0,2 a 0,9\%. (24,25,52-56) En nuestro país a la fecha no se dispone de datos oficiales que informen sobre la incidencia de este tipo de complicaciones en los pacientes hospitalizados por COVID-19.

Paralelamente se ha establecido una relación entre la incidencia de ACV y la severidad de la infección por COVID-19. Mientras la misma es menor al 1\% en pacientes con infección leve, en casos severos aumenta hasta un 6\% según registros internacionales. (54)

El desarrollo del ACV durante la internación, acorde a la evidencia disponible, se manifiesta clínicamente entre la primera y la tercera semana desde el diagnóstico de COVID-19. No obstante, se ha descripto en un número considerable de casos la presencia de síntomas y signos de ACV como manifestación inicial de la enfermedad, sin la presencia de síntomas compatibles con COVID-19. Este número en algunos registros ha superado el $30 \%$ de los pacientes con ACV y COVID-19, por lo que se ha adoptado la recomendación de realizar un testeo diagnóstico con hisopado a todo paciente que consulte a un servicio de emergencias por signos y síntomas de accidente cerebrovascular. (52,53,57-59)

\section{Características de los pacientes y pronóstico}

Los pacientes que desarrollan ACV en el transcurso de la infección por COVID-19 comparten numerosas características con aquellos que lo cursan sin COVID-19. Sin embargo, se han descripto algunas diferencias en el comportamiento clínico e imagenológico.

La edad promedio de afectación no difiere significativamente, aunque se han descripto numerosos casos de ACV isquémico en pacientes más jóvenes. En un registro de ACV en Estados Unidos que incluyó a 1143 pacientes con COVID-19 y ACV concomitante, la mediana de edad fue de 65,3 años (RIC 61,4-67,6) años, una diferencia mediana de $-6,0$ años (IC 95\% -12,3 a -1,4) con aquellos pacientes que cursaron un ACV pero sin COVID-19 en el mismo período. (52,60-62)

Se observó que los pacientes con ACV y COVID-19 presentaban menor frecuencia de hipertensión arterial previa, sin diferencias significativas en los otros factores de riesgo cardiovasculares. Se evidenció mayor presencia de oclusión de grandes vasos y mayor gravedad clínica manifestada por un score del National Institute of Health Stroke Scale (NIHSS) más elevado que en aquellos que no presentaron paralelamente infección por COVID-19.

En un metanálisis que incluyó casi 70000 pacientes, la etiología más común de ACV isquémico fue la criptogénica, con una mayor frecuencia respecto de controles históricos no asociados a COVID-19 (OR 3,98; IC 95\% 1,62-9,77). Esto podría sugerir mecanismos fisiopatológicos específicos de acción del virus que podrían jugar un rol crucial en el entendimiento de la asociación de ambas entidades. (63)

La embolia cardíaca secundaria a la injuria miocárdica fue también descripta, aunque en forma mucho más infrecuente, al igual que el compromiso de pequeños vasos. (64)

En cuanto al pronóstico, la presencia de un ACV en el contexto de la COVID-19 se ha asociado a mayores índices de morbimortalidad, en parte debido al score de NIHSS más elevado como hemos mencionado. $(59,65)$ Otra de las causas que pueden influir en la elevada mortalidad es el mayor retardo en la consulta de pacientes con ACV en el escenario de la pandemia, así como el acceso a terapias de reperfusión. Según datos del Big Data Observatory Stroke Center (BOSC) en China, entre enero y febrero del 2020 se registró una caída del 40\% de las consultas por ACV, así como también una caída del 26,7\% en el uso de fibrinolíticos y un 25,3\% en el uso de trombectomías comparando con el mismo periodo del 2019. (66)

El ACV isquémico evolucionó con mayores índices de discapacidad y de mortalidad. En el análisis de múltiples estudios que incluyeron un total de más de 55000 pacientes mayormente de Estados Unidos y el Reino Unido, se describió una mortalidad intrahospitalaria de pacientes con COVID-19 y ACV agudo de un 31,7\% (IC 95\% 17,7-47,3). Si este análisis se enfoca en el subgrupo de 260 pacientes que tuvieron formas graves de COVID-19, la incidencia de ACV fue de un 9,8\%, con una mortalidad que aumenta al 84,8\%. (53)

En estudios realizados en China al inicio de la pandemia en pacientes con COVID-19 se describió un aumento de 3 veces el riesgo de mortalidad intrahospitalaria con ACV respecto de aquellos que no lo presentaban. $(67,68)$ 


\section{Mecanismos involucrados en el IAM y en el ACV}

Se han descripto varios mecanismos involucrados en la fisiopatología de los eventos cardiovasculares con infección por COVID-19:

- un incremento en la actividad simpática asociada a la infección en pacientes con enfermedad coronaria previa.

- la sepsis como precipitante conocido de IAM tipo II

- La infección por COVID-19 estimula un proceso trombo-inflamatorio que puede desencadenar un SCA, como una tormenta de citoquinas que puede acelerar la formación de nuevas placas ateroscleróticas coronarias y su desestabilización y ruptura.

La infección se caracteriza por la infiltración de células inflamatorias que causan un exceso de producción de citoquinas, proteasas, factores de coagulación, radicales libres y moléculas vasoactivas que desencadenan disfunción endotelial e injuria, ruptura de la fibrosa de la placa e inicio de la cascada de coagulación generando un estado protrombótico, hecho que se evidencia en los altos niveles de dímero D que se hallan en los pacientes con COVID-19 que presentan un evento cardiovascular. Se ha podido evidenciar en un estudio de cohorte retrospectivo una incidencia 7 veces mayor en eventos trombóticos adjudicados a la COVID-19, respecto del virus Influenza. (57) A su vez la infección también puede provocar vasoconstricción y estimulación de la actividad plaquetaria. (69-72)

Se ha reportado un incremento de la carga trombótica en los pacientes COVID-19 que se presentan con IAMEST, comprometiendo tanto las coronarias como las cavidades cardiacas. $(73,74)$

En un estudio de 40 autopsias de pacientes fallecidos por COVID, el 35\% de los casos tenía signos de necrosis miocárdica, principalmente en el ventrículo izquierdo. Sólo el 21,4\% de ellos tenía evidencia de IAM (definido por un área de necrosis $\geq 1 \mathrm{~cm}^{2}$ ) mientras que el resto tenía evidencias de necrosis focales (áreas $\geq 0,05 \mathrm{~mm}^{2}$, pero $\left.<1 \mathrm{~cm}^{2}\right)$. $(75$ )

Un hallazgo interesante resultó que el 78,6\% de los pacientes con necrosis miocárdica tenían microtrombos intracardíacos, 2 pacientes trombos coronarios y el 64,3\% tenían microtrombos en los capilares miocárdicos, arteriolas y arterias musculares pequeñas. Los microtrombos tenían una composición diferente a la de un grupo control no COVID-19 con un mayor componente de fibrina y complemento. Sin embargo, los trombos intracoronarios hallados no difirieron de los hallados en pacientes con IAMEST sin COVID-19.

La presencia de trombos intracavitarios que pueden migrar a la circulación cerebral se han mencionado como un mecanismo de ACV cardioembólico, aunque es infrecuente al igual que el compromiso de pequeños vasos. (64) Se ha demostrado adicionalmente una mayor permeabilidad de la barrera hematoencefálica debido a la respuesta inflamatoria que puede explicar la transformación hemorrágica de muchos ACV inicialmente isquémicos, así como también casos reportados secundarios a trombosis trombocitopénica inducida por vacunas. $(52,53,76)$

No se encontraron evidencias de partículas virales en los miocitos ni en las células endoteliales por lo que la infección directa no sería el mecanismo principal para la formación de microtrombos en los pacientes con COVID-19.

En el caso del ACV hemorrágico, los mecanismos de su génesis no quedan completamente dilucidados. Se ha descripto daño viral directo en la pared de los vasos, con su consiguiente ruptura y también hemorragia intracerebral favorecida por coagulopatía por consumo. También la existencia de microhemorragias perivasculares se visualizó en algunas resonancias de individuos con COVID-19 y deterioro neurológico. Se localizan en cuerpo calloso, también a nivel subcortical y en la sustancia blanca profunda, con una distribución similar a la que se ve en la encefalopatía hipóxica, por lo que se cree que la hipoxia también puede contribuir a estas microhemorragias. En la mayoría de los registros, no obstante, la etiología más frecuente de ACV hemorrágico es la transformación de un ACV previamente isquémico, al cual pareciera contribuir el aumento de la permeabilidad de la barrera hematoencefálica descripto. $(52,53)$

\section{Conclusiones}

Si bien los datos de los estudios iniciales muestran una reducción marcada de las internaciones por IAM y ACV que se atribuyeron a las restricciones impuestas por las cuarentenas y fundamentalmente por el temor al contagio, los datos de los estudios poblacionales sugieren que el riesgo de IAM luego de la COVID-19 se incrementa entre 3 y 8 veces y el de ACV entre 3 y 7 veces.

En este sentido se hace necesario incrementar las medidas de prevención luego de la COVD-19 sobre todo en los pacientes de riesgo. Si bien no hay estudios post COVID que lo avalen, la presencia de una carga trombótica más alta, con mayores dimensiones del coágulo y peor blush miocárdico detectada en pacientes con COVID-19 asintomáticos internados por IAMEST (74) podría justificar la indicación de antitrombóticos y estatinas por al menos 6 meses en pacientes post COVID-19 con factores de riesgo elevados, como prevención del IAM y ACV.

\section{BIBLIOGRAFÍA}

1. Kwong JC, Schwartz KL, Campitelli MA, Chung H, Crowcroft NS, Karnauchow T, et al. Acute Myocardial Infarction after LaboratoryConfirmed Influenza Infection. N Engl J Med 2018;378:345-53.

2. Elkind MS. Why now? Moving from stroke risk factors to stroke triggers. Curr Opin Neurol 2007;20:51-7. 
3. Elkind MSV, Carty CL, O'Meara ES, Lumley T, Lefkowitz D, Kronmal RA, et al. Hospitalization for Infection and Risk of Acute Ischemic Stroke. Stroke 2011;42:1851-6.

4. Umapathi T, Kor AC, Venketasubramanian N, Lim CC, Pang BC, Yeo TT, et al. Large artery ischaemic stroke in severe acute respiratory syndrome (SARS). J Neurol 2004;251:1227-31.

5. Tsai LK, Hsieh ST, Chang YC. Neurological manifestations in severe acute respiratory syndrome. Acta Neurol Taiwan 2005;14:113-9.

6. Boehme AK, Luna J, Kulick ER, Kamel H, Elkind MSV. Influenza-like illness as a trigger for ischemic stroke. Ann Clin Transl Neurol 2018;5:456-63.

7. Smeeth L, Thomas SL, Hall AJ, Hubbard R, Farrington P, Vallance P. Risk of Myocardial Infarction and Stroke after Acute Infection or Vaccination. N Engl J Med 2004;351:2611-8.

8. Shao IY, Elkind MSV, Boehme AK. Risk Factors for Stroke in Patients With Sepsis and Bloodstream Infections. Stroke 2019;50:1046-51.

9. Lippi G, Lavie CJ, Sanchis-Gomar F. Cardiac troponin I in patients with coronavirus disease 2019 (COVID-19): Evidence from a metaanalysis. Prog Cardiovasc Dis 2020;63:390-1.

10. Lombardi CM, Carubelli V, Iorio A, Inciardi RM, Bellasi A, Canale C, et al. Association of Troponin Levels With Mortality in Italian Patients Hospitalized With Coronavirus Disease 2019: Results of a Multicenter Study. JAMA Cardiol 2020;5:1274-80.

11. Raad M, Dabbagh M, Gorgis S, Yan J, Chehab O, Dagher C, et al. Cardiac Injury Patterns and Inpatient Outcomes Among Patients Admitted With COVID-19. Am J Cardiol 2020;133:154-61.

12. Bavishi C, Bonow RO, Trivedi V, Abbott JD, Messerli FH, Bhatt DL. Special Article - Acute myocardial injury in patients hospitalized with COVID-19 infection: A review. Prog Cardiovasc Dis 2020;63:682-9.

13. Santoso A, Pranata R, Wibowo A, Al-Farabi MJ, Huang I, Antariksa B. Cardiac injury is associated with mortality and critically ill pneumonia in COVID-19: A meta-analysis. Am J Emerg Med 2021;44:352-7.

14. Zuin M, Rigatelli G, Zuliani G, Bilato C, Zonzin P, Roncon L. Incidence and mortality risk in coronavirus disease 2019 patients complicated by acute cardiac injury: systematic review and meta-analysis. J Cardiovasc Med (Hagerstown) 2020;21:759-64.

15. Li X, Guan B, Su T, Liu W, Chen M, Bin Waleed K, et al. Impact of cardiovascular disease and cardiac injury on in-hospital mortality in patients with COVID-19: a systematic review and meta-analysis. Heart 2020;106:1142-7.

16. Thygesen K, Alpert JS, Jaffe AS, Chaitman BR, Bax JJ, Morrow DA, et al. Fourth Universal Definition of Myocardial Infarction (2018). Circulation 2018;138:e618-e51.

17. Sandoval Y, Januzzi JL, Jr., Jaffe AS. Cardiac Troponin for Assessment of Myocardial Injury in COVID-19: JACC Review Topic of the Week. J Am Coll Cardiol 2020;76:1244-58.

18. Chapman AR, Bularga A, Mills NL. High-Sensitivity Cardiac Troponin Can Be an Ally in the Fight Against COVID-19. Circulation 2020;141:1733-5.

19. Wang Y, Shu H, Liu H, Li X, Zhou X, Zou X, et al. The peak levels of highly sensitive troponin I predicts in-hospital mortality in COVID-19 patients with cardiac injury: a retrospective study. Eur Heart J Acute Cardiovasc Care 2021;10:6-15.

20. Prasitlumkum N, Chokesuwattanaskul R, Thongprayoon C, Bathini T, Vallabhajosyula S, Cheungpasitporn W. Incidence of Myocardial Injury in COVID-19-Infected Patients: A Systematic Review and Meta-Analysis. Diseases 2020;8.

21. He Y, Zheng X, Li X, Jiang X. Key factors leading to fatal outcomes in COVID-19 patients with cardiac injury. Sci Rep 2021;11:4144.

22. Peretto G, Sala S, Caforio ALP. Acute myocardial injury, MINOCA, or myocarditis? Improving characterization of coronavirus-associated myocardial involvement. Eur Heart J 2020;41:2124-5.

23. Bilaloglu S, Aphinyanaphongs Y, Jones S, Iturrate E, Hochman J, Berger JS. Thrombosis in Hospitalized Patients With COVID-19 in a New York City Health System. JAMA 2020;324:799-801.

24. Tan YK, Goh C, Leow AST, Tambyah PA, Ang A, Yap ES, et al. COVID-19 and ischemic stroke: a systematic review and meta-summary of the literature. J Thromb Thrombolysis 2020;50:587-95.

25. Li Y, Li M, Wang M, Tambyah PA, Ang A, Yap ES, et al. Acute cerebrovascular disease following COVID-19: a single center, retrospective, observational study. Stroke Vasc Neurol 2020;5:279-84.

26. Lodigiani C, Iapichino G, Carenzo L, Cecconi M, Ferrazzi P, Sebastian T, et al. Venous and arterial thromboembolic complications in COVID-19 patients admitted to an academic hospital in Milan, Italy. Thromb Res 2020;191:9-14.

27. Modin D, Claggett B, Sindet-Pedersen C, Cecconi M, Ferrazzi P, Sebastian T, et al. Acute COVID-19 and the Incidence of Ischemic Stroke and Acute Myocardial Infarction. Circulation 2020;142:2080-2.

28. De Rosa S, Spaccarotella C, Basso C, Calabrò MP, Curcio A, Filardi PP, et al. Reduction of hospitalizations for myocardial infarction in Italy in the COVID-19 era. Eur Heart J 2020;41:2083-8.

29. Rodriguez-Leor O, Cid-Alvarez B, Perez de Prado A, Rossello X, Ojeda S, Serrador A, et al. Impact of COVID-19 on ST-segment elevation myocardial infarction care. The Spanish experience. Rev Esp Cardiol (Engl Ed) 2020;73:994-1002.

30. Rattka M, Winsauer C, Stuhler L, Thiessen K, Baumhardt M, Stephan T, et al. Outcomes of patients with ST-segment myocardial infarction admitted during the COVID-19 pandemic : A prospective, observational study from a tertiary care center in Germany. Herz 2021.

31. Mesnier J, Cottin Y, Coste P, Ferrari E, Schiele F, Lemesle G, et al. Hospital admissions for acute myocardial infarction before and after lockdown according to regional prevalence of COVID-19 and patient profile in France: a registry study. Lancet Public Health 2020;5:e536-e42. 32. Reinstadler SJ, Reindl M, Lechner I, Holzknecht M, Tiller C, Roithinger FX, et al. Effect of the COVID-19 Pandemic on Treatment Delays in Patients with ST-Segment Elevation Myocardial Infarction. J Clin Med 2020;9.

33. Daoulah A, Hersi AS, Al-Faifi SM, Alasmari A, Aljohar A, Balghith M, et al. STEMI and COVID-19 Pandemic in Saudi Arabia. Curr Probl Cardiol 2021;46:100656.

34. Hamadeh A, Aldujeli A, Briedis K, Tecson KM, Sanz-Sánchez J, Al Dujeili M, et al. Characteristics and Outcomes in Patients Presenting With COVID-19 and ST-Segment Elevation Myocardial Infarction. Am J Cardiol 2020;131:1-6.

35. Solomon MD, McNulty EJ, Rana JS, Leong TK, Lee C, Sung SH, et al. The Covid-19 Pandemic and the Incidence of Acute Myocardial Infarction. N Engl J Med 2020;383:691-3.

36. Solano-Lopez J, Zamorano JL, Pardo Sanz A, Amat-Santos I, Sarnago F, Gutiérrez Ibañes E, et al. Risk factors for in-hospital mortality in patients with acute myocardial infarction during the COVID-19 outbreak. Rev Esp Cardiol (Engl Ed) 2020;73:985-93.

37. Gramegna M, Baldetti L, Beneduce A, Pannone L, Falasconi G, Calvo F, et al. ST-Segment-Elevation Myocardial Infarction During COVID-19 Pandemic: Insights From a Regional Public Service Healthcare Hub. Circ Cardiovasc Interv 2020;13:e009413.

38. Fardman A, Zahger D, Orvin K, Oren D, Kofman N, Mohsen J, et al. Acute myocardial infarction in the Covid-19 era: Incidence, clinical characteristics and in-hospital outcomes-A multicenter registry. PLoS One 2021;16:e253524.

39. Rodriguez-Leor O, Cid Alvarez AB, Perez de Prado A, ossello X, Ojeda S, Serrador A, et al. In-hospital outcomes of COVID-19 ST-elevation myocardial infarction patients. EuroIntervention 2021;16:1426-33. 
40. D’Imperio HA, Gagliardi JA, Charask A, Zoni RC, Castillo Costa Y, Quiroga W. Internación por infarto agudo de miocardio con elevación del segmento ST durante el aislamiento obligatorio: reporte del Registro Continuo de Infarto ARGEN-IAM-ST. Rev Arg Med 2020;8:127-30. 41. Katsoularis I, Fonseca-Rodriguez O, Farrington P, Lindmark K, Fors Connolly AM. Risk of acute myocardial infarction and ischaemic stroke following COVID-19 in Sweden: a self-controlled case series and matched cohort study. Lancet 2021;398:599-607.

42. Magadum A, Kishore R. Cardiovascular Manifestations of COVID-19 Infection. Cells 2020;9.

43. Varga Z, Flammer AJ, Steiger P, Haberecker M, Andermatt R, Zinkernagel AS, et al. Endothelial cell infection and endotheliitis in COVID-19. Lancet 2020;395:1417-8.

44. Rosengren A, Hawken S, Ounpuu S, Sliwa K, Zubaid M, Almahmeed WA, et al. Association of psychosocial risk factors with risk of acute myocardial infarction in 11119 cases and 13648 controls from 52 countries (the INTERHEART study): case-control study. Lancet 2004;364:953-62. 45. Meisel SR, Kutz I, Dayan KI, Pauzner H, Chetboun I, Arbel Y, et al. Effect of Iraqi missile war on incidence of acute myocardial infarction and sudden death in Israeli civilians. Lancet 1991;338:660-1.

46. Allegra JR, Mostashari F, Rothman J, Milano P, Cochrane DG. Cardiac events in New Jersey after the September 11 , 2001 , terrorist attack. J Urban Health 2005;82:358-63.

47. Rivero F, Antuna P, Cuesta J, Alfonso F. Severe coronary spasm in a COVID-19 patient. Catheter Cardiovasc Interv 2021;97:E670-E2.

48. Popovic B, Varlot J, Metzdorf PA, Jeulin H, Goehringer F, Camenzind E. Changes in characteristics and management among patients with ST-elevation myocardial infarction due to COVID-19 infection. Catheter Cardiovasc Interv 2021;97:E319-E26.

49. Feuchtner GM, Barbieri F, Luger A, Skalla E, Kountchev J, Widmann G, et al. Myocardial injury in COVID-19: The role of coronary computed tomography angiography (CTA). J Cardiovasc Comput Tomogr 2021;15:e3-e6.

50. Bangalore S, Sharma A, Slotwiner A, Yatskar L, Harari R, Shah B, et al. ST-Segment Elevation in Patients with Covid-19 - A Case Series. N Engl J Med 2020;382:2478-80.

51. Stefanini GG, Montorfano M, Trabattoni D, Andreini D, Ferrante G, Ancona M, et al. ST-Elevation Myocardial Infarction in Patients With COVID-19: Clinical and Angiographic Outcomes. Circulation 2020;141:2113-6.

52. Nannoni S, de Groot R, Bell S, Markus HS. Stroke in COVID-19: A systematic review and meta-analysis. Int J Stroke 2021;16:137-49.

53. Siow I, Lee KS, Zhang JJY, Saffari SE, Ng A, Young B. Stroke as a Neurological Complication of COVID-19: A Systematic Review and Meta-Analysis of Incidence, Outcomes and Predictors. J Stroke Cerebrovasc Dis 2021;30:105549.

54. Mao L, Jin H, Wang M, Hu Y, Chen S, He Q, et al. Neurologic Manifestations of Hospitalized Patients With Coronavirus Disease 2019 in Wuhan, China. JAMA Neurol 2020;77:683-90.

55. Klok FA, Kruip MJHA, van der Meer NJM, Arbous MS, Gommers D, Kant KM, et al. Confirmation of the high cumulative incidence of thrombotic complications in critically ill ICU patients with COVID-19: An updated analysis. Thromb Res 2020;191:148-50.

56. Leasure AC, Khan YM, Iyer R, Elkind MSV, Sansing LH, Falcone GJ, et al. Intracerebral Hemorrhage in Patients With COVID-19. Stroke 2021;52:e321-e3.

57. Merkler AE, Parikh NS, Mir S, Gupta A, Kamel H, Lin E, et al. Risk of Ischemic Stroke in Patients With Coronavirus Disease 2019 (COVID-19) vs Patients With Influenza. JAMA Neurol 2020;77:1366-72.

58. Barlinn K, Siepmann T, Pallesen L-P, Winzer S, Sedghi A, Schroettner P, et al. Universal laboratory testing for SARS-CoV-2 in hyperacute stroke during the COVID-19 pandemic. J Stroke Cerebrovasc Dis 2020;29:105061.

59. Yaghi S, Ishida K, Torres J, Mac Grory B, Raz E, Humbert K, et al. SARS-CoV-2 and Stroke in a New York Healthcare System. Stroke 2020;51:2002-11.

60. Sweid A, Hammoud B, Bekelis K, Missios S, Tjoumakaris SI, Gooch MR, et al. Cerebral ischemic and hemorrhagic complications of coronavirus disease 2019. Int J Stroke 2020;15:733-42.

61. Majidi S, Fifi JT, Ladner TR, Lara-Reyna J, Yaeger KA, Yim B, et al. Emergent Large Vessel Occlusion Stroke During New York City's COVID-19 Outbreak: Clinical Characteristics and Paraclinical Findings. Stroke 2020;51:2656-63.

62. Srivastava PK, Zhang S, Xian Y, Xu H, Rutan C, Alger HM, et al. Acute Ischemic Stroke in Patients With COVID-19. Stroke 2021;52:1826-9. 63. Katsanos AH, Palaiodimou L, Zand R, Yaghi S, Kamel H, Navi BB, et al. The Impact of SARS-CoV-2 on Stroke Epidemiology and Care: A Meta-Analysis. Ann Neurol 2021;89:380-8.

64. Szekely Y, Lichter Y, Taieb P, Banai A, Hochstadt A, Merdler I, et al. Spectrum of Cardiac Manifestations in COVID-19. Circulation 2020;142:342-53.

65. Ntaios G, Michel P, Georgiopoulos G, Guo Y, Li W, Xiong J, et al. Characteristics and Outcomes in Patients With COVID-19 and Acute Ischemic Stroke. Stroke 2020;51:e254-e8.

66. Zhao J, Li H, Kung D, Fisher M, Shen Y, Liu R. Impact of the COVID-19 Epidemic on Stroke Care and Potential Solutions. Stroke 2020;51:1996-2001.

67. Trejo-Gabriel-Galán JM. Ictus como complicación y como factor pronóstico de COVID-19. Neurología 2020;35:318-22.

68. Chen R, Liang W, Jiang M, Guan W, Zhan C, Wang T, et al. Risk Factors of Fatal Outcome in Hospitalized Subjects With Coronavirus Disease 2019 From a Nationwide Analysis in China. Chest 2020;158:97-105.

69. Sheth AR, Grewal US, Patel HP, Thakkar S, Garikipati S, Gaddam J, et al. Possible mechanisms responsible for acute coronary events in COVID-19. Med Hypotheses 2020;143:110125.

70. Tedeschi D, Rizzi A, Biscaglia S, Tumscitz C. Acute myocardial infarction and large coronary thrombosis in a patient with COVID-19. Catheter Cardiovasc Interv 2021;97:272-7.

71. Wang X, Sahu KK, Cerny J. Coagulopathy, endothelial dysfunction, thrombotic microangiopathy and complement activation: potential role of complement system inhibition in COVID-19. J Thromb Thrombolysis 2021;51:657-62.

72. Vrints CJM, Krychtiuk KA, Van Craenenbroeck EM, Segers VF, Price S, Heidbuchel H. Endothelialitis plays a central role in the pathophysiology of severe COVID-19 and its cardiovascular complications. Acta Cardiol 2021;76:109-24.

73. Manolis AS, Manolis TA, Manolis AA, Papatheou D, Melita H. COVID-19 Infection: Viral Macro- and Micro-Vascular Coagulopathy and Thromboembolism/Prophylactic and Therapeutic Management. J Cardiovasc Pharmacol Ther 2021;26:12-24.

74. Marfella R, Paolisso P, Sardu C, Palomba L, D’Onofrio N, Cesaro A, et al. SARS-COV-2 colonizes coronary thrombus and impairs heart microcirculation bed in asymptomatic SARS-CoV-2 positive subjects with acute myocardial infarction. Critical Care 2021;25:217.

75. Pellegrini D, Kawakami R, Guagliumi G, Sakamoto A, Kawai K, Gianatti A, et al. Microthrombi as a Major Cause of Cardiac Injury in COVID-19: A Pathologic Study. Circulation 2021;143:1031-42.

76. Schultz NH, Sørvoll IH, Michelsen AE, Munthe LA, Lund-Johansen F, Ahlen MT, et al. Thrombosis and Thrombocytopenia after ChAdOx1 nCoV-19 Vaccination. N Engl J Med 2021;384:2124-30. 


\title{
Arritmias y disautonomía en COVID-19
}

\author{
FRANCISCO BERTOLOTTI, ARIEL ESTÉVEZ, YENIFERS TORRES, ALEJANDRO VILLAMIL
}

\section{Introducción}

La infección por SARS-CoV-2 puede cursar asintomática o manifestarse como una enfermedad, COVID-19, a predominio respiratorio con grados diversos de afectación.-

Entre el 20 y 30\% de los pacientes hospitalizados con COVID-19 han mostrado una variedad de afecciones miocárdicas y en la medida que la pandemia se expandió, las complicaciones arrítmicas se han tornado evidentes.

La COVID-19 está asociada con una variedad de mediadores pro inflamatorios que pueden jugar un rol importante en la fisiopatología de las complicaciones cardíacas y arrítmicas. Existen múltiples vías que pueden llevar a la injuria cardíaca, como el infarto, la miocarditis, la vasculitis, la trombosis, la fibrosis y el estrés.

Las arritmias son frecuentes en pacientes agudos hospitalizados por COVID-19, pero el mecanismo arrítmico y sus características, así como su tratamiento y seguimiento no han sido bien definidos. Algunas drogas que se han utilizado para el tratamiento del COVID-19, han mostrado efectos proarrítmicos intensos.

Dado que el SARS-CoV-2 es un nuevo patógeno, no existen aún datos fidedignos a largo plazo sobre la ocurrencia de arritmias en la fase de convalecencia de la enfermedad.

La extensión y distribución de la fibrosis podría generar anormalidades electrofisiológicas que predispongan al desarrollo de fibrilación auricular y arritmias ventriculares. Su detección e intervención precoz podría hipotéticamente mejorar la evolución de estos pacientes.

También se ha relacionado a la COVID-19 con el desarrollo de síntomas de disautonomía, tanto en la fase aguda como en la convalecencia, que pueden requerir evaluaciones y tratamientos específicos.

Finalmente, el desarrollo y aplicación de diversas vacunas con diferentes plataformas de mecanismo de acción generan respuestas inmunitarias intensas y efectos colaterales que en algunos casos podrían desencadenar arritmias y disautonomía, tema reciente que no se encuentra aún evaluado en profundidad.

Nuestro objetivo es analizar el conocimiento de las manifestaciones arrítmicas y disautonómicas, así como las estrategias diagnósticas y terapéuticas empleadas en pacientes internados por COVID-19 o en su seguimiento a largo plazo.

\section{Arritmias cardíacas en COVID-19}

Reportes iniciales señalan una incidencia de arritmias del 16,7\% en pacientes hospitalizados y de $44 \%$ en pacientes internados en áreas de cuidados intensivos. (1-3)

En el registro nacional de complicaciones en COVID-19 (RACCOVID-19), las arritmias fueron la segunda complicación más frecuente $(5,13 \%, 141$ pacientes), y la fibrilación auricular fue la arritmia más prevalente, en 74 pacientes $(2,69 \%)$. Se ha demostrado que tanto la taquicardia sinusal como la fibrilación auricular son predictores independientes de severidad, injuria miocárdica y peor evolución clínica durante la internación $(4,5)$

Dividiremos la enfermedad en dos etapas con el fin de caracterizar las arritmias más frecuentes en pacientes afectados por COVID-19; una fase aguda que abarca desde el inicio de los síntomas hasta la tercera semana, y la fase post-aguda que se extiende más allá de la tercera semana desde el inicio de los síntomas.(6)

\section{Fase aguda}

En la fase aguda existen múltiples mecanismos por los cuales aumenta el riesgo de presentar arritmias de novo o exacerbar arritmias preexistentes: los más frecuentes son la hipoxia, las alteraciones hidroelectrolíticas, las alteraciones del estado acido base y la hipertensión pulmonar.

\section{Taquiarritmias supraventriculares}

Dentro de este grupo, todas las series reportadas coinciden en que la taquicardia sinusal y la fibrilación auricular son las taquicardias supraventriculares (TSV) más frecuentes en la etapa aguda y durante la internación (7-9). En un reporte de la Heart Rhythm Society de pacientes internados por COVID-19 el 21\% presentó fibrilación auricular, el 5,4\% aleteo auricular, 3,5\% taquicardia auricular sostenida y 5,7\% taquicardia paroxística supraventricular (TPSV) (10). En una serie italiana de 99 pacientes en el grupo con enfermedad cardiovascular subyacente, la incidencia de fibrilación auricular aumentó al 36\%, con una mayor incidencia de fibrilación auricular en los pacientes que fallecieron durante la internación sobre los externados $42,1 \%$ vs $32,5 \%$ respectivamente. (11)

El tratamiento, no difiere del manejo de las taquiarritmias en otras enfermedades. Siempre deben corregirse las alteraciones metabólicas y los desencadenantes. 


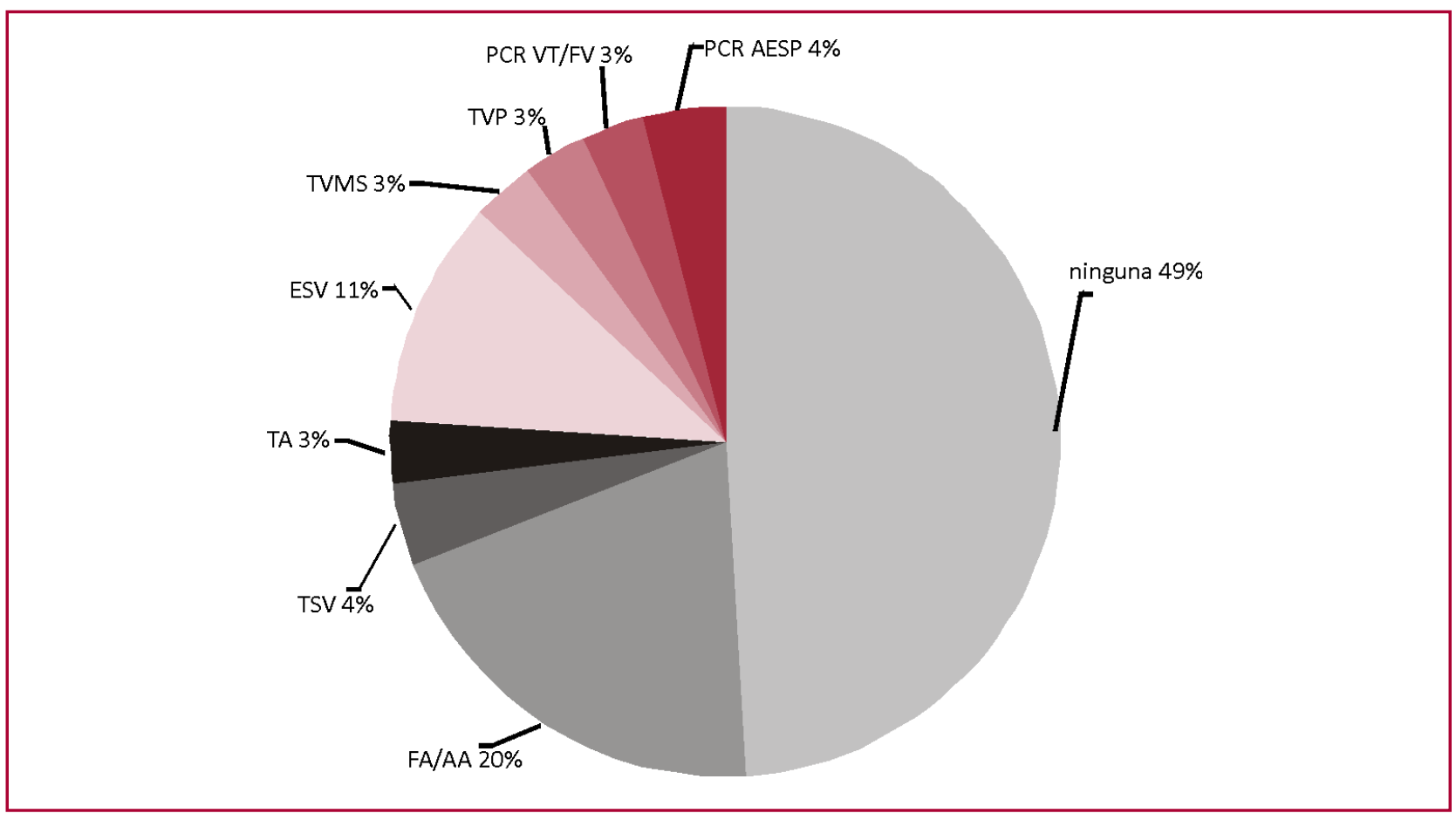

(Tomado de Rakesh Gopinathannair, Faisal M. Merchant. COVID-19 and cardiac arrhythmias: a global perspective on arrhythmia characteristics and management strategies. Journal of Interventional Cardiac Electrophysiology https://doi.org/10.1007/s10840-020-00789-9)

Fig. 1. taquiarritmias en pacientes Internados por COVID-19. FA: fibrilación auricular, TSV: taquicardia supreventricular, TA: taquicardia auricular, ESV: extrasístole supraventricular, TVMS: taquicardia ventricular monomorfa sostenida, TVP: taquicardia ventricular polimorfa, PCR: paro cardiorespiratorio, FV: fibrilación ventricular, AESP: actividad eléctrica sin pulso.

Dentro del abordaje farmacológico la adenosina puede ser utilizada para la reversión de episodios agudos de TPSV. La amiodarona se utilizó para casos de TSV refractarios a adenosina y para el control de ritmo de fibrilación auricular.

No hay estudios que comparen eficacia farmacológica de una droga antiarrítmica sobre otra, así como tampoco hay reportes de efectos adversos distintos a los habituales para cada una de las drogas antiarrítmicas.(3-12) Para control de frecuencia cardiaca en fibrilación auricular, aleteo auricular y taquicardias auriculares se han utilizado beta bloqueantes, bloqueantes de calcio y digoxina, sin que se hayan reportado a la fecha aumento de las complicaciones.

Cuando las drogas antiarrítmicas estuvieron asociadas a medicaciones antivirales como hidroxicloroquina, lopinavir/rotinavir y azitromicina, se reportaron eventos adversos vinculados a la prolongación del intervalo QT y bradiarritmias severas. Por lo antedicho, en caso de ser necesario se debe monitorizar el intervalo QT, la función sinusal y la conducción AV e intraventricular.(12)

Actualmente no disponemos de guías específicas para la anticoagulación por fibrilación auricular en pacientes cursando la fase aguda o crónica de COVID, por lo que se recomienda que su manejo sea similar a los pacientes no COVID. $(3,10,12)$

\section{Arritmias ventriculares}

Las arritmias ventriculares malignas, como la taquicardia ventricular y la fibrilación ventricular, son complicaciones conocidas de las miocarditis virales de otras etiologías, y se presentan en el 1 al $6 \%$ de los casos. $(9,13,14)$

En pacientes COVID-19 estas arritmias pueden deberse a la combinación de alteraciones metabólicas, drogas que prolongan el intervalo QT y a inflamación miocárdica, y son más frecuentes en pacientes que presentan valores elevados de troponina sérica.

Inicialmente se describió una incidencia alta de arritmias ventriculares, adjudicable a la utilización de hidroxicloroquina como parte del tratamiento antiviral. Esto se ve reflejado cuando comparamos la serie de Guo et al. de la ciudad de Wuhan, China, a principios del 2020 con una incidencia del 5,9\% con la serie de Goyal et al. de la ciudad de Nueva York a fines del 2020 donde la incidencia fue de solo el 0,3\%. (9) 
La amiodarona endovenosa es la droga de elección para el tratamiento de arritmias ventriculares complejas, y junto a la lidocaína endovenosa fueron utilizadas sin reportar efectos adversos no habituales.

En cuanto a la utilización de drogas que prolongan el intervalo QT en pacientes con QTc basal normal, se recomienda la suspensión del fármaco cuando el QTc es mayor de 500 mseg. o en quienes presenten aumento mayor a 60 mseg. del QTc basal a las 3 horas de comenzado el fármaco.(3-9)

\section{Bradiarritmias}

Las bradiarritmias se presentan con menor frecuencia que las taquiarritmias. Ocurren en el $11 \%$ al $24 \%$ de los pacientes lo que depende de las series y de la inclusión o no de la bradicardia sinusal.

En una serie de Gopinathannair et. al. que incluyó 683 pacientes, el 8\% presentó bradicardia sinusal severa, $8 \%$ bloqueo $\mathrm{AV}$ de tercer grado y el $6 \%$ bloqueo $\mathrm{AV}$ de primer y segundo grado.(10)

Se cree que la fisiopatología de las bradiarritmias puede ser secundaria a miocarditis por afectación directa del sistema de conducción así como la consecuencia del uso de drogas antiarrítmicas, sobre todo cuando se las asoció a tratamiento antiviral específico. $(8,9)$

La utilización de drogas como la hidroxicloroquina, lopinavir/rotinavir y azitromicina, sobre todo cuando se asociaron al uso de beta bloqueantes y bloqueantes de calcio, aumentaron la incidencia de bradiarritmias en general. Se recomienda evitar su utilización y en caso de ser necesario monitorear la función sinusal, la conducción $\mathrm{AV}$ y la conducción intraventricular.(3-12)

El tratamiento, no difiere de las bradiarritmias de otras etiologías. Deben corregirse las alteraciones metabólicas, suspender fármacos o asociaciones farmacológicas de conocido efecto cronotrópico negativo. El implante de un marcapasos transitorio debe ser considerado como una opción razonable debido a la naturaleza transitoria de estas bradiarritmias en pacientes críticamente enfermos. Una vez superada la fase aguda de la enfermedad debe reevaluarse la necesidad de estimulación permanente.

Debido a que no contamos actualmente con estudios específicos en pacientes COVID-19 el tratamiento de las taquiarritmias y bradiarritmias debe ser similar al de los pacientes que cursan otras infecciones y/o trastornos metabólicos transitorios.(3-7)

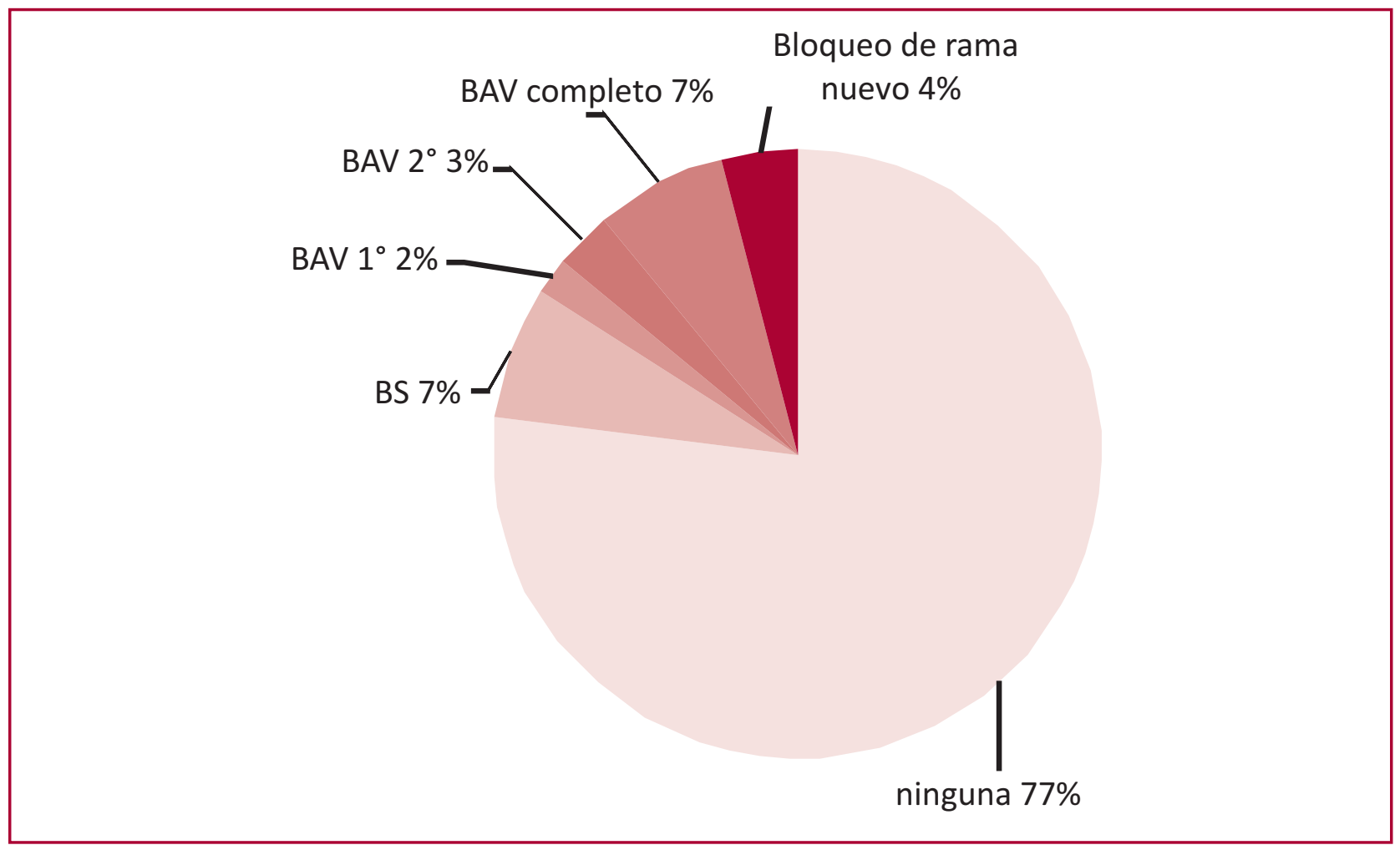

Tomado de Rakesh Gopinathannair, Faisal M. Merchant. COVID-19 and cardiac arrhythmias: a global perspective on arrhythmia characteristics and management strategies. Journal of Interventional Cardiac Electrophysiology https://doi.org/10.1007/s10840-020-00789-9 


\section{Arritmias en el post COVID-19}

En el seguimiento, la arritmia más frecuentemente registrada es la taquicardia sinusal persistente que se presenta hasta en el 40\% de los pacientes post externación.(3-15) De estos, el 9\% persiste sintomático por palpitaciones a los 6 meses. (16) En los pacientes sintomáticos que requirieron tratamiento farmacológico se administró ivabradina o betabloqueantes sin reporte de efectos adversos no esperados.

Por tratarse de una enfermedad relativamente nueva, contamos con datos limitados en lo que respecta al seguimiento a largo plazo, motivo por el cual las guías de tratamiento y seguimiento se encuentran en permanente evaluación.

En nuestra opinión la evaluación arritmológica de pacientes post COVID debe restringirse a aquellos con síntomas atribuibles a arritmias o que hayan presentado complicaciones arrítmicas durante la fase aguda. Con los datos actuales no recomendamos la realización de estudios complementarios específicos como screening en pacientes asintomáticos.

\section{Disautonomía en COVID-19}

\section{Síndrome de taquicardia postural ortostática (POTS)}

La enfermedad aguda por COVID-19 ha sido el foco inicial de la atención médica. Sin embargo, en la actualidad, nos enfrentamos a pacientes que desarrollan una constelación de síntomas luego de la resolución de esta etapa. Este síndrome, cuando persiste más allá de las 12 semanas, se ha denominado COVID prolongado.

Los síntomas incluyen una combinación de signos y síntomas como: dificultad para respirar, palpitaciones, malestar precordial, fatiga, deterioro cognitivo ("niebla mental"), alteraciones del sueño, intolerancia ortostática, neuropatía periférica (hormigueo y entumecimiento), malestar abdominal, náuseas, diarrea, artralgias y mialgias, ansiedad o depresión, erupciones cutáneas, cefalea y tinnitus.

Cuando estos últimos se combinan con taquicardia ortostática excesiva, pueden conducir al diagnóstico de síndrome de taquicardia postural (POTS) posterior a COVID-19 ("POTS post COVID"). (17)

El POTS es la disautonomía crónica más prevalente en individuos de mediana edad, más en mujeres (80\%). El diagnóstico se basa en la evidencia de taquicardia ortostática excesiva asociada a síntomas de intolerancia ortostática (aumento de la frecuencia cardíaca $>30$ latidos por minuto en adultos o $>40$ en pacientes menores de 19 años) al pararse o en los primeros minutos de inclinación en la prueba de Tilt Test. $(18,19)$

Hay varios mecanismos fisiopatológicos que podrían explicar la aparición de POTS luego de COVID-19.

1) La hipovolemia relativa debida a la fiebre, anorexia, náuseas, sudoración nocturna excesiva y el reposo prolongado en cama, pueden funcionar juntos para disminuir el volumen sanguíneo y en forma secundaria, aumentar la descarga excesiva del sistema simpático noradrenérgico (SNS) cardíaco. Este desacondicionamiento puede resultar en un círculo vicioso que genere intolerancia al ejercicio y fatiga.

2) El SARS-CoV-2 podría infectar y destruir neuronas posganglionares extracardíacas del SNS, y así aumentar secundariamente la descarga del mismo a nivel cardíaco. Esto puede incluir acumulación venosa esplácnica o un fallo de la vasoconstricción mesentérica refleja durante la ortostasis. (20)

3) El SARS-CoV-2 podría invadir el tronco encefálico y alterar funciones de los centros medulares, lo que podría resultar en un aumento directo del flujo simpático de una manera análoga al Takotsubo. (21)

4) Las respuestas inmunitarias dirigidas al virus están reguladas de forma dinámica, equilibrando el ataque del virus frente al ataque a las propias células del anfitrión. Si bien existe una gran cantidad de literatura que describe marcadores autoinmunes y autoanticuerpos en POTS, la misma no es suficiente para poder afirmar que la infección por COVID-19 altere esta homeostasis. $(22,23)$

Los protocolos de tratamiento disponibles para POTS recomiendan la ingesta de líquidos (agua) y sal, realizar contra-maniobras físicas y ejercicio aeróbico en posición reclinada para ayudar a corregir las anomalías fisiológicas.

La farmacoterapia incluye expansores de volumen, vasoconstrictores, y reguladores de la frecuencia cardíaca, pero los pacientes pueden permanecer sintomáticos e incapaces de trabajar. $(24,25)$

Ante esta situación surgen algunos interrogantes a resolver:

1. ¿Cómo es la historia natural del POTS asociado al COVID prolongado? ¿Es un trastorno que se autolimita o tardara tiempo prolongado en resolver?

2. ¿Cuál es la fisiopatología subyacente del POTS asociado al COVID prolongado? Están los síntomas relacionados con vías inflamatorias específicas o autoinmunidad? ¿El volumen sanguíneo bajo es una característica?

3. ¿Cuál es el tratamiento adecuado?

4. ¿Es el POTS post COVID igual al POTS no relacionado con el virus?

Claramente necesitamos más tiempo y experiencia clínica para poder dar respuesta a estas preguntas. 


\section{Efectos cardiovasculares post vacunas}

La pandemia impulsó la implementación de diversas medidas con el fin de contener un virus que se propaga a gran escala. Las vacunas ocuparon un rol preponderante para amortiguar las complicaciones graves, y alcanzar la inmunidad de rebaño. Dado el escaso tiempo desde su implementación y la diversidad de vacunas, nos encontramos aún en las primeras etapas de evaluación de sus potenciales efectos secundarios a mediano y largo plazo. (26)

Si bien han sido descriptos tras la vacunación mareos, presíncope y síncope, la prevalencia es baja y sin consecuencias posteriores.

Los recientes reportes de farmacovigilancia europeos y norteamericanos muestran una similitud en cuanto a efectos adversos hallados en relación temporal con la vacunación y su baja incidencia. Dentro de los que se encuentran bajo observación, la anafilaxia, la miocarditis y o pericarditis, los trastornos hormonales, neurológicos y trombóticos son los más prevalentes. (27-29)

Tanto en Estados Unidos como en España, fueron notificadas miocarditis y pericarditis en 2 casos por cada 1.000.000 de vacunados, predominando en varones adolescentes y adultos jóvenes, especialmente durante la primer semana de vacunación. Síntomas correlacionables con arritmias cardíacas fueron descritos en muchos de ellos, aunque la evolución finalmente fue favorable.

En cuanto a los fallecimientos durante la campaña de vacunación en estrecha asociación temporal con la administración de la vacuna, dado que otras causas siguen ocurriendo, es difícil encontrar una correlación clara con el hecho de haber sido vacunado. En los documentos de reporte de Estados Unidos, después de la revisión de la información clínica disponible, incluidos los certificados de defunción, autopsias e historias clínicas, no se encontró hasta hoy una relación causal con las vacunas.

\section{Conclusiones}

Analizada la evidencia sobre los efectos de la infección por COVID 19 en los trastornos del ritmo cardiaco, surge que las arritmias son un hecho frecuente y proporcional al grado de severidad de la enfermedad durante la fase aguda.

Por otro lado, el uso de diversas drogas proarrítmicas en pacientes con compromiso moderado a severo han hecho confuso el análisis de la real ocurrencia de las arritmias en la COVID-19.

Superada esta etapa inicial de desconocimiento, impresiona que la arritmia durante la COVID-19 no es mucho mayor a la encontrada en infecciones graves de tracto respiratorio y su manejo se asemeja al indicado en esas condiciones.

Durante la etapa post COVID-19, se han reportado casos de arritmias y disautonomía, a veces difíciles de diferenciar de condiciones previas del paciente y en general con buen pronóstico, que requieren de tratamientos como la rehabilitación, los beta bloqueantes y la ivabradina entre otros por algunos meses.

La aplicación de la vacuna contra COVID-19 ha demostrado hasta nuestros días una alta eficacia, pero sus efectos a largo plazo son aún desconocidos, así como la posibilidad de influir en el desarrollo de enfermedad cardíaca y arritmias, por lo que la farmacovigilancia es imperativa.

Finalmente, es nuestro parecer que los pacientes post COVID-19 deberían ser controlados por síntomas adjudicables a arritmias, como palpitaciones, síncope, presíncope y disautonomía o ante la sospecha de compromiso miocárdico (miopericarditis, IAM, TEP, etc.), con la metodología habitual para cada caso.

\section{BIBLIOGRAFÍA}

1. Driggin E, Madhavan MV, Bikdeli B, et al. Cardiovascular considerations for patients, health care workers, and health systems during the COVID-19 pandemic. J Am Coll Cardiol. 2020;75:2352-71.

2. Long B, Brady WJ, Koyfman A, Gottlieb M. Cardiovascular complications in COVID-19. Am J Emerg Med. 2020; 38: 1504-1507

3. Dherange P, Lang J, Qian P, Oberfeld B, Sauer WH, Koplan B, et al. Arrhythmias and COVID-19: a review. JACC Clin Electrophysiol. 2020;6:1193-1204

4. Long B, Brady W, Bridwell R, Ramzy M, Montrief T, Singh M et al. Electrocardiographic manifestations of COVID- 19, Am J Emerg Med. 2021; 41: 96-103

5. Wang Y, Chen L, Wang J, et al. Electrocardiogram analysis of patients with different types of COVID-19. Ann Noninvasive Electrocardiol. 2020 Sep; 20:e12806. https://doi.org/10.1111/anec.12806.

6. Lobo Marquez L, Echazarreta D, Perna E, Piskorz D, Perrone S, Aguinaga L, Zapata G. . Dudas y certezas en la evolución post-COVID-19: rol del cardiólogo en la evaluación estructurada de pacientes recuperados. L Lobo Marquez et al / Rev Fed Arg Cardiol. 2021;50 (Suplemento 1): 4-12 7. Nunes Kochi A, Tagliari A, Forleo G. Cardiac and arrhythmic complications in patients with COVID-19. J Cardiovasc Electrophysiol. 2020;31:1003-1008.

8. ESC Guidance for the Diagnosis and Management of CV Disease during the COVID-19 Pandemic. Available at: https://www.escardio.org/ Education/COVID-19-and-Cardiology/ESCCOVID-19-Guidance. May 19, 2020. 
9. Hu L, Gong L, Jiang Z, Wang Q, Zou Y, Zhu L. Clinical analysis of sinus bradycardia in patients with severe COVID-19 pneumonia. Crit Care 2020; 24: 257.

10. Gopinathannair R, Merchant F, Lakkireddy D, Etheridge S, Feigofsky S, Han J, et al. COVID-19 and cardiac arrhythmias: a global perspective on arrhythmia characteristics and management strategies. J Interv Card Electrophysiol. 2020 Nov;59(2):329-336. doi: 10.1007/s10840020-00789-9. Epub 2020 Jun 3. PMID: 32494896; PMCID: PMC7268965.

11. Inciardi RM, Adamo M, Lupi L, Cani DS, Di Pasquale M, Tomasoni D, Italia L, Zaccone G, Tedino C, Fabbricatore D, et al. Characteristics and outcomes of patients hospitalized for COVID-19 and cardiac disease in Northern Italy. Eur Heart J. 2020;41:1821-182

12. Rattanawong P, Shen W, El Masry H, Sorajja D, Srivathsan K, Valverde A, Scott L.Guidance on Short-Term Management of Atrial Fibrillation in Coronavirus Disease 2019. J Am Heart Assoc. 2020;5302:e017529. DOI: 10.1161/JAHA.120.017529

13. Elias P, Poterucha TJ, Jain SS, et al. The prognostic value of electrocardiogram at presentation to emergency department in patients with COVID-19. Mayo Clin Proc. 2020;95(10):2099-109. https://doi.org/10.1016/j.mayocp.2020.07.028.

14. Haseeb S, Gul EE, Çinier G, et al. Value of electrocardiography in coronavirus disease 2019 (COVID-19) [published online ahead of print, 2020 Aug 6]. J Electrocardiol. 2020;62:39-45. https://doi.org/10.1016/j.jelectrocard.2020.08.007

15. Ståhlberg M, Reistam U, Fedorowski A, Villacorta H, Horiuchi Y, Bax J, et al. Post-Covid-19 Tachycardia Syndrome: A distinct phenotype of Post-acute Covid-19 Syndrome. Am J Med. 2021 Aug 11:S0002-9343(21)00472-1. doi: 10.1016/j.amjmed.2021.07.004

16. Huang C, Huang L, Wang Y, Li X, Ren L, Gu X, et al. 6-month consequences of COVID-19 in patients discharged from hospital: a cohort study. Lancet. 2021;397(10270):220-32.

17. Goldstein DS. The possible association between COVID-19 and postural tachycardia syndrome. Heart Rhythm. 2021 Apr;18(4):508-509

18. Fedorowski A. Postural orthostatic tachycardia syndrome: clinical presentation, aetiology and management. J Intern Med 2019;285:352-66.

19. Bryarly M, Phillips LT, Fu Q, Vernino S, Levine BD. Postural orthostatic tachycardia syndrome: JACC focus seminar. J Am Coll Cardiol 2019;73:1207-28.

20. Fu Q, Vangundy TB, Galbreath MM, et al. Cardiac origins of the postural orthostatic tachycardia syndrome. J Am Coll Cardiol 2010;55:285868.

21. Akashi YJ, Goldstein DS, Barbaro G, Ueyama T. Takotsubo cardiomyopathy: a new form of acute, reversible heart failure. Circulation 2008;118:2754-2762.

22. Goldstein DS. The extended autonomic system, dyshomeostasis, and COVID-19. Clin Auton Res 2020;30:299-315.

23. Miller AJ, Raj SR. Pharmacotherapy for posturaltachycardia syndrome. Auton Neurosci 2018;215:28-36.

24. Johansson M, Ståhlberg M, Runold M, Nygren-Bonnier M, Nilsson J, Olshansky B, et al. Long-Haul Post-COVID-19 Symptoms Presenting as a Variant of Postural Orthostatic Tachycardia Syndrome: The Swedish Experience. JACC Case Rep. 2021;3(4):573-80. doi: 10.1016/j. jaccas.2021.01.009.

25. Raj SR, Arnold AC, Barboi A, Claydon VE, Limberg JK, Lucci VM, et al. Long-COVID postural tachycardia syndrome: an American Autonomic Society statement . Clin Auton Res. 2021;31:365-8.

26. Polack FP, Thomas SJ, Kitchin N, et al. Safety and efficacy of the BNT162b2 mRNA Covid-19 vaccine. N Engl J Med 2020;383:2603-15.

27. Reporte de Seguridad sobre reacciones adversas después de vacunación COVID 19. VAERS - CDC. USA Sep 2021

28 Informe de Farmacovigilancia sobre Vacunas Covid 19. Sep 2021. Ministerio de Sanidad. Gobierno de España. Sep 2021

29 The Government of the Hong Kong Special Administrative Region Department of Health. COVID-19 vaccine adverse event online reporting. https://www.drugoffice.gov. hk/eps/do/en/healthcare_providers/adr_reporting/index.html (accessed July 4, 2021). 


\title{
Enfermedad Tromboembólica Venosa en COVID-19
}

\author{
ADRIÁN LESCANO
}

Los trastornos cardiovasculares y pulmonares tienen una incidencia elevada en los pacientes con COVID-19 y constituyen un motivo frecuente de prolongación de la estadía hospitalaria y la mortalidad. La infección por el virus SARS-CoV-2 se asocia a un aumento sustancial de los eventos trombóticos, como la trombosis venosa profunda (TVP), el tromboembolismo de pulmón (TEP) y la trombosis arterial sistémica. (1) La mayor proporción de pacientes con TVP/TEP se encuentran en las áreas de cuidados críticos, aunque puede afectar a la población no grave y ambulatoria post COVID-19. $(2,3)$

\section{Epidemiología}

La TVP/TEP es una entidad multifactorial con elevada morbilidad y mortalidad. A pesar de los avances en los métodos diagnósticos y los tratamientos específicos, es uno de los principales problemas durante la fase de hospitalización de patologías generales. La incidencia anual de la enfermedad venosa aguda se encuentra entre 23 y 69 casos por 10000 habitantes, distribuidos en un tercio de pacientes con TEP y dos tercios con TVP. El 10\% de los pacientes con TEP mueren durante los primeros 8 meses, el 1\% de los pacientes admitidos en hospitales fallecen por TEP y el 10\% de todas las muertes intrahospitalarias tienen relación con la TVP/TEP. (4)

La alteración de los procesos de coagulación y la escasa movilidad determinan un escenario propicio para el desarrollo de trombosis in situ en el sistema vascular en los pacientes que presentan COVID-19. Esto explica en parte la elevada prevalencia de trombosis venosa antes y durante la internación e incluso hasta 30 días posteriores al egreso institucional.

La incidencia de TVP/TEP en esta entidad oscila entre un 13 y $35 \%$ y predomina en aquellos que se encuentran internados en áreas críticas. Diversas observaciones demuestran la reducción de la mortalidad nosocomial con la utilización sistemática de heparinas en este subgrupo, lo cual resalta la importancia del diagnóstico y tratamiento precoz. (5)

El registro argentino de complicaciones cardiovasculares en pacientes con COVID-19 (RACCOVID-19), incluyó 2750 pacientes internados (edad media $57 \pm 18$ años, $60,2 \%$ sexo masculino, actores de riesgo coronario $67,4 \%$ y antecedentes cardiovasculares 44,3\%) con una incidencia de 47 casos de embolias, 1,7\% de la población global y $11,1 \%$ de los 420 con complicaciones. (6)

Las complicaciones derivadas de la TVP/TEP son diversas y muchas pueden ser graves, lo que aumentaría el riesgo de mortalidad asociado a la COVID-19 y jerarquiza la necesidad de un diagnóstico precoz.

Diferentes factores se asocian con el incremento de la probabilidad de desarrollar TVP/TEP, entre los que podemos destacar a la edad mayor, el sexo masculino, neoplasias, obesidad, Dímero-D elevado, necesidad de intubación y estadía hospitalaria prolongada. (7)

\section{Fisiopatología}

El SARS-CoV-2 infecta a las células endoteliales que expresan el receptor de superficie de la angiotensina II. Este daño endotelial activa el factor tisular, que genera trombina a partir de la protrombina por acción del factor $\mathrm{X}$ activado; las plaquetas circulantes activadas se agregan y proporcionan la superficie fosfolipídica adecuada para la adhesión de los diferentes compuestos de la cascada de la coagulación con la generación de gran cantidad de trombina. (8) Diferentes mecanismos participan en el compromiso pulmonar y vascular, donde la disfunción endotelial y la trombosis de la microvasculatura tienen un rol preponderante. Las autopsias posteriores a la infección por COVID-19 han evidenciado extensa trombosis pulmonar asociada a microangiopatía y microtrombosis a nivel de los capilares alveolares. $(9,10)$

Los mecanismos fisiopatológicos son multifactoriales, con un rol protagónico del estado persistente de hipercoagulabilidad, con activación de las citoquinas, del complemento y del sistema inmunológico. Estos fenómenos se suman a factores conocidos de riesgo como la inmovilización, la edad avanzada, la obesidad, los antecedentes de enfermedad oncológica, el consumo de anticonceptivos o la trombofilia, entre otras. Por este motivo, este subgrupo de pacientes presenta indicación de utilizar heparinas como profilaxis a dosis intermedia. $(11,12)$

Una de las complicaciones que se observan en los cuadros severos de COVID-19, con hipoxemia severa, es atribuible a la falla del ventrículo derecho (VD). Diferentes mecanismos generan incremento de las resistencias vasculares pulmonares y deterioro de la función del VD, como la atelectasia alveolar y la vasoconstricción hipoxémica, lo cual nos obliga al diagnóstico diferencial con la trombosis pulmonar. (13) 


\section{Diagnóstico}

La sospecha clínica es una piedra angular en el diagnóstico del compromiso venoso vascular y los diferentes métodos complementarios, a través de imágenes o parámetros de laboratorios permiten confirmar la patología.

\section{Angiotomografía pulmonar}

La técnica de elección para el diagnostico de TEP agudo es la angiotomografía de tórax (angioTAC), ya que permite visualizar la circulación pulmonar, la anatomía y el compromiso de las cámaras cardiacas derechas. En la población con afección por COVID-19 la Sociedad Europea de Radiología y la Sociedad Europea de Imágenes Torácicas recomiendan este método para excluir el diagnóstico en aquellos pacientes con compromiso pulmonar y necesidad de oxigeno suplementario. (14) La Sociedad Europea de Cardiología (ESC) sugiere la realización de una angioTAC de tórax cuando la presencia de insuficiencia respiratoria no se justifica por la TAC de tórax sin contraste, y en algunas series se ha detectado en estos casos una elevada prevalencia $(46,2 \%)$. (15)

Se ha descripto una distribución de las lesiones trombóticas en forma predominante sobre las arterias segmentarias y subsegmentarias y con menor frecuencia las arterias principales / lobares $(66,7 \%$ y $33,3 \%$, respectivamente), probablemente asociado al contexto de la inflamación extensa, las lesiones alveolares y el intenso estado protrombótico. (16-18)

En diversos trabajos se informó la implicancia pronostica de la dilatación del (VD), definida como una relación VD/VI (ventrículo izquierdo) $\geq 1$ en la angiotomografia de tórax con contraste endovenoso. Esta dilatación se asocia a un incremento de la mortalidad $(58,3 \%$ vs $11,5 \%, \mathrm{p}=0,002)$ similar a los eventos agudos pulmonares sin COVID-19.

\section{Ultrasonografía cardiovascular}

Este método complementario cumple un lugar esencial en el algoritmo diagnóstico y pronóstico de la enfermedad. El Doppler venoso de miembros inferiores es la técnica de screening de elección en el diagnóstico de TVP: la ausencia de colapso y la presencia de material endoluminal nos brindan la confirmación de trombosis. En aquellos pacientes donde los estudios pulmonares no son factibles o no aportan un diagnóstico definitivo y cuando existe una fuerte sospecha clínica de TEP, esta técnica es una herramienta alternativa. Aunque tiene una baja sensibilidad (40\%), la especificidad es muy elevada (96\%) lo que permite guiar el tratamiento ante la sospecha clínica de trombosis pulmonar (IIA). (19)

El ecocardiograma Doppler permite la evaluación funcional y anatómica del ventrículo derecho, definir la velocidad del reflujo tricuspídeo y determinar la probabilidad de hipertensión pulmonar, y/o excluir otros diagnósticos diferenciales (disfunción del VI, derrame pericárdico, valvulopatías). Los hallazgos de dilatación de cavidades derechas, deterioro de la función sistólica del ventrículo derecho y el signo de Mc Connell (dilatación y disfunción del ventrículo derecho y su pared libre, con preservación de la contractilidad del ápex), orientan al diagnóstico de TEP masivo o submasivo. Asimismo, en los pacientes con inestabilidad hemodinámica (donde no es factible el traslado) o las imágenes no son concluyentes, la presencia de disfunción del ventrículo derecho nos orienta hacia el diagnóstico de TEP (excluyendo otros diagnósticos diferenciales) y permite comenzar el tratamiento especifico (Nivel de evidencia I Clase A). Otro hallazgo confirmatorio es la presencia de trombo en tránsito en la circulación pulmonar o en las cavidades derechas. (Figura 1)

\section{Diagnóstico bioquímico}

Se han demostrado alteraciones en la cascada de la coagulación en pacientes con infección grave, en particular del dímero D. Un patrón sospechoso es el ascenso constante de los niveles del dímero D a pesar de que otros parámetros típicamente alterados en esta enfermedad como la ferritina, LDH y proteína C tienden a normalizarse. Cuando esto ocurre se plantea el diagnóstico diferencial con TEP como complicación de la enfermedad.

Los niveles elevados de dímero D indican actividad de la cascada de la coagulación y el nivel de hiperfibrinólisis, y son ampliamente utilizados en la práctica clínica para el diagnóstico diferencial de enfermedad trombótica vascular. Su cuantificación se encuentra dentro del algoritmo diagnóstico de TVP/TEP. Su elevación tiene una elevada sensibilidad y baja especificidad. Valores menores de $0,5 \mathrm{ug} / \mathrm{ml}$ se utilizan para descartar la presencia de TVP/TEP. $(20,21)$

Un estudio publicado sobre el valor del dímero D en población asiática con COVID-19 informó un valor predictivo negativo (VPN) para TVP del 92,5\% con un punto de corte de 3,0 $\mu \mathrm{g} / \mathrm{ml}$. Asimismo, un nivel elevado de dímero $\mathrm{D}$ presentó un alto valor predictivo positivo. (22)

La concentración elevada de PCR (Proteína C reactiva) tiene capacidad predictiva de TVP/TEP en la población con COVID-19 y expresa la asociación entre la cascada inflamatoria y la coagulación. (23) 


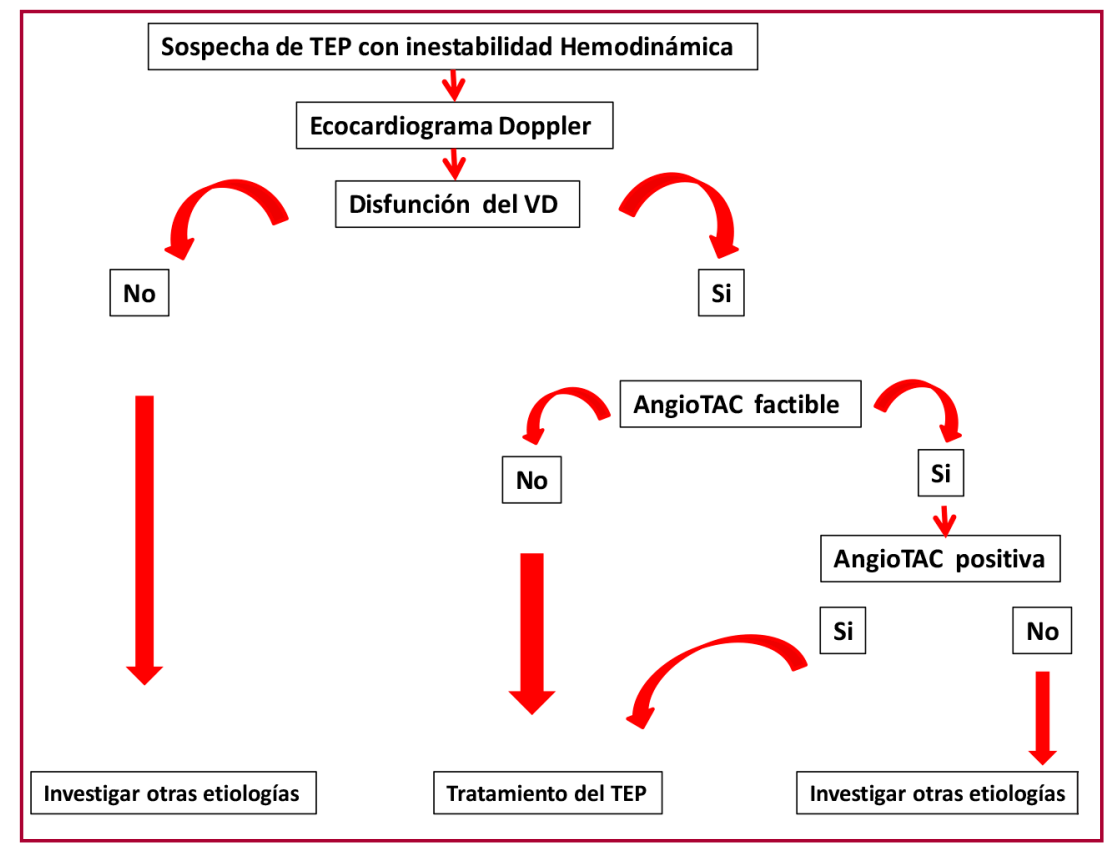

TEP: Tromboembolismo de pulmón; VD: Ventrículo derecho; TAC: Tomografía computada

Fig. 1. Algoritmo Diagnóstico en pacientes con Inestabilidad Hemodinámica

\section{Resumen sobre diagnóstico}

Es fundamental la sospecha clínica de TVP/TEP ya que afecta pacientes en estado crítico por infección COVID-19 con un mal pronóstico evolutivo. La detección de niveles elevados de dímero D y PCR contribuye a la sospecha diagnóstica. El ecocardiograma Doppler y el Doppler venoso de miembros inferiores son herramientas útiles de screening, que brindan información sobre parámetros indirectos y hemodinámicos de alta sospecha de TVP/ TEP y se encuentran al alcance de la mayoría de los servicios de cuidados críticos. La angioTAC es el método de elección para confirmar el diagnóstico. Cuando no lo confirma y persiste la elevada sospecha clínica, debe realizarse una angiografía pulmonar.

\section{Tratamiento}

Las recomendaciones terapéuticas son similares a la población sin la presencia de COVID-19, aunque un amplio porcentaje de estos pacientes presentan condiciones que limitan el tratamiento convencional (hemorragias, asistencia respiratoria mecánica, anemia, plaquetopenia, edad avanzada, etc.).

Los pacientes con TVP/TEP de riesgo bajo e intermedio/bajo requieren comenzar con tratamiento anticoagulante en forma inmediata. El compromiso clínico indicará la necesidad de la estrategia de elección: esquema oral (acenocumarol, warfarina o anticoagulantes directos), heparina subcutánea o intravenosa.

En los pacientes con TEP de alto riesgo las guías recomiendas la utilización de trombolíticos sistémicos, cuando no existan contraindicaciones. La trombólisis percutánea guiada por catéter se encuentra indicada cuando la administración sistémica está contraindicada o se presenta falla terapéutica (Clase II, Nivel de evidencia C). (24) El tratamiento trombolítico directo por catéter y asistido por ultrasonografia se asocia a mayor reducción de la dilatación del VD, mejoría de su función sistólica y disminución de la carga trombótica en pacientes con TEP masivo y submasivo. Esta técnica utiliza una dosis más baja de tPA en comparación con la trombólisis estándar, por lo cual se asocia a menor incidencia de hemorragias graves e intracerebrales y constituye una alternativa para esta población con elevada tasa de comorbilidades. $(25,26)$

\section{Prevención del TVP/TEP}

Para la prevención de la enfermedad tromboembólica venosa, es fundamental el cuidado integral que disminuye las tasas de complicaciones en los pacientes hospitalizados o críticos. Los protocolos actuales de tratamiento recomiendan la administración preventiva de fármacos anticoagulantes como las heparinas de bajo peso molecular. Estos fármacos se administran durante toda la estadía de hospitalización dentro del área de cuidados críticos, 
valorando de manera individual la necesidad de continuar este tratamiento al alta en casos de pacientes con TEP confirmado o factores protrombóticos persistentes.

\section{Prevención de la trombosis luego del alta}

Se han reportado casos de trombosis venosa, tromboembolismo pulmonar y muerte súbita post alta de la internación por COVID-19, lo que ha suscitado una inquietud sobre la adopción de medidas de profilaxis. Ante la carencia de ensayos controlados, los consensos han propuesto indicaciones no homogéneas en este contexto. $(27,28)$

La incidencia de trombosis venosa post-alta no es elevada. En una serie de 1877 pacientes dados de alta postCOVID-19 la incidencia fue de 9 casos, 4,8/1000 altas, con un odds ratio de 1,6 respecto a una cohorte de control de 18159 pacientes de alta por otros motivos (3,1/1000). La incidencia es muy baja y no sugiere la necesidad de tromboprofilaxis en todos los casos. (29)

En una exploración de las conductas institucionales post-COVID-19 con cuadros severos, el 70\% de las instituciones recomendaba tromboprofilaxis post alta. La selección de los agentes se orientó a heparinas de bajo peso molecular (30\%), anticoagulantes directos (30\%), y heparina no fraccionada $10 \%$. La preferencia por la duración fue de 0-14 días en el $50 \%$ y hasta un mes en el $20 \%$ restante. (28)

Sobre la base de esta información, la indicación de profilaxis post-alta deberá ajustarse a los factores de riesgo previos, la gravedad del curso clínico durante la internación, la necesidad de reposo prolongado y factores de eventual riesgo de sangrado.

\section{Conclusiones}

La incidencia de la TVP/TEP es elevada en los pacientes con COVID-19, asociada a la presentación moderada y grave. La profilaxis en estos casos se recomienda en forma sistemática y ha disminuido la frecuencia de complicaciones. Cuando se sospecha TEP la evaluación del compromiso hemodinámico, el impacto sobre la anatomía vascular y la funcionalidad del VD son parámetros de utilidad para definir los diferentes esquemas. El tratamiento anticoagulante o la estrategia trombolítica óptima deben ser seleccionados en forma adecuada, según el riesgo del cuadro de TVP/TEP y las probabilidades de hemorragias.

\section{BIBLIOGRAFÍA}

1. Klok FA, Kruip MJHA, Van der Meer NJ, Arbous MS, Gommers DA, Kant KM, et al. Incidence of thrombotic complicationsin critically ill ICU patients with COVID-19. Thromb Res 2020; 191:145-7.

2. Gervaise A, Bouzad C, Peroux E, Helissey C. Acute pulmonary embolism in non-hospitalized COVID-19 patients referred to CTPA by emergency department. Eur Radiol 2020;30(11):6170-7. http://doi.org/10.1007/s00330-020-06977-5.

3. Wichmann D, Sperhake JP, Lütgehetmann M, Steurer S, Edler C, Heinemann A, et al. Autopsy findings and venous thromboembolism in patients with COVID-19: a prospective cohort study. Ann Intern Med 2020;173:268-77.

4. Tobiki A, Kurzyna M, Konstantinides S. The ESC Textbook of Intensive and Acute Cardiovascular Care. England: Oxford University Press; 2015. DOI: $10.1093 / \mathrm{med} / 9780199687039.003 .0066$ update 003.

5. Tang N, Bai H, Chen X, Gong J, Li D, Sun Z. Anticoagulant treatment is associated with decreased mortality in severe coronavirus disease 2019 patients with coagulopathy. J Thromb Haemost. 2020;18(5):1094-9. doi: 10.1111/jth.14817. .

6. Kazelian LR, Zapata G, Pereiro González SM, Maydana M, Lescano A, Lorenzatti A, y cols. RACCOVID-19: primer Registro Argentino de Complicaciones Cardiovasculares en pacientes con COVID-19. Rev Argent Cardiol 2021;89:285-92.

7. Bompard F, Monnier H, Saab I, Tordjman M, Habdoul H, Fournier L, et al. Pulmonary embolism in patients with Covid-19 pneumonia. Eur. Respir. J [revista en internet]. 2020 [citado 15 de agosto 2020]; 56(1): 2001365.

8. Yuki K, Fujiogi M, Koutsogiannaki S. COVID-19 pathophysiology: A review. Clin Immunol 2020;215:108427

9. McGonagle D, O’Donnell JS, Sharif K, Emery P, Bridgewood C. Immune mechanisms of pulmonary intravascular coagulopathy in COVID-19 pneumonia. Lancet Rheumato 2020; 12(7):e437-e445.

10. Ackermann M, Verleden SE, Kuehnel M, Haverich A, Welte T, Laenger F, et al. Pulmonary vascular endothelialitis,thrombosis, and angiogenesis in Covid-19. N Engl J Med 2020; 383:120.

11. Giannis D, Ziogas IA, Gianni P. Coagulation disorders in coronavirus infected patients:COVID-19, SARS-CoV-1, MERS-CoV and lessons from the past. J Clin Virol 2020;127:104362.

12. Marietta M, Ageno W, Artoni A, De Candia E, Gresele P, Marchetti M, et al. COVID-19 and haemostasis: A position paper from Italian Society on Thrombosis and Haemostasis (SISET). Blood Transfus 2020;18(3):167-9.

13. Ioan A, Lopez A, Martínez-Milla J, Perez-Calvo C, Santos A. Pulmonary embolism in COVID-19. When nothing is what it seems. Rev Esp Cardiol. 2020;73(8):665-87.

14. Revel MP, Parkar AP, Prosch H, Silva M, Sverzellati N, Gleeson F, et al. COVID-19 patients and the radiology department advice from the European Society of Radiology (ESR) and the European Society of Thoracic Imaging (ESTI). Eur Radiol 2020;30:4903

15. Bikdeli B, Madhavan MV, Jimenez D, Chuich T, Dreyfus I, Driggin E et al. Supported by the ESC Working Group on Pulmonary Circulation and Right Ventricular Function. COVID-19 and Thrombotic or Thromboembolic Disease: Implications for Prevention, Antithrombotic Therapy, and Follow-Up: JACC State-of-the-Art Review. J Am Coll Cardiol. 2020;75:2950-73.

16. van Dam LF, Kroft LJM, van der Wal LI, Cannegieter SC, Eikenboom J, de Jonge E, et al. Clinical and computed tomography characteristics of COVID-19 associated acute pulmonary embolism: a different phenotype of thrombotic disease? Thromb Res 2020;193:86-9. 
17. Xu Z, Shi L, Wang Y, Zhang J, Huang L, Zhang C, et al. Pathological findings of COVID-19 associated with acute respiratory distress syndrome. Lancet Respir Med 2020;(4):420-2.

18. Deshpande C. Thromboembolic findings in COVID-19 autopsies: pulmonary thrombosis or embolism? Ann Intern Med 2020;173(5):394-5. 19. Guía ESC 2019 para el diagnóstico y tratamiento de la embolia pulmonar aguda§ Grupo de Trabajo de la Sociedad Europea de Cardiología (ESC) para el diagnóstico y tratamiento de la tromboembolia pulmonar aguda. Rev Esp Cardiol. 2020;73:452-610.1016

20. Koch V, Biener M, Müller-Hennessen M, Vafaie M, Staudacher I, Katus HA, et al. Diagnostic performance of D-dimer in predicting venous thromboembolism and acute aortic dissection. Eur Heart J Acute Cardiovasc Care. 2020 Mar 18:2048872620907322. doi: $10.1177 / 2048872620907322$.

21. Crawford F, Andras A, Welch K, Sheares K, Keeling D, Chappell FM. D-dimer test for excluding the diagnosis of pulmonary embolism. Cochrane Database Syst Rev. 2016;2016(8):CD010864. doi: 10.1002/14651858.CD010864.

22. Cui S, Chen S, Li X, Liu S, Wang F. Prevalence of venous thromboembolism in patients with severe novel coronavirus pneumonia. J Thromb Haemost. 2020;18(6):1421-4. doi: 10.1111/jth.14830.

23. Kermali M, Khalsa RK, Pillai K, Ismail Z, Harky A. The role of biomarkers in diagnosis of COVID-19 - A systematic review. Life Sci. 2020;254:117788. doi: 10.1016/j.lfs.2020.117788.

24. Konstantinides SV, Meyer G, Becattini C, Bueno H, Geersing GJ, Harjola VP, et al; ESC Scientific Document Group. 2019 ESC Guidelines for the diagnosis and management of acute pulmonary embolism developed in collaboration with the European Respiratory Society (ERS). Eur Heart J. 2020;41(4):543-603. doi: 10.1093/eurheartj/ehz405.

25. Piazza G, Hohlfelder B, Jaff MR, Ouriel K, Engelhardt TC, Sterling KM, et al. A prospective, single-arm, multicenter trial of ultrasoundfacilitated, catheter-directed, low-dose fibrinolysis for acute massive and submassive pulmonary embolism: the SEATTLE II Study. JACC Cardiovasc Interv 2015;8(10):1382-92.

26. Tapson VF, Sterling K, Jones N, Elder M, Tripathy U, Brower J, et al. A randomized trial of the optimum duration of acoustic pulse thrombolysis procedure in acute intermediate-risk pulmonary embolism: the OPTALYSE PE trial. JACC Cardiovasc Interv 2018;11(14):1401-0.

27. Spyropoulos AC, Levy JH, Ageno W, Connors JM, Hunt BJ, Iba T, et al; Subcommittee on Perioperative, Critical Care Thrombosis, Haemostasis of the Scientific, Standardization Committee of the International Society on Thrombosis, Haemostasis+. Scientific and Standardization Committee Communication: clinical guidance on the diagnosis, prevention and treatment of venous thromboembolism in hospitalized patients with COVID-19. J Thromb Haemost 2020;18(8):1859-65. doi:10.1111/jth.14929.

28. Moores LK, Tritschler T, Brosnahan S, Carrier M, Collen JF, Doerschug K, et al. Prevention, Diagnosis, and Treatment of VTE in Patients With Coronavirus Disease 2019: CHEST Guideline and Expert Panel Report. Chest. 2020;158(3):1143-63. doi: 10.1016/j.chest.2020.05.559.

29. Roberts LN, Whyte MB, Georgiou L, Giron G, Czuprynska J, Rea C, et al. Postdischarge venous thromboembolism following hospital admission with COVID-19. Blood. 2020;136(11):1347-50. doi: 10.1182/blood.2020008086. 


\title{
Evaluación post-COVID en deportistas para el retorno a la actividad física
}

\author{
IGNACIO DÁVOLOS, DIEGO IGLESIAS
}

La inactividad física es un factor de riesgo reconocido tanto para la salud física como para la salud mental, que se asocia con un aumento de la mortalidad por todas las causas. Los efectos de la inactividad pueden modificar rápidamente el metabolismo de un individuo. Durante las primeras etapas de la pandemia de SARS-CoV-2, hubo una disminución documentada de la actividad física, que se asoció a conductas no saludables. (1) Es importante considerar los efectos de esta relativa inactividad al examinar el riesgo de expresión de enfermedades crónicas antes de reiniciar la actividad física.

$\mathrm{Al}$ momento de prescribir actividad física post-COVID-19 podemos encontrarnos con cuatro escenarios y una gran variabilidad de edades: un individuo sedentario, un deportista recreativo, un amateur competitivo, y deportistas o atletas profesionales. Los dos primeros son más frecuentes, pero en todos los casos se aconseja una consulta médica post-COVID, que definirá si además del examen pre participativo habitual (interrogatorio, examen físico y electrocardiograma) es necesario profundizar con estudios complementarios. Esta necesidad estará asociada a la gravedad de la presentación clínica del cuadro que cursó el paciente. No es lo mismo un caso leve asintomático que un caso grave que requirió internación en una unidad cerrada. Estas apreciaciones son importantes debido a las cada vez más observadas secuelas a largo plazo secundarias a esta infección.

Los deportistas recreativos y de competencia, sean amateurs o profesionales, tienen un riesgo bajo de complicaciones o enfermedades graves similar a la población general; sin embargo, no se encuentran libres de las mismas, y pueden presentar una respuesta inflamatoria exagerada con daño pulmonar, miocárdico y tromboembolia. (2)

En los capítulos anteriores se han resumido las posibilidades de afectación cardíaca, con lesión miocárdica, arritmias, complicaciones trombembólicas y precipitación de infarto o accidente cerebrovascular. No debemos explorar solamente la posibilidad de complicaciones cardíacas. (3) La afectación hiperinflamatoria del SARS-CoV-2 exacerba el proceso de inmunosenescencia. Además, la inactividad física impuesta, el encierro, la cuarentena o la hospitalización aguda con reposo en cama intensifican el proceso de sarcopenia aguda. (4)

\section{Detección de miocarditis}

Una mención especial debemos hacer en aquellos deportistas que tuvieron COVID-19 en forma asintomática (detectados en estudios de rastrillaje), o sintomáticos leves que cursaron la enfermedad en forma ambulatoria, en quienes la evaluación pre reinicio de la actividad competitiva está centrada en detectar o descartar la presencia de miocarditis clínica o subclínica. En las diversas series recientemente publicadas, la presencia de miocarditis ronda el 0,4\% al 3,8\% de los atletas. La detección de esta complicación cardíaca está centrada en los posibles riesgos de la asociación de miocarditis con la muerte súbita (MS). En las series de MS pre pandemia, la miocarditis es la causa del $6 \%$ de los casos. Un entrenamiento riguroso en los deportistas que estén cursando una miocarditis podría tener consecuencias negativas sobre el remodelado cardíaco y la función ventricular.

La estrategia de detección para el retorno a la competición se basa en la clínica, el electrocardiograma, las troponinas y el ecocardiograma. En casos selectos se recurre a la resonancia magnética nuclear cardíaca $(5,6)$, pero no se aconseja como estudio rutinario. En el caso de que se detecte una miocarditis, el seguimiento y tratamiento será el propio de esta enfermedad de acuerdo con las guías correspondientes.

\section{Evaluación rutinaria previa al retorno al deporte durante la pandemia}

Es necesaria la evaluación de los deportistas previo al retorno a la actividad física, hayan sufrido la infección, o no. Teniendo en cuenta que la mayoría de las personas interrumpieron o redujeron su entrenamiento físico durante la pandemia, se recomienda que, antes de reanudarlo, se sometan a una nueva evaluación pre participativa. Sería conveniente considerar esta consulta médica como una oportunidad para realizar un análisis de laboratorio a aquellos individuos que no tienen controles previos e incluso para recomendar actividad física a aquellos individuos que antes de la infección por SARS-CoV-2 no eran físicamente activos.

Los mayores de 35 años que presentan uno o más factores de riesgo para enfermedad cardiovascular, que no han sufrido la infección por SARS-CoV-2 y desean retornar a su práctica deportiva, deben ser evaluados acorde con las indicaciones actuales para retornar a la actividad física; para brindar un marco de seguridad, en prevención de MS, especialmente la MS cardíaca. Estas recomendaciones deben ser revisadas y actualizadas de acuerdo al avance en los conocimientos de las complicaciones causas por la infección por SARS-CoV-2. 
Nuestro algoritmo, oportunamente presentado por la Sociedad Argentina de Cardiología y la Federación Argentina de Cardiología, y que ha sido revisado y actualizado de acuerdo a los avances en las complicaciones relacionadas con la infección por SARS-CoV-2, involucra a todos los conceptos sobre movimiento: actividad física, ejercicio físico y deporte; $\mathrm{y}$ a todos los grupos de personas que los realizan, ya sea un deportista amateur recreativo o competitivo, o un deportista profesional, e intenta brindar un enfoque sobre cómo evaluar a diferentes grupos de deportistas hayan sufrido o no enfermedad por SARS-CoV-2 para el retorno seguro a su actividad física habitual. (Figura)

En el último año se han publicado otros algoritmos para el regreso a la actividad física, entrenamiento o deporte, (7-11) que sugieren a quiénes y/o cómo realizar dicho retorno, pero resulta infrecuente encontrar recomendaciones en torno a cuánta actividad física prescribir o recomendar, en términos de volumen y carga. Las más recientes directrices señalan que luego de un período de enfermedad o inactividad, debemos considerar "esperable" el desacondicionamiento físico para una actividad determinada. Se requiere así un cierto grado de evaluación subjetiva que incluya una actividad física y el nivel de condición física del paciente (por ejemplo la Escala de Borg); que se contemple una progresión graduada e individualizada, que incluya aumentos de volumen (duración de la actividad) e intensidad. (12)

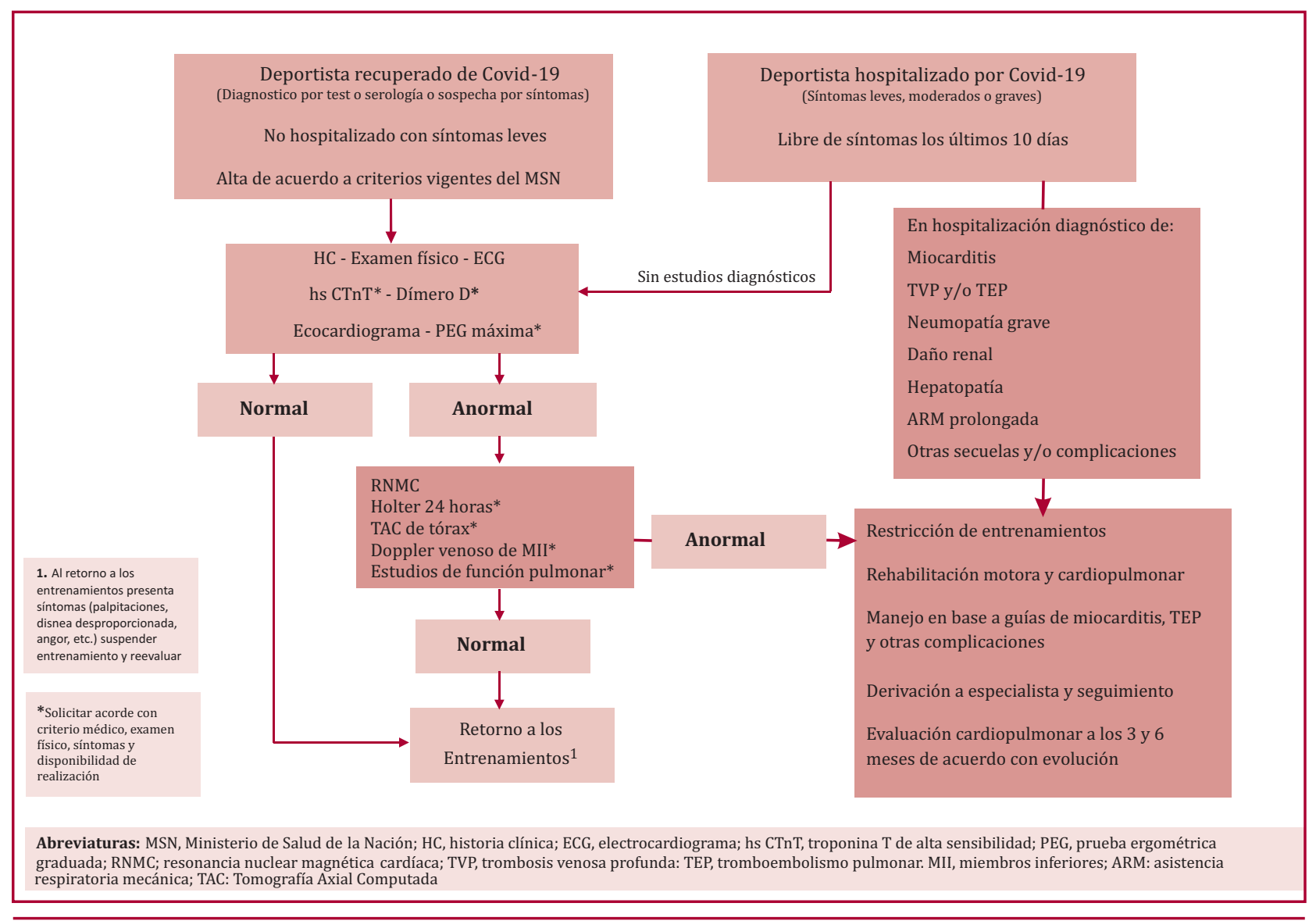

Fig. Algoritmo diagnóstico para el retorno de los deportistas a la práctica deportiva post infección por el COVID-19 


\section{BIBLIOGRAFÍA}

1. Mattioli AV, Sciomer S, Cocchi C, Maffei S, Gallina S. Quarantine during COVID-19 outbreak: Changes in diet and physical activity increase the risk of cardiovascular disease. Nutrition, Metabolism \& Cardiovascular Diseases 2020;30:1409e1417

2. Wu Z, McGoogan JM. Characteristics of and important lessons from the coronavirus disease 2019 (COVID-19) outbreak in China: summary of a report of 72314 cases from the Chinese Center for Disease Control and Prevention JAMA. 2020;323(13):1239-42. doi:10.1001/jama.2020.2648 3. Ibarrola M, Dávolos I. Myocarditis in athletes after COVID-19 infection: The heart is not the only place to screen. Sports Med Health Sci. 2020 Sep;2(3):172-173. https://doi.org/10.1016/j.smhs.2020.09.002

4. Piotrowicz K, Gąsowski J, Michel JP, Veronese N. Post-COVID-19 acute sarcopenia: physiopathology and management. Aging Clin Exp Res. 2021 Jul 30:1-12. https://doi.org/10.1007/s40520-021-01942-8

5. Moulson N, Petek BJ, Drezner JA, Harmon KG, Kliethermes SA, Patel MR, et al. SARS-CoV-2 cardiac involvement in young competitive athletes. Circulation. 2021;144:256-66. DOI:10.1161/CIRCULATIONAHA.121.054824

6. Martinez MW, Tucker AM, Bloom OJ, Green G, DiFiori JP, Salomon G, et al. Prevalence of inflammatory Heart Disease Among Professional Athletes with prior COVID-19 infection who recieved systematic return-to-plat cardiac screening. JAMA Cardiol. 2021;6(7):745-52. . doi:10.1001/jamacardio.2021.0565

7. Schellhorn P, Klingel K, Burgstahler C. Return to sports after COVID-19 infection. Eur Heart J. 2020;41(46):4382-4. doi:10.1093/eurheartj/ ehaa448

8. Verwoert GC, de Vries ST, Bijsterveld N, Willems AR, vd Borgh R, Jongman JK, et al. Return to sports after COVID-19: a position paper from the Dutch Sports Cardiology Section of the Netherlands Society of Cardiology. Neth Heart J 2020;28:391-5. https:/doi.org/10.1007/ s12471-020-01469-z

9. Halle M, Bloch W, Niess AM, Predel HG, Reinsberger C, Scharhag J, et al. Exercise and sports after COVID-19—Guidance from a clinical perspective. Transl Sports Med. 2021;4:310-8. DOI: 10.1002/tsm2.247

10. Colombo CSSS, Leitão MB, Avanza Jr. AC, Borges SF, Silveira AD, Braga F, et al. Position Statement on Post-COVID-19 Cardiovascular Preparticipation Screening: Guidance for Returning to Physical Exercise and Sports - 2020. Arq Bras Cardiol. 2021; 116(6):1213-26

11. Metzl JD, McElheny K, Robinson JN, Scott DA, Sutton KM, Toresdahl BG. Considerations for Return to Exercise Following Mild-toModerate COVID-19 in the Recreational Athlete. HSSJ (2020) 16 (Suppl 1):S102-S107

12. Salman D, Vishnubala D, Le Feuvre P, Beaney T, Korgaonkar J, Majeed A. Returning to physical activity after covid-19. BMJ 2021;372:m4721. http://dx.doi.org/10.1136/bmj.m4721 


\title{
Evaluación cardiovascular de los pacientes post-COVID-19
}

\author{
CARLOS TAJER
}

La infección por el virus SARS-CoV-2 puede cursar asintomática o generar COVID-19 con grados variables de afectación clínica que se han clasificado como casos leves, moderados o graves. En los capítulos anteriores de este documento hemos analizado las complicaciones cardiovasculares durante la fase aguda. Los períodos sintomáticos del cuadro se han dividido arbitrariamente en 1) Agudo: signos y síntomas en las primeras cuatro semanas. 2) Sintomático persistente: de cuatro a 12 semanas; 3) Post-COVID-19: luego de las 12 semanas. Para simplificar el análisis, tomaremos las dos etapas posteriores al primer mes como post-COVID con un límite un poco más difuso, que dependerá de la afectación inicial y la longitud de la internación si fue requerida. Luego de la etapa aguda muchos pacientes cursan con diferentes sintomatologías, con frecuencia invalidantes, que requieren una evaluación pormenorizada y en algunos casos consultas cardiovasculares. Se ha propuesto la denominación Long-COVID (1), COVID largo, para la persistencia o aparición de síntomas posteriores a la fase aguda, pero para este documento lo referiremos como post-COVID. Nuestra intención es puntualizar el rol de los cardiólogos y la indicación de estudios de la especialidad en esta etapa evolutiva.

\section{Espectro clínico post-COVID}

Diferentes series han informado la persistencia o aparición de sintomatologías variadas post-COVID. La guía del NICE (2) las ha clasificado por sistemas (Tabla 1)

En la serie de 1276 pacientes egresados de internación en Wuhan (3) se analizó la frecuencia de sintomatología a seis meses y un año. La proporción con por lo menos una sintomatología disminuyó del $68 \%$ a los seis meses al $49 \%$ al año. La disnea se incrementó de $26 \%$ a 30\%. La fatiga muscular bajó del 52\% al 20\%, el insomnio del 27 al 17\%, y se mantuvo estable la referencia de palpitaciones, 10 y $9 \%$, y de dolor torácico, $5 \%$ y $7 \%$. Los hallazgos de debilidad muscular, ansiedad y depresión fueron más frecuentes en mujeres. (Tabla 2).

En una serie italiana de 143 pacientes evaluados a los dos meses de la internación por COVID-19, la mayoría permanecían sintomáticos. Los síntomas más frecuentes eran la fatiga $(53,1 \%)$, la disnea $(43,4 \%)$, el dolor articular $(27,3 \%)$ y el dolor torácico $(21,7 \%)$. (4)

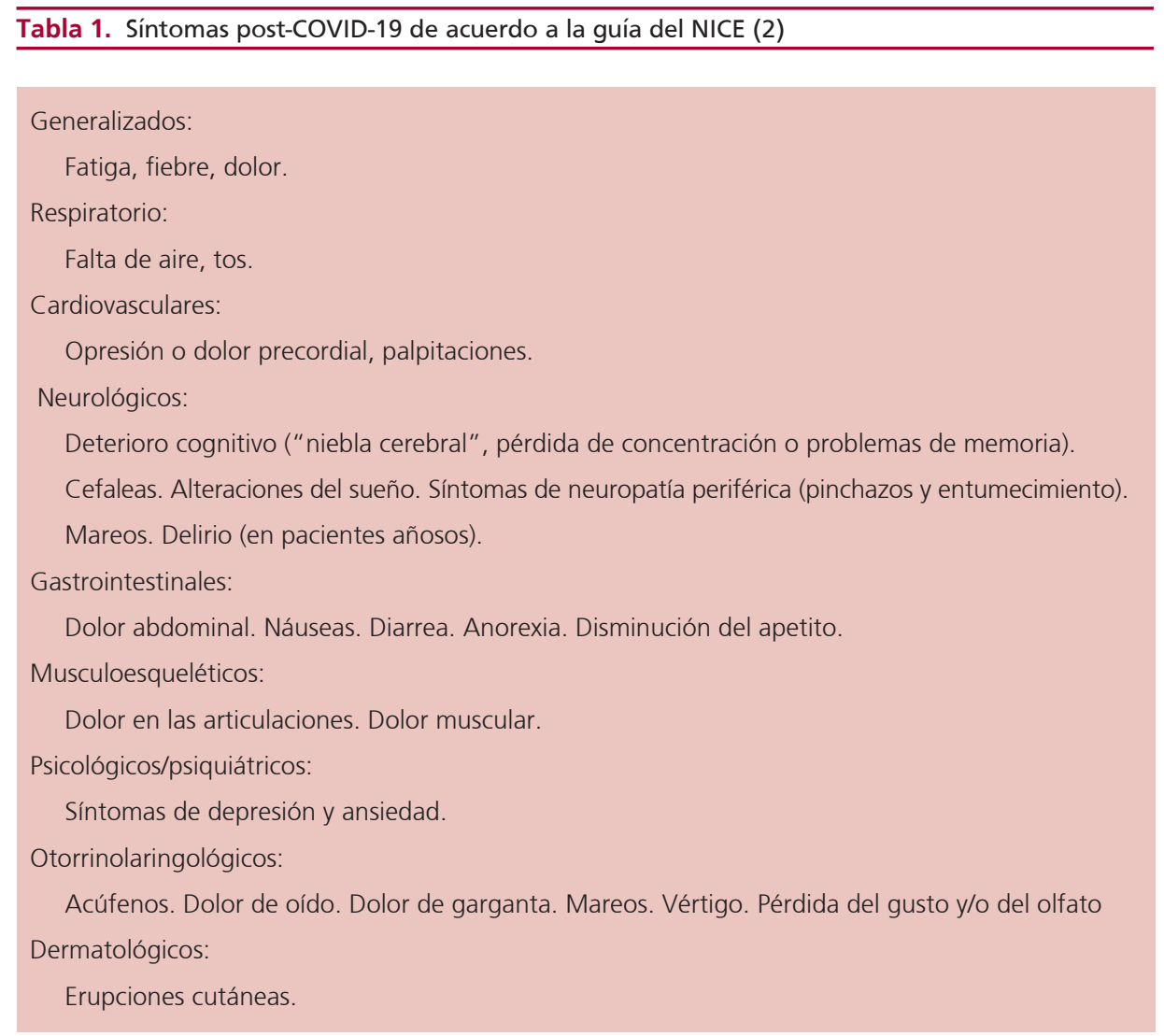




\begin{tabular}{lcc}
\hline $\begin{array}{l}\text { Tabla 2. Sintomatología referida a los seis meses en pacientes egre- } \\
\text { sados por COVID-19 en Wuhan (3) }\end{array}$ \\
\hline $\begin{array}{l}\text { Población } 1655 \text { pacientes } \\
\text { Sintomatología }\end{array}$ & $\mathbf{n}$ & $\%$ \\
\hline Algún síntoma & 1265 & 76 \\
\hline Fatiga o debilidad muscular & 1038 & 63 \\
\hline Dificultades con el sueño & 437 & 26 \\
\hline Caída del cabello & 359 & 22 \\
\hline Anosmia & 176 & 11 \\
\hline Palpitaciones & 154 & 9 \\
\hline Dolor articular & 154 & 9 \\
\hline Disminución del apetito & 138 & 8 \\
\hline Dolor torácico & 75 & 5 \\
\hline
\end{tabular}

En otra serie los investigadores contactaron 478 casos por vía telefónica a los cuatro meses de la internación, de los cuales $244(51 \%)$ refirieron diferentes sintomatologías que no padecían previamente a la COVID-19. Los síntomas más frecuentes fueron la fatiga (31\%), problemas cognitivos (21\%) y nueva disnea en 16\%. En 177 casos que fueron investigados con minuciosidad, la causa identificable de disnea fue la persistencia de afectación pulmonar en la tomografía de tórax. (5) En 83 casos indicaron evaluaciones ecocardiográficas; solo 8 tuvieron fracción de eyección menor al 50\% y ninguno menor al $40 \%$.

Otra serie contrastó 233 casos leves de COVID-19, de los cuales solo 8 requirieron internación, con una cohorte de pacientes sin COVID-19. El 43,4\% de los pacientes COVID-19 tenía por lo menos un síntoma por más de 30 días y el $24 \%$ luego de 90 días. El síntoma más frecuente fue la disnea, vinculado con el mismo síntoma durante la fase aguda. (6)

Una investigación generada por una red de pacientes recolectó 3762 participantes que informaron en 96\% de los casos síntomas post-COVID-19. (7) Aunque la prevalencia por las características de este tipo de encuesta exagere el porcentaje global, guarda interés analizar la frecuencia relativa de malestares cardiovasculares. En esta serie fueron muy frecuentes: palpitaciones $68 \%$, taquicardia $63 \%$, ardor o dolor torácico $53 \%$, bradicardia $18 \%$, desmayos $12 \%$. La mayoría de los síntomas aparecieron luego de las primeras semanas y se mantuvieron por varios meses, con disminuciones o exacerbaciones periódicas.

El estudio PHOSP-COVID (8) evaluó 1077 pacientes luego de una mediana de 5 meses de la internación. La edad promedio fue de $58 \pm 13$ años, habían requerido asistencia respiratoria mecánica el $27 \%$ y el $50 \%$ tenía por lo menos dos comorbilidades. Los pacientes fueron citados a una entrevista clínica, y se aplicaron una serie de cuestionarios sobre calidad de vida y limitaciones funcionales, sumados a estudios complementarios de laboratorio o imágenes cuando fueron considerados necesarios. Sólo el 29\% se consideraba totalmente recuperado, un 20\% tenía una nueva sintomatología diferente a la fase aguda y el $18 \%$ no seguía trabajando (entre los dos tercios de pacientes laboralmente activos previos). Los factores asociados a dificultad en la recuperación fueron el sexo femenino, dos o más comorbilidades y el curso más grave durante la internación. Dividieron el grado de limitación en cuatro niveles, con valor 1 para el grupo más grave y 4 para el más leve. De los estudios de laboratorio, fue más frecuente el hallazgo de PCR elevada en pacientes con mayor grado de afectación (16,5\% en el grupo 1 vs $6 \%$ en el grupo 4), no así de BNP o NT-proBNP (7,9\% vs 8\% respectivamente). El 42,2\% tenía comorbilidades cardiovasculares previas, la mayoría hipertensión arterial (35\%), con un 6\% de antecedentes de cardiopatía isquémica, $4,5 \%$ de fibrilación auricular y $5 \%$ de accidente cerebrovascular. Los síntomas más comunes fueron la fatiga (48\%), disnea (56\%), dolores musculares o articulares $(33,7 \%)$, trastornos cognitivos e insomnio $(41,8 \%)$. La disnea se asoció a mayor compromiso durante la internación y con la severidad de los hallazgos funcionales respiratorios. Los síntomas cardiovasculares más frecuentes fueron el dolor precordial (27\%), palpitaciones $(20,2 \%)$ y cerca de un $2 \%$ refirieron desmayos.

En el estudio prospectivo C -Morev (9) se incluyeron 50 pacientes egresados por COVID-19 y se los comparó con 30 casos de similares características demográficas, con múltiples estudios de imágenes y funcionales. A los 2-3 meses de evolución el 64\% refería dificultades respiratorias y el 55\% fatiga muscular. En los estudios de imágenes fue muy frecuente el hallazgo de alteraciones pulmonares en los estudios funcionales y en la resonancia magnética. En la exploración cardiovascular, durante la internación el 8\% de los casos habían cursado con injuria miocárdica detectada por elevación de la troponina. La fracción de eyección de ambos ventrículos fue normal sin diferencias con el grupo control. En la resonancia se observaron alteraciones en el T1 en el miocardio basal en el $26 \%$ de los casos y leves hallazgos de fibrosis. Se encontraron alteraciones cerebrales en el tálamo y otras 
regiones que se asociaron a disturbios cognitivos. La tolerancia al esfuerzo estaba alterada, y guardaba relación con los marcadores séricos de inflamación y la severidad del curso inicial.

Un elemento común a todas las series es la complejidad y diversidad de la sintomatología, a la cual se suma el daño generado por la internación y aspectos emocionales vinculados al estrés postraumático. En los pacientes sintomáticos por disnea el origen habitual es la persistencia de afectación pulmonar, confirmada por estudios funcionales respiratorios, tomografía y resonancia. La fatiga habitualmente es atribuible a afectación muscular por el reposo prolongado.

Si bien no es común el hallazgo de nuevos problemas cardiovasculares post COVID-19, la frecuencia de síntomas de disnea, fatiga, dolor precordial y palpitaciones genera la necesidad de consultas y evaluaciones cardiológicas. Es importante analizar la estratificación de estudios en forma racional de acuerdo a una serie de parámetros epidemiológicos y clínicos.

\section{¿Qué evaluaciones cardiológicas deben ser efectuadas post-COVID-19?}

En la Figura 1 resumimos un algoritmo que puede orientar a las indicaciones y complejidad de las evaluaciones cardiológicas post-COVID-19, que explicaremos a continuación.

La mayoría de los síntomas que padecen los pacientes post-COVID-19 no se vinculan con el corazón. El cardiólogo clínico se enfrentará ante la demanda de consulta con diferentes escenarios que intentamos graficar en el diagrama anterior.

\section{Pacientes con graves complicaciones durante la internación}

Los pacientes que cursan con COVID-19 y grave compromiso respiratorio que los lleva a asistencia respiratoria mecánica cursan en forma similar a las neumonías graves, con múltiples complicaciones vinculadas a la sepsis y afectación multiorgánica. También pueden complicarse con problemas cardiovasculares, con injuria miocárdica, infarto de miocardio, tromboembolismo, diferentes arritmias e insuficiencia cardíaca, en particular si tienen cardiopatías preexistentes. La evolución posterior al alta en estos casos requerirá en muchos casos un trabajoso esquema de rehabilitación motora, y el enfoque médico se deberá ajustar al cuadro agudo y su patología de base, en forma individual, de tal manera que no resulta útil establecer pautas generales.

Luego de un período de rehabilitación, si superadas las complicaciones persisten los síntomas referidos a problemas cardíacos, deberá evaluarse en forma similar a los pacientes que cursaron en forma ambulatoria o con COVID-19 no complicado.

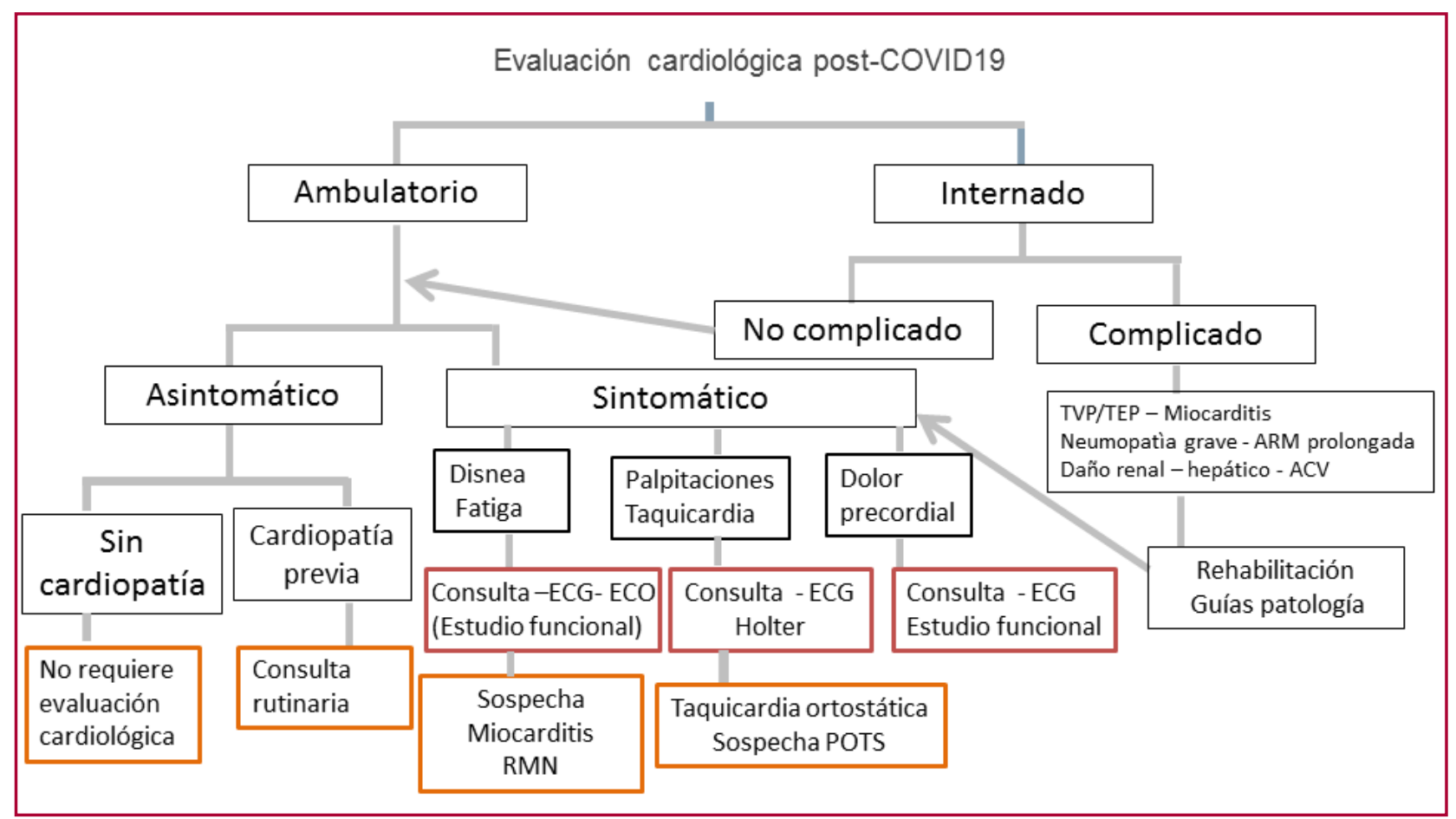

Fig. 1. Algoritmo de evaluación cardiológica post-COVID-19. Abreviaturas: TVP/TEP: trombosis venosa profunda/tromboembolismo de pulmón; ARM: asistencia respiratoria mecánica; ECG: electrocardiograma; ECO: ecocardiograma; RMN: resonancia magnética nuclear cardíaca; POTS: sindrome de taquicardia postural. ACV: accidente cerebrovascular 
Pacientes sin graves complicaciones durante la internación y casos ambulatorios asintomáticos

Tanto en los pacientes que requirieron internación con formas leves o moderadas, como en los casos ambulatorios, la conducta deberá guiarse por la presencia o no de sintomatología. En los pacientes asintomáticos no creemos necesaria la evaluación cardiológica, salvo casos especiales que requieran una demanda física intensa. Este aspecto está tratado en el capítulo de evaluación para la actividad deportiva.

\section{Pacientes con cardiopatías previas}

Es prudente que los pacientes consulten con su cardiólogo de cabecera luego de haber superado la etapa aguda del COVID-19. La evaluación clínica dependerá de la sintomatología y antecedentes y debe efectuarse en forma individualizada de acuerdo a la práctica habitual.

\section{Pacientes que persisten sintomáticos}

La sintomatología que pueden presentar los pacientes post-COVID-19 es muy variada, como hemos resumido en la Tabla 1. Los casos referidos al cardiólogo son los que presentan disnea no explicada por estudios pulmonares, así como las sintomatologías cardiovasculares más específicas, como el dolor precordial, palpitaciones, taquicardia y desmayo.

En la figura ordenamos los estudios en forma empírica de acuerdo a la sintomatología. En todos los casos cabe comenzar por una evaluación clínica con un interrogatorio detallado para aclarar adecuadamente la sintomatología, así como un electrocardiograma.

\section{Disnea}

En los pacientes con disnea no explicada por hallazgos respiratorios, será necesario efectuar un ecocardiograma para caracterizar la función biventricular, la presencia de signos de incremento de la presión de llenado, la presión sistólica pulmonar, entre otros parámetros. El Doppler tisular es más sensible para detectar anomalías, pero probablemente no explique la sintomatología si la función sistólica está conservada. Puede ser de utilidad la evaluación de marcadores de inflamación como la PCR y de insuficiencia cardíaca como el BNP o Pro-BNP. Como hemos comentado en los capítulos precedentes, la frecuencia de miocarditis es muy baja y los hallazgos de anomalías en la resonancia resultan frecuentes. Por ese motivo solo deberían estudiarse con resonancia pacientes con elevada sospecha de miocarditis, de acuerdo a los hallazgos clínicos y ecocardiográficos. Aunque en la mayoría de los pacientes que cursan con elevación de troponina en la fase aguda los valores se normalizan en la evolución, el hallazgo tardío de troponina elevada se ha observado en pacientes con inflamación y edema en la resonancia. (10) La evaluación por ejercicio cardiopulmonar puede también contribuir a precisar la capacidad funcional.

\section{Palpitaciones - Taquicardia - Desmayo}

COVID-19 puede evolucionar complicada con diferentes arritmias durante la fase aguda. En la evolución más tardía es frecuente la persistencia de taquicardia y la percepción de palpitaciones. La evaluación habitual es a través del Holter de 24 horas y la conducta con las diferentes arritmias que puedan hallarse no difiere de lo habitual.

Un hallazgo característico del post-COVID-19 es la persistencia de taquicardia, que puede atribuirse a un estado inflamatorio o a la posibilidad de disautonomía con taquicardia ortostática excesiva (en inglés POTS, síndrome de taquicardia postural), que se sospecha cuando la frecuencia cardíaca se eleva en más de 30 latidos al adoptar la postura erecta. (11) Las conductas frente a este hallazgo son complejas y están relatadas en el capítulo de arritmias. Ante la presencia de desmayos sin etiología clara puede efectuarse el tilt-test como complemento de la evaluación.

\section{Dolor precordial}

El dolor precordial es frecuente en pacientes post-COVID-19. Aunque fisiopatológicamente es claro que el virus puede afectar el endotelio y por diversos mecanismos precipitar cuadros de infarto clásicos, la progresión de coronariopatía no ha sido hasta ahora un cuadro frecuente. Existen a la vez referencias como casos de reporte de angina microvascular en ausencia de compromiso de las arterias epicárdicas. (12) La evaluación del dolor precordial en estos pacientes debería seguir la rutina habitual de evaluaciones funcionales frente a la sospecha de angina, en particular cuando se suman factores de riesgo para aterosclerosis.

\section{Comentarios finales}

El capítulo de las complicaciones cardiovasculares de la COVID-19 y su evolución alejada sigue abierto y en evaluación. Hemos intentado resumir una propuesta de evaluación post-COVID-19 con un balance entre la gravedad de la internación, la sintomatología posterior y los antecedentes cardiovasculares previos, que esperamos resulte útil para el cardiólogo práctico. 


\section{BIBLIOGRAFÍA}

1. Perego E, Callard F, Stras L, Melville-Jóhannesson B, Pope R, Alwan NA. Why we need to keep using the patient made term "Long Covid." The BMJ Opinion. Published October 1, 2020.

2. COVID-19 rapid guideline: managing the long-term effects of COVID-19. NICE guideline. Published: 18 December 2020. www.nice.org. uk/guidance/ng188

3. Huang L, Yao Q, Gu X, Wang Q, Ren L, Wang Y, et al. 1-year outcomes in hospital survivors with COVID-19: a longitudinal cohort study. 2021:398:747-58

4. Carfi A, Bernabei R, Landi F, Gemelli Against COVID-19 Post-Acute Care Study Group. et al. Persistent Symptoms in Patients After Acute COVID-19. JAMA. 2020;324(6):603-5. doi:10.1001/jama.2020.12603

5. Writing Committee for the COMEBAC Study Group, Morin L, Savale L, Pham T, Colle R, Figueiredo S, Harrois A, et al. Four-Month Clinical Status of a Cohort of Patients After Hospitalization for COVID-19. JAMA. 2021;325(15):1525-34.

6. Cirulli ET, Schiabor Barrett KM, Riffle S, Bolze A, Neveux I, Dabe S, et al. Long-term COVID-19 symptoms in a large unselected population. medRxiv 2020: 2020. https://doi.org/10.1101/2020.10.07.20208702

7. Davis H, Assaf G, McCorkell L, Wei H, Low RJ, Re'em Y, et al. Characterizing Long COVID in an International Cohort: 7 Months of Symptoms and Their Impact Hannah. medRxiv preprint doi: https://doi.org/10.1101/2020.12.24.20248802

8. PHOSP-COVID Collaborative Group. Physical, cognitive and mental health impacts of COVID-19 following hospitalisation - a multi-centre prospective cohort study. medRxiv preprint doi: https://doi.org/10.1101/2021.03.22.21254057

9. Raman B, Cassar M, Tunnicliffe E, Filippini N, Griffanti L, Alfaro-Almagro F, et al. Medium-term effects of SARS-CoV-2 infection on multiple vital organs, exercise capacity, cognition, quality of life and mental health, posthospital discharge. EClinicalMedicine;2021: https:// doi.org/10.1016/j.eclinm.2020.100683

10. Puntmann VO, Carerj ML, Wieters I, Fahim M, Arendt C, Hoffmann J, et al. Outcomes of cardiovascular magnetic resonance in patients recently recovered from coronavirus disease 2019 (COVID-19). JAMA Cardiol. 2020;5(11):1265-73. doi:10.1001/jamacardio.2020.3557

11. Fedorowski A. Postural orthostatic tachycardia syndrome: clinical presentation, aetiology and management. J Intern Med 2019;285:352-66.

12. Vallejo N, Teis A, Mateu L, Bayés-Genís A. Persistent chest pain after recovery of COVID-19: microvascular disease-related angina? Eur Heart J Case Rep. 2021;5(3):ytab105. doi: 10.1093/ehjcr/ytab105. PMID: 34113774 